\title{
High-Flux Solar Photon Processes: Opportunities for Applications
}

J.I. Steinfeld, S.L. Coy, H. Herzog, J.A. Shorter, M. Schlamp, J.W. Tester, W.A. Peters

Massachusetts Institute of Technology Cambridge, Massachusetts

NREL Technical Monitor: Meir Carasso 
On September 16, 1991 the Solar Energy Institute was designated a national laboratory, and its name was changed to the National Renewable Energy Laboratory.

\section{NOTICE}

This report was prepared as an account of work sponsored by an agency of the United States government. Neither the United States government nor any agency thereof, nor any of their employees, makes any warranty, express or implied, or assumes any legal liability or responsibility for the accuracy, completeness, or usefulness of any information, apparatus, product, or process disclosed, or represents that its use would not infringe privately owned rights. Reference herein to any specific commercial product, process, or service by trade name, trademark, manufacturer, or otherwise does not necessarily constitute or imply its endorsement, recommendation, or favoring by the United States government or any agency thereof. The views and opinions of authors expressed herein do not necessarily state or reflect those of the United States government or any agency thereof.

\section{Printed in the United States of America \\ Available from:}

National Technical Information Service

U.S. Department of Commerce

5285 Port Royal Road

Springfield, VA 22161

Price: Microfiche AO1

Printed Copy A05

Codes are used for pricing all publications. The code is determined by the number of pages in the publication. Information pertaining to the pricing codes can be found in the current issue of the following publications which are generally available in most libraries: Energy Research Abstracts (ERA); Government Reports Announcements and Index (GRA and 1); Scientific and Technical Abstract Reports (STAR); and publication NTIS-PR-360 available from NTIS at the above address. 


\section{PREFACE}

This report is the outcome of a study carried out at the Massachusetts Institute of Technology under subcontract XM-0-10135-1 from the National Renewable Energy Laboratory (formerly the Solar Energy Research Institute), Golden, Colorado, between October 1, 1990, and March 31, 1991. Dr. Meir Carasso was the contract monitor. The study was performed by an interdisciplinary team centered in the MIT Energy Laboratory, as described in the body of the report. The authors would like to thank the numerous experts, listed in Section 2 of the report, for contributing their time and expertise. In particular, we acknowledge the contributions of Dr. John Haggerty to the areas of materials processing and ceramics, Prof. Roland Winston of the University of Chicago for arranging a visit to his facility, Mr. Zheng Chen of the MIT Energy Laboratory for literature searches and preparation of figures, Ms. Bonnie Santos and Ms. Mary Elliff of the MIT Energy Laboratory and Mr. Paul Stewart of the Chemistry Department for secretarial support, Ms. Hea Kyung Chung for preparing the final typed version of the project report, Ms. Barbara Johnson for help with figures, and other MIT Energy Laboratory personnel for assistance with contract administration and preparation of this report. 


\section{EXECUTIVE SUMMARY}

The overall goal of this study was to identify new high-flux solar photon (HFSP) processes which show promise of being feasible and in the national interest. Electric power generation and hazardous waste destruction were excluded from this study at sponsor request.

Our specific objectives were:

- $\quad$ to survey pertinent information bases;

- to construct and assemble in prescribed electronic forrn a bibliography of relevant literature;

- $\quad$ to prepare an initial list of potentially promising HFSP applications;

- $\quad$ to define a set of criteria for evaluating potential HFSP applications;

- to carry out more detailed evaluations of some of the more promising applications;

- to provide recommendations on HFSP process applications indicating special promise;

- to discuss the status of current relevant research; and

- to recommend research needed to advance basic understanding of HFSP applications and to further their potential for practicality.

Our approach was to carry out the project with a core team of researchers providing expertise over a broad array of foundational topics, viz., chemical physics, optics, spectroscopy, photochemistry, high-temperature reactions, industrial chemistry, and chemical process engineering. Because of the wide range of scientific and engineering disciplines relevant to the study goals and the relatively short time available for the study, members of the core team carried out intense, round-table discussions with invited experts in a diverse sphere of pertinent disciplines, e.g., pure and applied optics, solar energy, furnace design, combustion, materials science and engineering, etc. Core team members conferred with experts at the Solar Energy Research Institute (SERI) (now known as the National Renewable Energy Laboratory, NREL) and the University of Chicago, and with participants in related studies being conducted by the National Academy of Sciences and SRI International, Inc. PC-compatible software was used to carry out an in-depth survey of post1985 literature and to assemble in electronic form a bibliographic data base of important publications. Our approach emphasized the importance of delineating critical scientific and engineering foundations for identifying, evaluating, and discriminating among potentially promising options for HFSP applications. For example, limitations on solar photon intensity and wavelength and temporal variations in solar insolation impact process capacily, duty cycle, and controllability. Competition from alternative sources of intense pr won fiuxes was also considered in some detail. Formal economic and engineering cost estimates were outside our charter, but the study noted the importance of considering both conventional and externalized factors (e.g., environmental impacts, national security, global competitiveness, quality of fossil or other energy displaced) in determining overall costs of HFSP and competing options.

Our overall conclusion is that there is promise for new applications of concentrated solar photons, especially in certain aspects of materials processing and premium materials synthesis. Evaluation of the full potential of these and other possible applications (see below), including opportunities for commercialization, requires further research and testing.

Our specific recommendations are:

- NREL should establish, at their Golden. Colorado, solar furnace site, a user research facility including a support program for extramural participation. Drawing on previous models of DOE-funded user facilities, this NREL ii 
operation would be a national resource to provide world class scientific and engineering foundations for proposed and yet-to-be identified applications of concentrated solar photons in research, materials and systems testing, and commercial processing. This extramural support program would be an incentive to user participation and would catalyze further innovations in solar photon applications. A wide variety of concentrators could be part of this facility to accommodate low-, medium-, high-, and ultrahigh tlux requirements and multiple users. A corollary of this recommendation is that construction of large-scale demonstration facilities should await further research and evaluation at smaller scale. NREL can achieve maximum leverage in a season of limited resources, by avoiding large hardware programs, and by emphasizing the acquisition of sound scientific and engineering foundations to advance commercialization of HFSP.

- Synthesis, processing, and testing of selected materials are among the most promising areas with potential for applications at larger scale. In particular, further research and evaluation should be performed on:

$$
\begin{aligned}
& \text { synthesis of premium value products, e.g., certain fine ceramic powders and } \\
& \text { specialized carbon forms; } \\
& \text { - thin-film deposition of metals or inorganic compounds; } \\
& \text { - } \\
& \text { - } \\
& \text { marface treatment of metals and alloys; and } \\
& \text { aerothermal protection and propulsion systems for space exploration and } \\
& \text { defense applications. }
\end{aligned}
$$

- A research emphasis on high-temperature, high-intensity, photochemistry is highly recommended. Such research could lead to significant new applications of concentrated solar energy.

- Applications are also possible in more specialized situations because of pressing environmental considerations or unavailability of alternative energy sources. Examples include recyling chemical process wastes to useful intermediates or starting materials; heat sources for Stirling engines for shaft power and pumped water storage in remote locations.

- Drawing on the evaluation criteria developed in this and other studies, NREL should adopt and frequently update methodologies for systematic. continuing evaluation of candidate HFSP applications. Such evaluations should take account of technica! feasibility, economic tractability, competing solar and non-solar options, potential domsstic and international markets, and less-traditional factors such as environmental impacts, reduced energy importation, and stewardship of national and global resources.

- Detailed economic and technical analyses of a small number of preferred and more far-reaching candidate applications should be performed. The process modeling and analysis tools described in Section 4 of this report may be used for such analyses.

- High priority should be given to involving industry in identifying refining, and developing new ard improved applications for concentrated solar photons. New opportunities for collaboration with NREL, e.g., hands-on testing 
of new ideas at the proposed user facility, while protecting intellectual property rights, should be communicated to industry.

- There is need to bring about increased awareness among the general public. industry, state and local governments, and the scientific and engineering research community, of the growing opporturities to participate in, and obtain external funding for, research and technology development in the field of concentrated solar energy. We believe this will help enrich the intellectual base for new ideas and applications by reinvolving "old-timers" who had perhaps abandoned hope for significant support in this domain, and by attracting newcomers who will bring fresh perspectives to the field. 


\section{TABLE OF CONTENTS}

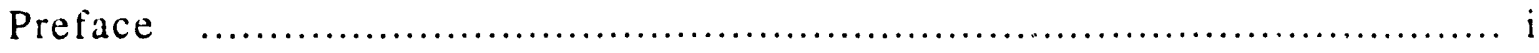

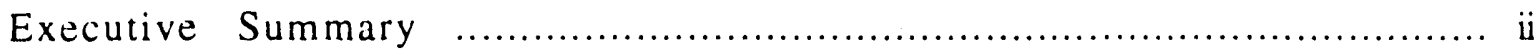

Table of Contents …..................................................................

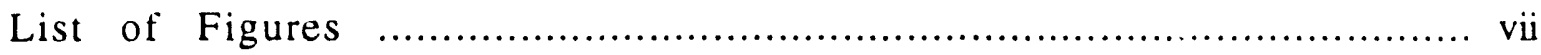

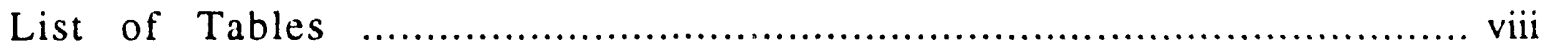

1. Introduction

1.1. Background ................................................. $1-1$

1.2. Objectives and Approach …..................................... 1 - 2

2. Methodology

2.1. Project Core Team

$2-1$

2.2. Invited Experts

2.3. Interactions with NREL and with Other Studies ....................... 2 - 3

2.4. Bibliographic Data Bases ......................................... 2 - 3

3.Characteristics of Concentrated Solar Energy and Competing Technologies

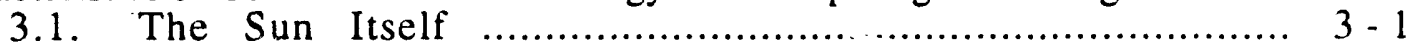

3.2. Concentration of Solar Energy........................................ 3 - 2

3.2.1. Theoretical and Practical Limits in Solar Furnace Design...... 3 - 2

3.2.1.1. Maximum Concentration in Air................... 3-2

3.2.1.2. Maximum Concentrations in Dielectric Materials.. $3-6$

3.2.1.3. Collection Efficiency................................. 3- 3 - 7

3.2.2. Capabilities of the NREL Solar Furnace........................ 3-7

3.2.2.1. Concentration Parameters......................... 3- 3-7

3.2.2.2. Heating with the NREL Solar Furnace............. 3- 3-8

3.2.2.3. Heating Rates................................. 3 - 8

3.3. Costs and Characteristics of Radiative Sources ........................... $3-9$

3.3.1. Cost of Solar Photons.............................................. $3-10$

3.3.2. Cost of Arc Lamp Photons...................................... 3- 11

3.3.3. Cost of Laser Photons........................................ 3- 3 - 11

3.3.4. Cost of Product Processed by Photons........................ $3-12$

4. Evaluation and Decision Criteria

4.1. Scientific and Technical Feasibility ......................................... 4 - 1

4.2. Economic and Practical Considerations .................................... 4 - 2

4.2.1. Qualitative Cost Considerations...................................... 4 - 2

4.2.2. Related Operational Issues........................................ 4 - 3

4.2.3. Analysis Tools................................................ 4 - 4

4.2.4. Responsiveness to National Needs.............................. 4-4

4.2.5. Global Cost Comparison Methods................................ 4 - 8 
5. Specific Processes Showing Potential Promise

5.1. Basic Photochemistry ................................................ $5-1$

5.1.1. Evaluation of Multiphoton Processes ………................ 5- 1

5.1.2. Example of New Photochemistry Possibilities ................. 5 - 2

5.2. Photothermal Conversion ................................................ 5 - 3

5.3. Photochemical Applications ….................................... $5 \cdot 5$

5.3.1. High-Intensity Laser-Jet Photochemistry..................... 5-5

5.3.2. Photoelectrochemistry at High Intensities....................... 5-6

5.3.3. Photomedicine and Photobiology ............................ 5- 5

5.4. Materials Processing and Surface Photochemistry......................... 5 - 7

5.4.1. Surface treatment …......................................... $5-8$

5.4.2. Deposition .............................................. 5 - 10

5.4.2.1. Gas-Phase Deposition Systems................. 5- 5-10

5.4.2.2. Liquid-Phase Deposicion Systems................ 5 - 12

5.4.3. Etching ….............................................. 5 - 14

5.4.3.1. Gas-Phase Systems............................ 5- 5-14

5.4.3.2. Liquid-Phase Systems.............................. $5-14$

5.4.4. Materials Testing …...................................... $5-14$

5.4.5. Synthesis of Ceramic Powders ………….................. 5 - 15

5.5. Solar-Pumped Lasers ….......................................... 5 - 19

5.5.1. Direct Solar Pumping...................................... 5 - 19

5.5.2. Black-Body Pumping................................... 5 - 20

5.6. Special Applications …………........................................ 5 - 20

6. Findings and Recommendations ..................................................... 6 - 1

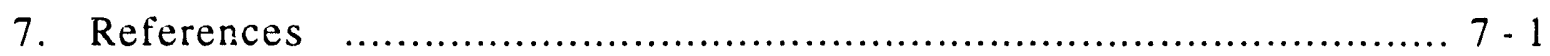

Appendix A. General Principles of Photon-Driven Chemistry

Appendix B. A Guide to the Data Bases

Appendix C. Initial List of Potential Processes for Utilization of Concentrated Solar Energy 


\section{LIST OF FIGURES}

Figure 1. Standard AM-1 Solar Spectrum and Wavelengths of Various Lasers..... 3 - 3

Figure 2. Variation of Solar Flux Intensity .......................................... 3 - 4

Figure 3. Relative Costs of Photon Energy from Various Sources ................ 3 - 14

Figure 4. A. Generic Chemical Process Flowsheet ………........................ 4 - 5

Figure 5. Typical Inputs and Models Used in Chemical Process Simulations....... 4- 6

Figure 6. Generic Cycle Flow Chart ……...................................... 5 - 4

Figure 7. Comparison of AM-1 Spectrum with Metal Absorptivities ............... 5 - 9

Figure 8. Cost estimates for SiC Powders as a Function of Particle Size ......... 5- 17

Figure 9. Hourly Mass Flow Rates Per Unit Volume as a Function of Residence (growth) Time..................................................... $5-18$

Figure A1. Price-Production Volume Correlation for Industrial Chemicals........... A - 2 


\section{LIST OF TABLES}

Table 1. Concentration Ratios for Various Reflectors.............................. 3 - 6

Table 2. NREL Solar Furnace Specifications..................................... $3-8$

Table 3. Equivalent Temperature at Different Flux Levels.............................. $3-8$

Table 4. Photons -.- Their Energy and Cost .................................... 3-13

Table 5. Photon-driven Surface Chemistry Materials and Processes................... 5 - 7

Table 6. Yield of Coal Extractables from Controlled Heating Without External Hydrogen or Donor Solvents.......................................... $5-22$ 


\section{SECTION 1}

\section{INTRODUCTION}

\subsection{Background}

The sun is the ultimate source of nearly all the energy we use on earth. Fossil oil and coal combustion, biomass, hydropower, wind power, tidal energy, human and animal muscular exertion -- all derive from the radiation reaching the earth from the solar reactor 93 million miles out in space. Only the relatively small amounts of geothermal, nuclear fission, and fusion energy released during the past several decades does not have a solar origin.

As we have come to recognize the many undesirable environmental, political, and economic consequences of intense utilization of secondary energy sources, particularly fossil fuel combustion, attempts to use effectively the primary energy source, solar radiation, have gained increasing impetus. One of the major limitations of solar energy use is that solar energy, while ubiquitous, is a widely dispersed and intermittent resource. The solar radiation flux reaching the earth's surface is approximately $1 \mathrm{~kW} / \mathrm{m}^{2}$, or about $0.95 \mathrm{Btu} \mathrm{sec}-1 \mathrm{~m}^{-2}$. This value is an upper bound average, of course, which decreases substantially under overcast or nocturnal conditions. Many applications, such as propulsion engines, electricity generation, and thermal processing of chemical feedstocks and materials, require or function more efficiently at higher energy densities. Some sort of concentration of the available energy is therefore necessary for such applications. Fossil fuel combustion is itself a form of concentration, with energy harvested over millions of years of growth and decay being released in the few seconds required to oxidize the fuel in a furnace. It is only recently, however, that we have come to recognize the formidable, negative consequences associated with intensive use of fossil fuels, including resource depletion, global climate change, other environmental degradations such as acid rain, the human cost of coal and oil extraction, and the political and military conflicts arising from competition for control of these resources.

An alternative approach might be to use the solar energy available in "real time" by spatially concentrating the dispersed solar flux. Concentrated tluxes of solar energy could find beneficial applications in several areas of modern science and technology. While the full range of possibilities remains to be established, there is potential for significant impacts on several nationally important problems, such as hazardous waste management, synthesis and processing of high-technology materials, water decontamination, and development of new technologies for international export. Recent advances in solar concentrator technology at the National Renewable Energy Laboratory, (NREL) formerly known as the Solar Energy Research Institute, (SERI) (Carasso and Lewandowski 1990), and at the University of Chicago (Gleckman et al. 1989; Welford and Winston 1989; Winston 1991) have demonstrated the potential of very high flux density solar furnaces, capable of furnishing peak photon intensities of up to 50,000 times the natural solar insolation at the earth's surface.

With this capability in mind, NREL commissioned three separate detailed assessments of opportunities for applying concentrated solar photons to practical and scientific problems. The goals of these assessments are to suggest innovative, high-flux solar photon processes that show promisc of being feasible and in the national interest; to identify potential technical impediments to promising applications; and to recommend research to help overcome those barriers. The present report is the result of one such study conducted by the MIT Energy Laboratory. 


\subsection{Objectives and Approach}

The primary goal of this study was to identify new high-flux solar photon processes which show promise of being feasible and in the national interest. Additional goals were to identify barriers to effective use of concentrated solar photons and to identify research that could enhance the likelihood of realizing useful applications of this energy source. Our recommendations and conclusions, with supporting documentation, form the body of this report.

We specifically excluded detailed consideration of photovoltaic and solar thermal electricity generation and detoxification of hazardous waste, because those areas are addressed by other ongoing programs and studies. Particular emphasis was given to innovative photochemical technologies.

To accomplish these objectives, the project team undertook the following tasks:

- We surveyed the current state of knowledge in modern photochemistry to identify major U.S. centers of research excellence in disciplines directly relevant to utilization of concentrated solar energy. This was accomplished by interviewing a number of experts in the fields of solar energy, lasers, and photochemical processing, and carrying out a detailed literature search using electronic bibliographic software. The preliminary results of the screened search were provided to SERI on electronic media at the beginning of December, 1990, and a final version was delivered in early February 1991 (see appendix B).

- We sought to identify current and potential beneficial applications of high-flux solar photons for fundamental and practical problems. Particular emphasis was placed on science and technology that could affect pressing national issues such as manufacture of advanced materials and development of innovative chemical processing or other technologies with high export potential. An initial list of innovative processes was generated (appendix C), and a set of evaluation and decision criteria for screening and assessment of specific applications was formulated (Section 4).

- For each process identified as having high or moderate potential, we sought to identify technical barriers to the applications of high-flux solar photons specified above, and to recommend research priorities for overcoming these barriers. Discussions of specific applications, and the conclusions of our study, are presented in Sections 5 and 6 of this report.

The methodology we employed is described in Section 2. Following a review of the basic parameters characteristic of concentrated solar energy, and the identification of evaluation and decision criteria for assessment of specific applications, specific processes and applications showing potential promise are discussed. Finally, we present a set of recommendations for research and development in the utilization of concentrated solar energy. 


\section{SECTION 2}

\section{METHODOLOGY}

To fulfil the study objectives, it was necessary to assemble and review critically a broad body of scientific and engineering information on optics, photochemistry, solar concentrators, photon-matter interactions, materials science and engineering, and chemical processing. Our approach was therefore to assemble a core study team representing broad expertise in several critical study areas, and to buttress that team by promoting succinct but intensive interactions with invited experts on a wide range of topics viewed to be particularly relevant to identifying novel applications for concentrated solar photons.

\subsection{Project Core Team}

The core team provided expertise in photochemistry, spectroscopy, optics, laser science and engineering, and in various aspects of chemical process science and engineering including high-temperature reactions and chemical engineering practice. The core team members, their areas of technical expertise, and their role in this project were:

Pror. Jefirey I. Steinfeld: Professor of Chemistry, MIT, Project Principal Investigator. Areas of expertise include spectroscopy; chemical physics; molecular energy transfer; photochemistry; laser applications to chemistry.

Dr. William A. Peters: Principal Research Engineer and Associate Director, MIT Energy Laboratory. Project Principal Investigator. Areas of expertise include applied kinetics; fuels technulogy; industrial chemistry; thermal chemical reactions of condensed phase and fluid-solids media; environmental health effects of anthropogenic pollutants.

Prof. Jefferson W. Tester: Professor of Cheraical Engineering, MIT, Director, MIT Energy Laboratory, Project Principal Investigator. Areas of expertise include geothermal energy; prccessing of wastes in supercritical water; chemical process engineering; applications of high-intensity lasers in hard rock drilling.

Mr. Howard Herzog: Researrh Engineer, MIT Energy Laboratory. Areas of expertise include energy conservation and end use managemient; process design and simulation; chemical process engineering; technologies for management of greenhouse gases.

Dr. Stephen Coy: Project Consultant. Areas of expertise include spectroscopy; laser science and engineering; pure and applied optics.

Mr. Michael Schlamp: Undergraduate student, Department of Chemistry, MIT. Project task was assembly, editing and updating of compuierized bibliographic data base using Pro-Cite Softwaie requested by SERI for use in this study.

Mr. Jeffrey Shorter: Graduate Student, Department of Chemistry, MIT. Project task was assembly and review of litiature on potential applications of concentrated solar photons in the synthesis or processing of materials.

\subsection{Invited Experts}

To obtain up-to-date information on specialized topics, mcetings of about one to two hours duration were held with experts invited from within and outside MIT. Prior to the scheduled date of the meeting, invited guests were sent written materials summarizing the 
capabilities of the SERI Solar Furnace in Golden, Colorado, and the goals of the current study. After a brief oral presentation on the SERI Solar Furnace by Prof. Steinfeld, each meeting generally took the form of an open-ended round-table discussion in which guests and core team members exchanged comments on the potential applicability of solar furnaces to research or commercial problems in their areas of expertise. In these brainstorming sessions, potential opportunities as well as possible limitations and problem areas in equipment design, scale-up, or operation were discussed. Detailed notes were taken and later rewritten and typed up for the project files and for use in the project final report. These gatherings (Solar Seminars) functioned as a seminar in the neoclassical sense, and proved to be one of the most valuable sources of information for the project core team.

The invited guests and their affiliations and areas of technical expertise were:

Seminar 1: Prof. Michael S. Feld, and Drs. Ramachandra R. Dasari, Irving Itzkan, G. Sargent Janes, and Richard Rava, Harrison Spectroscopy Laboratory, MIT: pure and applied spectroscopy; laser science and engineering; optical devices and instrumentation; and practical applications of lasers.

Seminar 2: Dr. John S. Haggerty, MIT Materials Processing Center: laser synthesis of ceramics and other specialized materials; materials science and engineering; high-temperature processing; materials properties at high temperatures; and solar energy technology.

Seminar 3: Prof. Hoyt C. Hottel, Dept. of Chemical Engineering, MIT, and Prof. Jack B. Howard, Dept. of Chemical Engineering, MIT: solar energy; solar furnace design and scale-up; radiative heat transfer; combustion; fuels and energy technology; flame synthesis of carbon forms including diamondlike carbons and "buckminsterfullerene" $C_{60}$ and $\mathrm{C}_{70}$ cluster structures; flame chemistry; coal and biomass pyrolysis; high-temperature reactions of solid fuels; and soot and polycyclic hydrocarbons formation in hightemperature processes.

Seminar 4: Prof. Roy G. Gordon, Dept. of Chemistry, Harvard University: solar energy including scientific research and commercial applications; Prof. Peter Langhoff, Department of Chemistry, Indiana University, Visiting Professor, Harvard University; solar photochemistry; and solar thermal engines.

Seminar 5: Profs. Thomas F. Deutsch and Irene Kochevar, Wellman Laboratories, Massachusetts General Hospital and Harvard Medical School: photomedicine, photobiology, and applications of lasers in medicine.

Seminar 6: Prof. Adel F. Sarofim, Department of Chemical Engineering, MIT: radiative heat transfer; solar energy; applied chemical kinetics; high temperature fluid-solid reactions; synergisms between thermal, photochemical, and catalytic processing; hazardous substances management; and formation and control of pollutant emissions.

Seminar 7: Prof. Mark S. Wrighton, Provost of MIT and Ciba-Geigy Professor of Chemistry: inorganic photochemistry; catalysis; photoelectrochemistry; surface chemistry; and molecular electronics.

Seminar 8: Prof. Roland Winston, Dept. of Physics, University of Chicago: design, operation, and application of solar concentrators providing ultrahigh solar flux densities. (Prof. Winston was an invited speaker in the Spring 1991 Modern Optics and Spectroscopy Seminar series.) 


\subsection{Interactions with NREL and with Other Studies}

To facilitate further timely assimilation, communication and updating of study findings, the core team interacted with the SERI technical project officer, Dr. Meir Carasso. Three core team members visited SERI shortly after the startup of the project to consult with SERI scientists, engineers, and technical managers interested in solar concentrators and their applications (including Drs. J. Anderson, D. Blake, M. Carasso, J. Connolly, B. Gupta, S. Hauser, A. Lewandowski, T. Milne, L. Murphy, M. Nimlos, A. Nozik, R. Pitts, and M. Seibert), to provide an oral presentation on the scope and methodology of the then just starting project, and to view the SERI solar concentrator and related hardware and instrumentation facilities first hand. Approximately four weeks later, two core team members attended a workshop at SERI headquarters set up to brief members of a National Academy of Sciences study panel the Committee on Potential Applications of Concentrated Solar Photons. Similar to the current study, this panel was examining opportunities for promising applications of solar furnaces. Unlike the current study, hazardous waste detoxification was specifically included in their charter. Our core team members participated in several of the topical sessions at this workshop, including Introductory Plenary; Materials Processing and Synthesis; Plenary on European Perspectives; Solar Pumping of Lasers; Photochemical Synthesis; Advanced Research; and the Wrap-up Plenary With Reports From Individual Session Rapporteurs. Our team members spoke one-on-one with several experts in the field and met with members of a second and also independent study team from SRI International, Inc. Based on those interactions and a follow-on telephone conversation and letter, is was agreed that the SRI and MIT teams would carry out their studies independently with each team giving special, but by no means exclusive, attention to areas deemed to be particularly appropriate for them in light of their own technical expertise and access to other experts.

Two core team members also visited the laboratory of Prof. Roland Winston in the Dept. of Physics at the University of Chicago to view, first hand, Prof. Winston's specialized solar concentrators that provide, within selected dielectric media, solar flux densities exceeding 8 $\mathrm{kW} / \mathrm{cm}^{2}$.

\subsection{Bibliographic Data Bases}

The methodology employed in the construction of the bibliographic data bases can be clearly divided into two processes: (1) searching for/collecting of citations and (2) cleaning/sorting of citations. The searching and collecting involved the initial interactions with various outside inforrnation sources whereas the sorting and cleaning was carried out entirely within the Pro-Cite bibliographic management software program.

Although many citations arose independently in the course of the everyday work of the members of the project team, the majority of them were retrieved from the computerized Science Citation Index (SCI) available in the MIT Science Library. The search focused on material published between January 1987 and June 1990, although a fair degree of material from 1985 and 1986 was also reviewed. With the use of both chemical intuition and trial and error, a working set of criteria emerged, which, when used to search the SCI, yielded a great many pertinent citations. Each set of criteria produced a separate Pro-Cite data base -thus 14 existing data bases correspond to 14 distinct searches, with 2 data bases arising from sources other than the SCI (primarily an earlier Pro-Cite data base received from Dr. D. M. Blake at SERI). It should be made clear that the SCI limited itself to title searches only, and while it is conceivable that some relevant citations "fell through" our extremely broad net of criteria due to the phrasing of their titles, this was the only practical alternative and did in fact yield a rich variety of pertinent material. 
The citations that were retained (some 6000 in all) were downloaded onto floppy disks and transferred directly into the Pro-Cite data base for review and sorting.

At this point, the gathered citations were scanned individually and critical decisions were made concerning their relevance for the next phase of review. In all, approximately $60 \%$ (or 3600 ) of those citations downloaded from the SCI were particularly relevant and examined in more detail. The remainder were immediately deleted. Some records that were retained were copied and moved to ensure that each citation appeared in all the Pro-Cite data bases to which it was relevant, and in only those to which it was relevant. Indeed, while most citations appear in the final collection of data bases only a single time, some of the more interdisciplinary material may appear two or even three times.

Appendix B contains a cietailed description of the criteria used to construct each data base as well as a guide for efficient internal searching within Pro-Cite. 


\section{SECTION 3.}

\section{CHARACTERISTICS OF CONCENTRATED SOLAR ENERGY AND COMPETING TECHNOLOGIES}

\subsection{The Sun Itself}

The sun is a main sequence star with approximately another 5 billion years of life before it becomes a red dwarf and expands radially outward to a point somewhere in the asteroid belt beyond Mars, evaporating the inner planets (Smoluchowski 1983). On this time scale, the only viable energy sources are renewable ones. Such resources shouid be developed as soon as possible, because many of the nonrenewable resources are much more valuable as chemical feedstocks than as fuels for combustion, and will be necessary during the long (or short) history of humanity.

The radiative energy density $\rho$ at the surface of the sun may be calculated by the StefanBoltzmann law for a black-body (Richtmyer et al. 1955). The Stefan-Boltzmann lic $w$ is

$$
\rho=\sigma \mathrm{T}^{4}
$$

where $\sigma=7.56 \times 10^{-15} \mathrm{erg} /\left(\mathrm{cm}^{3}-\mathrm{deg}\right)$.

In order to convert this energy density to a directional flux (e.g., $\left.\mathrm{kW} / \mathrm{cm}^{2}\right), \rho$ must be multiplied by one-quarter the speed of light. A factor of $1 / 2$ is introduced to select energy propagating away from the sun from that propagating toward the sun, and the second factor of $1 / 2$ is introduced in calculating the flux through an imaginary surface by averaging the velocity normal to the surface. The flux is then

$$
\mathrm{F}=\mathrm{A} \mathrm{T}^{4}
$$

where $A=5.666 \times 10^{-15}\left(\mathrm{~kW} / \mathrm{cm}^{2}\right) /\left(\mathrm{deg}^{4}\right)$.

Black body-fluxes for various temperatures are illustrated in Neugebauer and Becklin (1973). They are quite smooth, with each higher temperature exceeding the radiation from lower temperatures at all wavelengths. Absorption bands in the solar atmosphere modify the spectral distribution from that of a black-body and reduce the effective temperature when viewed from outside the earth's atmosphere. The actual temperature of the photosphere varies from about $6600 \mathrm{~K}$ to $4300 \mathrm{~K}$ over its $500-\mathrm{km}$ depth. The effective temperature of the photosphere is estimated to be $5800 \mathrm{~K}$ giving $6.4 \mathrm{~kW} / \mathrm{cm}^{2}$ (Noyes 1976). Gleckman et al. (1989) give the flux at the sun's surface as $6.3 \mathrm{~kW} / \mathrm{cm}^{2}$, which corresponds to an effective black-body temperature of $5775 \mathrm{~K}$.

The actual AM0 spectrum (air mass zero outside the earth's atmosphere) is reported by Thekaekara (1974) and shows more structure than the black-body curve, especially in the visible and ultraviolet (UV). The integrated solar flux above the atmosphere is known as the solar constant, and is given by Thekaekara as $.1352 \mathrm{~W} / \mathrm{cm}^{2}$. Using the square law to calculate the flux at the solar surface from the solar constant gives $6.03 \mathrm{~kW} / \mathrm{cm}^{2}$, so that about $4 \%$ of the energy is absorbed in the sun's own atmosphere. Buhl et al. (1984) reported the effective solar irradiance at different air masses and zenith angles using two different computer codes for modeling radiative transport. They report total fluxes for AM1 (solar radiance through clear air at sea level) in the vicinity of $0.1 \mathrm{~W} / \mathrm{cm}^{2}$ for midday levels, decreasing to $0.07 \mathrm{~W} / \mathrm{cm}^{2}$ at zenith angles of 45 degrees. Thus concentrated solar 
radiation of 10,000 suns corresponds to a total flux of $1 \mathrm{~kW} / \mathrm{cm}^{2}$, with the spectral distribution shown in Fig. 1.

The useful solar flux in any particular location is further reduced by clouds, haze, and smog, so that clear-sky locations and batch-processing applications are favored. Fig. 2 shows a sequence of solar flux records for Cambridge, Massachusetts, illustrating the types of intermittency that occur in a non-ideal location. Superimposed on the normal diurnal variation are fluctuations from passing clouds or other obstructions. On two out of the five days, the available solar flux is reduced to nearly zero by overcast conditions. Even on a bright but hazy day [trace (f)], direct sunlight reaching the photoreceptor (equivalently, a. primary concentrator) is degraded by up to a factor of 3 .

\subsection{Concentration of Solar Energy}

\subsubsection{Theoretical and Practical Lımits in Solar Furnace Design}

In this section we consider both theoreucal and practical limits to flux levels that can be achieved with a solar source, with emphasis on estimating practical working fluxes. Nonimaging concentrators are sometimes seen as the answer to all requirements for collection and concentration of solar radiation, necessarily providing a dramatic increase in available solar fluxes. In fact, non-imaging concentrators, even though they may attain very high fluxes exactly at the concentrator exit, become comparable to imaging systems when the focus is at significant working distances from the concentrator. This limitation may be especially important to material processing applications. We examine the specific requirements of concentrators: high concentration in air, high concentration in dielectric materials, and good collection efficiency.

\subsubsection{Maximum Concentrations in Air}

The thermodynamic limit, or, equivalently, the limit from geometric optics, for concentration in a material with index of refraction $n=1.0$, is (Bassett et al. 1989)

$$
C_{\max }=\sin ^{2} \Theta^{\prime} / \sin ^{2} \Theta
$$

where $\Theta^{\prime}$ is the maximum angle from the normal of radiation striking the target and $\Theta$ is the maximum angle from the normal to the collector aperture of incoming radiation. The highest concentrations are achievable for hemispherical illumination of the target, corresponding to $\Theta^{\prime}=90^{\circ}$. The important number in determining the peak concentration is the f number: the ratio of the object distance to the final aperture diameter for a non-imaging concentrator, or to the collection diameter for imaging systems. Practically achievable lens systems are limited to f numbers of 0.5 to 1.0 , providing maximum concentrations about a factor of 4 lower.

Hemispherical illumination of the target corresponds to a target placement in the exit plane of the concentrator. With any optical system, the closer the object, the higher the possible magnification. It is this ability to concentrate very close to the concentrator itself, and to illuminate from all directions of a hemisphere, that accounts for the greater peak concentrations achievable with non-imaging optics. It is also this requirement that limits the usefulness of the fluxes achieved because ablation of the target may destroy the 


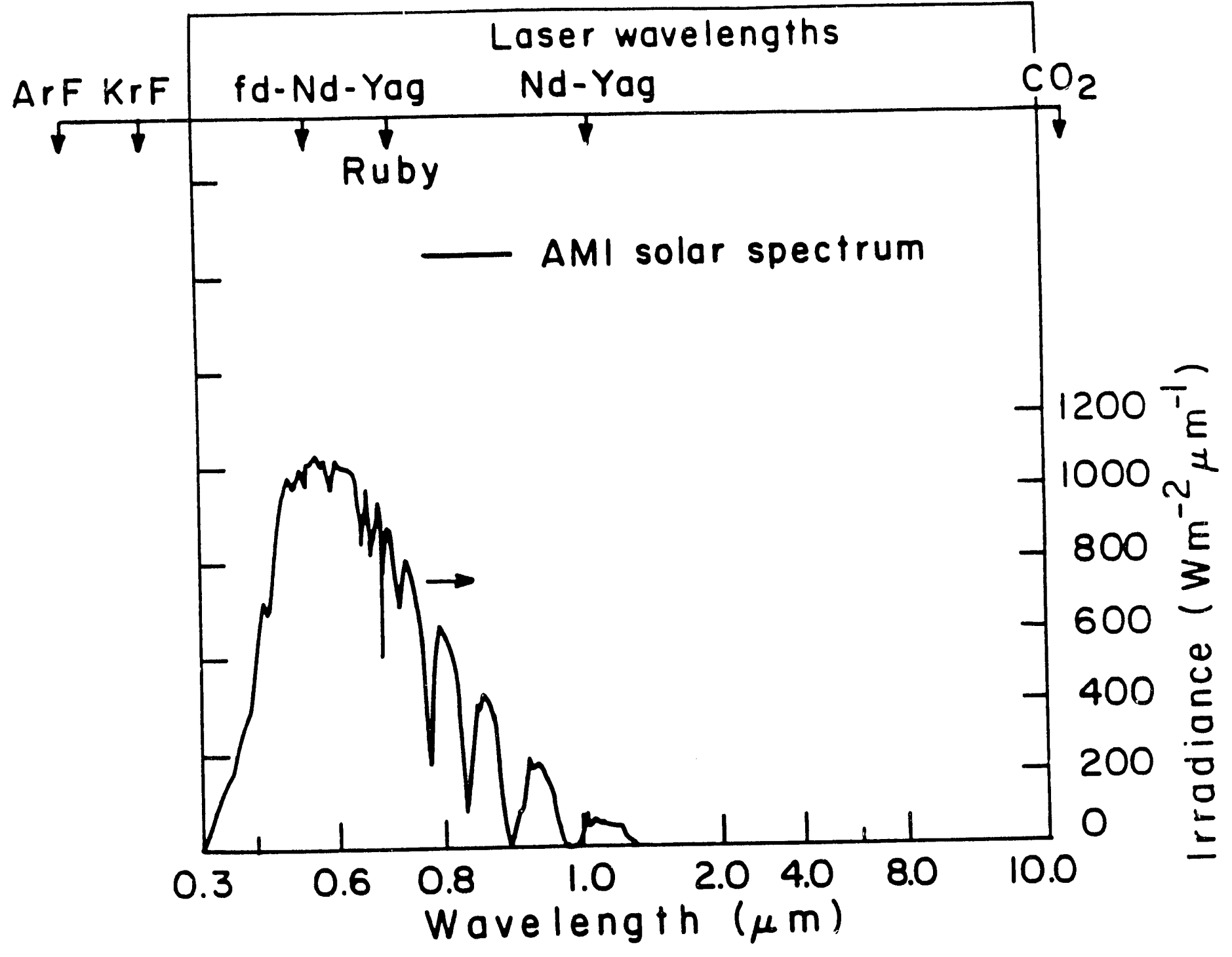

Figure 1. Standard AM1 solar spectrum and wavelengths of various lasers. 


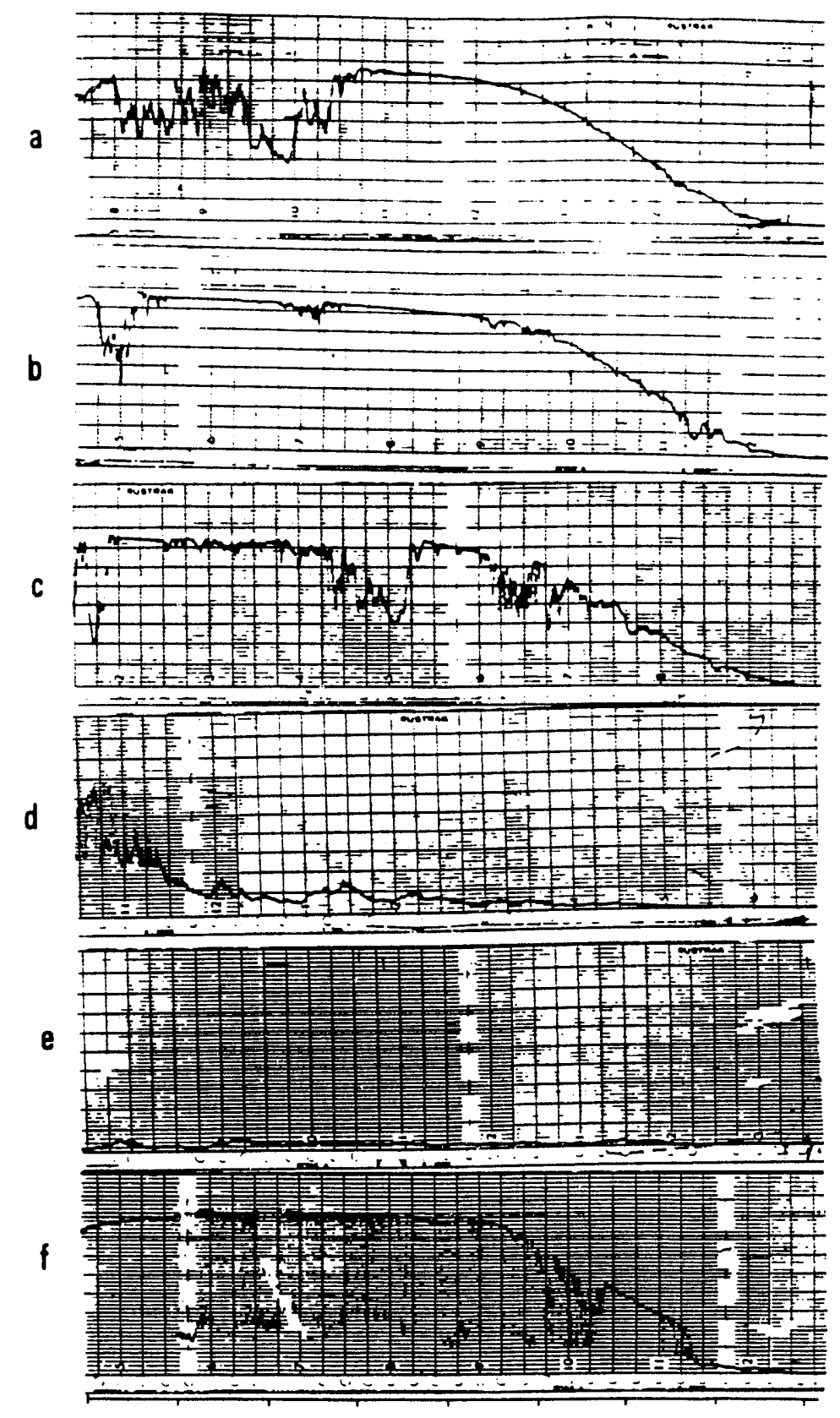

Figure 2. Variation of solar flux intensity. These traces record the short-circuit current from a silicon solar cell mounted on the roof of an MIT building in Cambridge, Massachusetts, at a fixed south-facing position approximately $45^{\circ}$ from horizontal, between 8:30 a.m. and 5:00 p.m. Traces a - e were recorded in a consecutive five-day period in early February, 1991. Variations caused by solar aspect and passing clouds are readily apparent, as is the essentially complete unavailability of the solar source on two overcast days, $d$ and $e$. Trace $f$, recorded on an earlier day, shows the effect of haze or high, thin clouds. Although the average brightness is high, the receiver sees high-frequency fluctuations with a modulation depth of more than $70 \%$. These traces were provided by Mobil Solar Energy Corp. of Billerica, Massachusetts. 

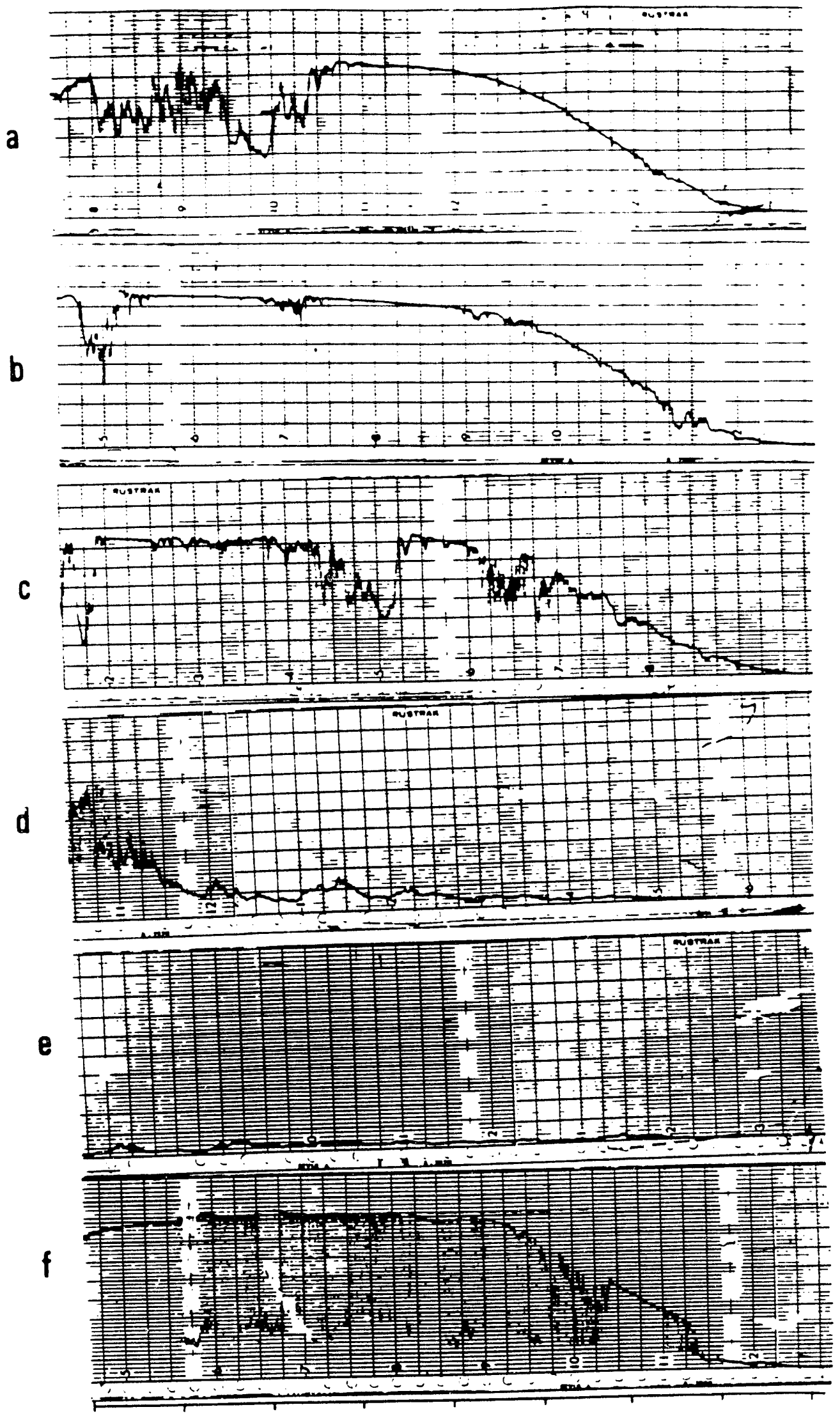

Figure 2.

$3-5$ 
concentrator, and the target cannot be isolated. Imaging and non-imaging optical systems will provide similar concentrations at target distances within the capabilities of imaging systems. Peak achievable concentrations in air are computed using eqn. 2.4 in Basselt et al. (1989), the fundarnental theorem in non-imaging optics, which is given above. Concentrations for a paraboloidal reflector are computed from Winston (1991) and are computed only for target illumination angles up to $45^{\circ}$ off axis, which give the highest concentration. Both are given in the Table 1.

\section{Table 1. Concentration Ratios for Various Reflectors}

\begin{tabular}{cccc} 
f number & $\begin{array}{c}\mathrm{C}_{\max } \\
\text { (ratio in air) }\end{array}$ & $\mathrm{C}_{\max } / \mathrm{C}_{\max }(\mathrm{f}=0)$ & Paraboloidal \\
\hline 0.00 & 44000 & $\cdots$ & not feasible \\
0.25 & 35200 & 1.00 & $" 1$ \\
0.50 & 22000 & 0.80 & 11000 \\
0.71 & 14667 & 0.50 & 10864 \\
0.75 & 13539 & 0.33 & 8250 \\
1.00 & 8800 & 0.31 & 3133 \\
$1.8^{*}$ & 3152 & 0.20 & 2578 \\
2.0 & 2588 & 0.072 &
\end{tabular}

("NREL primary concentrator value)

The peak value, 44000 , is equal to the square of the ratio of the earth-to-sun distance to the radius of the sun. The average earth-to-sun distance is $146.9 \times 10^{6} \mathrm{~km}$, and the radius of the sun is approximately $0.7 \times 10^{6} \mathrm{~km}$. The maximum concentration, $\mathrm{C}_{\max }$, gives the limit to the ratio of concentrated-to-unconcentrated sunlight determined by geometric optics or, equivalently, by combined application of the first and second laws of thermodynamics. The peak intensity in $\mathrm{kW} / \mathrm{cm}^{2}$ depends on the local insolation, which varies with air mass, humidity, etc.

In some cases, a primary dish concentrator designed for $\mathrm{f}=0.75$ or $\mathrm{f}=1$ may provide higher usciul flux on target than a primary/secondary combination designed for a large object distance. This is in spite of the fact that a standard parabolic reflector has sufficient optical distortion (coma) that low $f$ numbers do not achieve the theoretical concentration. Longer focal lengths have the additional advantage of making axial placement of the target less sensitive.

\subsubsection{Maximum Concentrations in Dielectric Materials}

The sizes of images formed inside a dielectric material are reduced in each dimension by $n$, the index of refraction of the material. This reduction may be viewed as a result of the reduction in wavelength, which occurs inside a dielectric, and may be derived using the conservation of radiance (Bassett et al. 1989).

Thus, $C_{\max }$ is higher within a dielectric by a factor of $n^{2}$ on a surface, and $n$ on a line than it is in air. This increase is not specific to non-imaging systems. Concentrations achieved inside a dielectric cannot propagate outside and exceed the theoretical maximum in air because of the variation of the critical angle for total internal reflection with the index of refraction of the dielectric; the required fraction of the flux is internally reflected at the 
boundary. Similarly, a dielectric black-body cavity cannot be heated to a super-solar temperature because its energy density is higher by $n^{3}$ than an emply cavity at the same temperature.

Indeed. concentrated solar energy coupled to a dielectric material can reach the highest possible concentration only if the concentrator has the same dielectric constant and is coupled directly to the object.

\subsubsection{Collection Efficiency}

The methods of non-imaging optics provide design principles that build in efficient collection of solar radiation. Nonetheless, imaging systems, including refractive or reflective systems, are able to collect incoming radiation with the same types of efficiencies, limited by the reflection at surfaces or absorption losses in materials.

The requirement for a significant concentrator-to-object distance appears to limit the peak working solar flux to values in the 2000 to 5000 sun range for primary concentrators, and to the 10,000 sun range for combined primary/secondary systems.

\subsubsection{Capabilities of the NREL Solar Furnace}

\subsubsection{Concentration Parameters}

The NREL Solar Furnace consists of a tracking heliostat of $38 \mathrm{~m}^{2}$ that fills a primary concentrator of $12 \mathrm{~m}^{2}$. The NREL primary concentrator was designed with a relatively high $f$ number of 1.8 for a theoretical maximum concentration ratio of 3133 in order to minimize optical aberration of the off-axis paraboloidal design. Because values of 2300 suns have been measured, the primary concentration is achieving $73 \%$ of the theoretical level, which is consistent with reflectivity losses. This efficiency value assumes that the 2300 value quoted by $A$. Lewandowski of NREL is a concentration ratio rather than a total flux value based on a nominal insolation of $1 \mathrm{~kW} / \mathrm{m}^{2}$. Much of the UV in the solar spectrum is preserved because of the use of front-surface aluminum mirrors. The primary provicies a Gaussian-profile beam of $9 \mathrm{~kW}$ total power, with about $6 \mathrm{~kW}$ centered in an area of $88 \mathrm{~cm}^{2}$. The wavelength distribution between 300 and $2500 \mathrm{~nm}$ is shown in Fig. 1 .

A secondary concentrator available at the NREL. Solar Furnace was designed specifically to match the primary. Its input aperture is $6 \mathrm{~cm}$ and the output is $1.4 \mathrm{~cm}$, for a reduction in area of about 18. The target location is in the output aperture plane. It has achieved an enhancement of the flux from the primary of about a factor of 10, reaching 21,000 suns. This value is $48 \%$ of the maximum theoretical value in air. 
Table 2. NREL Solar Furnace Specifications

Heliostat

Primary

Secondary

Fluxes achieved

Primary alone

Primary and Secondary
$38 \mathrm{~m}^{2}$, planar front-surface aluminum mirrors

$12 \mathrm{~m}^{2}$, front-surface aluminum mirrors, off-axis paraboloid constructed from segments

Ag-coated, water-cooled $\mathrm{Cu}-\mathrm{Te}$ alloy with an output aperture of $1.4 \mathrm{~cm}$

Gaussian beam, $9 \mathrm{~kW}$ total power

2300 suns peak power, $8 \mathrm{~kW}$ in $88 \mathrm{~cm}^{2}$

21,000 suns, hemispherical

illumination of a $1.4-\mathrm{cm}$. diameter area.

\subsubsection{Heating with the NREL Solar Furnace}

The temperatures achievable with a given energy flux depend on the absorptivity and emissivity of the target, and their match to the incoming spectrum. For a target that is a small opening in an ideal black-body cavity. Table 3 gives equivalent temperatures at different flux levels.

Table 3. Equivalent Temperature at Different Flux Levels

\section{Concentration}

100

500

1000

2000

5000

10000

15000

20000

\begin{tabular}{c} 
Flux, $\mathrm{kW} / \mathrm{cm}^{2}$ \\
\hline 0.01 \\
0.05 \\
0.1 \\
0.2 \\
0.5 \\
1.0 \\
1.5 \\
2.0
\end{tabular}

Equivalent Blackbody T,K

1153

1724

2050

2440

3065

3645

4034

4334

\subsubsection{Heating Rates}

Radiation provides surface heating that must propagate inward by conduction or be carried away by radiation, evaporation, or pyrolysis. Solar radiation at the 1000-sun level provides a heat flux of $100 \mathrm{~W} / \mathrm{cm}^{2}$, which can in principle provide heating rates in the $10^{6}$ ${ }^{\circ} \mathrm{C} / \mathrm{sec}$. range for small particles. In discussing the heating rate and its effects on the chemical or physical transformation of condensed phase media, it is important to specify what fraction of the total volume of the workpiece is undergoing rapid heating and to determine whether or not spatial or temporal variations in the temperature field within the sample are exerting significant effects on reactivity or other desired behavior (e.g., annealing). Hajaligol et al. $(1988,1991)$ discuss quantitative approaches in this regard, with particular reference to effects on the global kinetics of the rapid pyrolysis of solids such as coal and cellulose, and identify several other studies pertinent to this topic. 
In particular, Hajaligol et al. (1988) noted that time and spatial temperature gradients within pyrolyzing coal particles can exert strong effects on devolatilization behavior including apparent pyrolysis kinetics. In response, they mathematically modeled transient and spatial nonisothermalities within a single, spherical coal particle underguing pyrolysis, with temperature-invariant thermal and physical properties. Analyses were performed for two surface heating conditions of practical interest, a constant rate of increase in surface temperature, and a constant surface heat flux density. The treatment provides three distinct time-dependent indices of heal-transfer effects by quantitatively predicting the extent of agreement between (a) center-line and surface temperature (i.e., the classical index based on spatial gradients in temperature alone), and between (b) volume-averaged pyrolysis rate [or (c) volume-averaged pyrolysis weight loss], and the corresponding quantity calculated by using the particle surface temperature for the entire particle volume. Regimes of particle size, surface heating rate or surface heat flux density, and reaction time, where particle "isothermality" according to each criterion (a-c) is met to within prescribed extents, were computed for conditions of interest in entrained gasification and pulverized-coal combustion, including pyrolysis under nonthermally neutral conditions. The concept of distinct, "non-isothermality" indices for temperature, for rate, and for ':onversion can in principle be extended and applied to any condensed phase system of interest for processing in solar furnaces. The rate and conversion indices were intentionally formulated to take account of the effects of spatial and temporai variations in sample temperature on conversion rates and conversion itself. Thus, they may prove more useful in evaluating how sample temperature variations can be expected to impact reactor sizing, process control and operability, and practically attainable yields of desired products.

Applications of this analysis to interpretation of the global kinetics of pyrolysis of cellulose sheets of different thickness led Hajaligol et al. (1991) to some further conclusions especially relevant to understanding effects of the ultrahigh (surface) heating rates attainable with solar concentrators. Their study predicted, for rates of change of surface temperature on the order of $10^{5} \sim 10^{6} \mathrm{C} / \mathrm{sec}$ (by endothermic reaction of the substrate, or by high external insolation under thermo-neutral conditions), the existence of a second domain of sample non-isothermality where heat transfer into the sample and near-surface chemical reaction become essentialy decoupled, at least temporarily. Under these conditions, the chemical reaction is confined to a surface layer too thin to support significant temperature non-uniformities and pyrolysis (or other reactions) occur virtually free of heat transfer linitations. In practice such conditions might well arise in some applications of solar concentrators, e.g., during pyrolysis of very reactive, low thermal conductivity materials and in so-called ablative pyrolysis of solids.

The above analyses of Hajaligol et al. $(1988,1991)$ are a useful starting point for estimating solar-concentrator-derived values of heat flux densities for which significant effects on sample non-isothermality can be expected.

\subsection{Costs and Characteristics of Radiative Sources}

Radiative sources for rapid heating, materials processing, and chemical production include arc lamps, pulsed excimer, pulsed and c.w. $\mathrm{CO}_{2}$ and YAG lasers, as well as the solar furnace. For comparison with the commodity chemical costs in appendix A, we sought to obtain estimates of the costs associated with various radiation sources. We find that the cost of solar photons is quite competitive with that for arc lamps for batch applications, based on the analysis of Kolb (1990), and with $\mathrm{CO}_{2}$ laser sources, and is lower than the cost of laser-generated UV photons in the solar wavelength regime. 


\subsubsection{Cost of Solar Photons}

In order to compare solar concentrator costs with costs from other sources on a common basis, a levelized approach was used. The methodology is consistent with Kolb's (1990) economic analysis of a $1(X)-\mathrm{kW}$ arc lamp system. Total direct capital costs are scaled using a constant factor to estimate indirect costs associated with installation. Annualized costs are then estimated using an annual tixed charge rate multiplied by total direct and indirect costs. Annual operating costs are then added to obtain total annual cost. Levelized costs are then determined by dividing these annualized costs by the useful energy delivered to the target during one year of operation. The final result can be expressed in dollars per kilowatt-hour thermal, dollars per gigajoule $(G J)$, dollars per mole of photons, or some other equivalent unit.

A wide range of levelized costs for solar photons have been reported. The stated values range over a fuctor of 200 . We discuss. three recent estimates below. For comparison with other energy sources, and with previous economic analyses, we examine both the cost per energy unit and the cost per mole of photons. The energy content of radiation is given by

$$
\begin{gathered}
\mathrm{E}_{\mathrm{N} O=\mathrm{N}_{0} h v}=\mathrm{N}_{0} \mathrm{hc} / \lambda=(119624 / \lambda(\mathrm{nm})) \mathrm{kJ} / \mathrm{mole} \\
=(33.229 / \lambda(\mathrm{nm})) \mathrm{kWh} / \text { mole }
\end{gathered}
$$

At the approximate peak of the AM1 solar distribution near $550 \mathrm{~nm}$, this formula gives $217.5 \mathrm{~kJ} / \mathrm{mole}$.

Approximately $30 \%$ of the solar photons in the AM1 spectrum (see Fig. 1) in terms of number density are between 300 and $700 \mathrm{~nm}$. This number is a lower limit to the fraction of the solar energy appearing in that range because the remaining energy is in the infrared (IR). We thus estimate $50 \%$ to be a reasonable energy fraction for the 300 -to- $700-\mathrm{nm}$ range, with the remaining energy in the IR.

At the November 7-8, 1990, NAS/NRC meeting, E. Bilgen gave the lowest recent cost values, estimating the cost of high-temperature solar heat at $\$ 1$ to $\$ 3 / G J$ from dish systems and $\$ 5$ to $\$ 10 / \mathrm{GJ}$ for central receiver systems (Hammache and Bilgen 1988).

Based on those references, the cost in $\$ /$ mole of solar radiation between 300 and $700 \mathrm{~nm}$ is approximately, for dish collectors, $0.0002175 \times(\$ 1$ to $\$ 3) / 0.5=\$ 0.000435$ to $\$ 0.001305 / \mathrm{mole}$, and for central receivers, $\$ 0.002175$ to $\$ 0.00435 / \mathrm{mole}$. If we assume that the average wavelength of the IR available in the other half of the spectral energy is about $1100 \mathrm{~nm}$, then the costs of IR are about half of the values given above per mole of photons.

The data in M. Carasso's letter of September 1990 give an installed cost of $\$ 400$ to $\$ 500$ $/ \mathrm{kWt}$ (kilowatt thermal) of high-temperature solar heat at the 1000 sun-level. To this figure must be added an estimate of the system lifetime, maintenance costs, and duty factor. Lifetimes in the 10-to-20-year range, with maintenance costs about $10 \%$ of the installed cost per year, give values near $\$ 10 / G J$. A comparison of the economics of solar furnaces and arc lamps in the 1000-to-5000-sun range (Kolb 1990) gives higher figures. In particular, his lower bound on the installed cost of a $48-\mathrm{kW}$ (target energy) furnace is $\$ 6312 / \mathrm{kW}$, and a levelized energy cost is quoted of approximately $\$ 0.75 / \mathrm{kWht}$ (kilowatthour thermal) for 4 hours operation per day (typical electrical costs are $\$ 0.10 / \mathrm{kWh}$ ). This corresponds to $\$ 208 / \mathrm{GJ}$ of energy delivered on target, or $\$ 0.042 /$ mole of photons for a nominal wavelength of $600 \mathrm{~nm}$. If only a portion of the total solar spectrum is actually 
utilized in a process, then the $r$ levelized costs are estimated i.

.ur that portion is correspondingly higher. For example,

- $\$ 0.091 / \mathrm{mole}$ in the 300-to-700-nm band (center $550 \mathrm{~nm}$ )

- $\$ 0.045 / \mathrm{mole}$ in the 700 - IR band (center $1100 \mathrm{~nm}$ )

The available estimates of the cost of solar photons vary by a factor of 200 , from high to low.

\subsubsection{Cost of Arc Lamp Photons}

The source closest in character to the solar spectrum is the Vortek arc. It is an electrically driven, compact, high-inicnsity source that attains temperatures in the arc itself of more than $10,000 \mathrm{~K}$, hotter than the sun's surface. It has been used for the pumping of highpower YAG lasers, and a variety of materials processing applications.

G. Kolb of Sandia National Laboratory has presented an economic analysis (Kolb 1990), which indicates thai a dedicated solar furnace for batch processing applications is approximately equal in 'evelized energy cost to the Vortek arc for processes requiring 1000 sun fluences and 4-hours-per-day operation. For fluences at the 5000-sun level, the economics more strongly favors the solar furnace. Assuming an average emission frequency of $500 \mathrm{~nm}(0.06546 \mathrm{kWh} /$ mole $)$ the costs are:

- at 1000 suns -- $\$ 1.3 / \mathrm{kWht}$ or $\$ 0.086 / \mathrm{mole}$

- at 5000 suns -- $\$ 2.2 / \mathrm{kWht}$ or $\$ 0.146 / \mathrm{mole}$

A primary system alone at a solar furnace is capable of providing levelized power at the 1000-sun level. Levelized power at 5000 suns requires a secondary concentrator. A secondary concentrator can be designed with a useful concentrator-workpiece distance and still achieve $\epsilon$ nough excess power to operate at a constant 5000 suns.

Disadvantages of the solar furnace discussed by Kolb include the need to modify or redesign existing buildings to couple the solar power to the processing line. The primary advantages of this energy source include little or no need for external electrical sources, no need for cooling water, lower operat'ng and maintenance costs, and higher concentrator-totarget distances.

\subsubsection{Cost of Laser Photons}

Woodin et al. (1990), give $\$ 10$ to $\$ 70 /$ mole of $193-\mathrm{nm}$ photons from an excimer laser (incorrectly identified as a $\mathrm{KrF}$ laser rather than an ArF laser). They give two conflicting values for the cost of $\mathrm{CO}_{2}$ photons. A direct cost of $\$ 0.10$ to $\$ 0.50 / \mathrm{mole}$ for $\mathrm{CO}_{2}$ photons is given, but they also quote a value of $\$ 11.40 / \mathrm{kWht}$ for $\mathrm{CO}_{2}$ photons, corresponding to $\$ 0.038 / \mathrm{mole}$. The presentation by $\mathrm{W}$. Short dated November, 16,1989 , on a comparison of solar furnace costs versus c.w. $\mathrm{CO}_{2}$ lasers, gives a levelized cost of about $5.5 / \mathrm{kWh}$ for $\mathrm{CO}_{2}$ laser energy, a still lower cost.

Although the Woodin et al. values for UV photon costs may be somewhat high, earlier versions of Fig. 3 showed unrealistically low costs for excimer lasers as primary sources, perhaps supplied by a laser salesman of that era. It is now recognized by workers in the field that excimer lasers are more expensive than other primary laser sources, and are at 
least comparable to costs of Nd-YAG-pumped or flash-lamp-pumped dye lasers (secondary sources).

\subsubsection{Cost of Product Processed by Photons}

The cost estimate from Woodin et al. (1990) of $\$ 10$ to $\$ 70 /$ mole of UV photons is considerably more expensive than the cost of solar photons given above, even considering the 2.85 ratio between the energy of ArF photons at $193 \mathrm{~nm}$ and the solar peak at about 550 $\mathrm{nm}$. Table 4 and Figure 3 compare the costs of photon energy from various sources, normalized to a common basis of dollars per gigajoules energy delivered.

As Woodin et al.(1990) note, quantum yield is the key parameter in translating the $\$ 0.091 /$ mole quoted above for solar photons into dollars per pound of processed material. For example, assuming a quantum yield of 1 and a molecular weight of product of 100 , the cost of solar photon energy per pound of product is

$$
\$ 0.091 / \mathrm{mole} \times 1 / 100 \mathrm{~mole} / \mathrm{g} \times 453.6 \mathrm{~g} / \mathrm{lb}=\$ \mathbf{0 . 4 1} / \mathrm{lb} \text {. }
$$

Industrial processes involving chain reactions or catalytic effects would reduce this cost by the ratio of the quantum yield. 


\section{Table 4. Photons .. Their Energy and Cost}

$\mathrm{E}_{0}(\mathrm{~kJ} / \mathrm{mole})$

Cost $(\$ /$ mole $)$

$\operatorname{Cost}(\$ / G J)$

Broadband sources

Solar furnace

1000 - 5000 suns

(600 $\mathrm{nm}$ center wavelength)

200

0.042

208

Vortek arc

$$
\begin{aligned}
& 1000 \text { suns } \\
& 5000 \text { suns }
\end{aligned}
$$

239

0.086 360

239

0.146

$\mathrm{CO}_{2}$

$\mathrm{Nd}: Y A G(1064 \mathrm{~nm})$

.12

112

0.03

2,500

Alexandrite $(720-800 \mathrm{~nm})$

158

Frequency-doubled-YAG (532 nm)

225

Pulsed dye (600 nm, YAG-pump)

200

Argon ion

250

3.94

35,000

4.05

15.75

40,000

46.00

70,000

13.75

230,000

620

40.00

55,000

64,500

Solar-Pumped Lasers

Nd:YAG

Dye $(600 \mathrm{~nm})^{\mathrm{a}}$

Cr:Nd:GSGGa
112

200

112
1.80

2.20

1.12
16,000

11,000

10,000

a Under development by R. Winston, University of Chicago. We thank Prof. R. Winston for providing these data. 


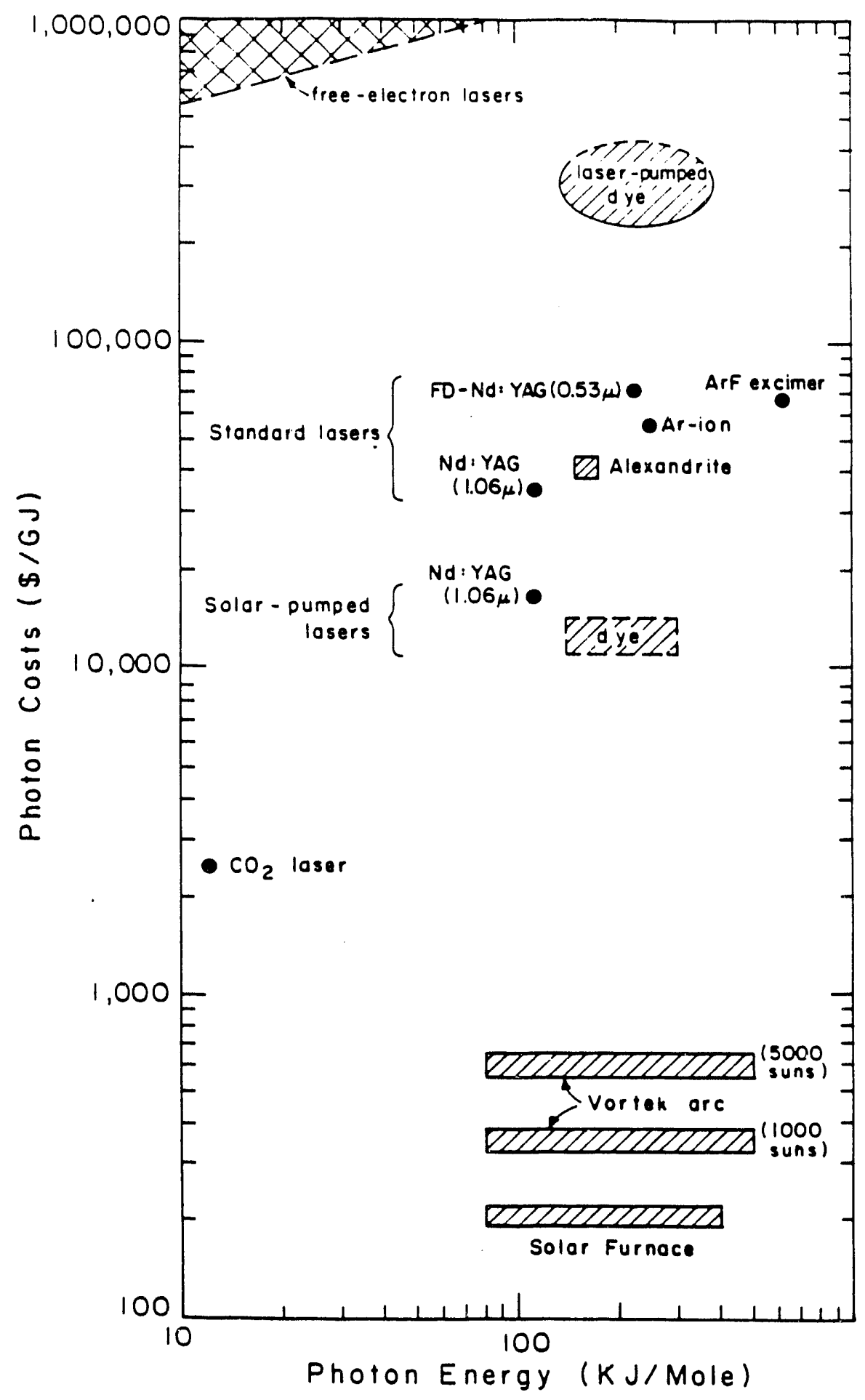

Figure 3. Relative costs of photon energy from various sources.

Adapted from a figure by Dr. J. Yardley (Allied Signal Corporation), which originally appeared in J.I. Steinfeld et al., Laser Photochemistry and Diagnostics: Recent Advances and Future Prospects: Report on an NSF/DOE Seminar for Government Agency Representatives (June 1979). 


\section{SECTION 4}

\section{EVALUATION AND DECISION CRITERIA}

We developed two complementary sets of criteria for screening potential innovative processes for beneficial utilization of concentrated solar energy. We identified those processes showing the greatest promise, and specified the research required for understanding the basic mechanisms involved in the process and for possible eventual demonstration of technical feasibility. These criteria are grouped as scientific and technical feasibility, and economic and practical considerations.

\subsection{Scientific and Technical Feasibility}

In attempting to assess the technical feasibility of suggested applications of concentrated solar erergy, we first considered whether an existing, identified application for photon energy could be done better with concentrated solar energy than with alternative sources, such as conventional process heat, laser sources, or arc lamps. By "better", in this context, we mean one or more of the following:

- increased efficiency gained by using the solar source;

- higher throughput:

- decreased side products and/or undesired effects; and

- reduced fossil energy consumption per unit of product.

In Section 3 we summarized comparisons that have been made among concentrated solar energy and arc lamps (such as the Vortek arc) and laser sources for thermal processing, specifically, the $\mathrm{CO}_{2}$ laser. Several general conclusions can be drawn from these comparisons. First, even though the solar source will always consume less fuel than lasers and arc lamps for a given amount of energy delivered to the source, the economic cost of that energy is by far the smallest component of the overall process cost. As discussed in Section 4.2, the capital cost of the solar concentrator is the determining component for any process.

The second general conclusion is that any gain in throughput or efficiency resulting from the bandwidth and/or light flux advantages of the solar source must be prorated over the limited availability of the source resulting from diurnal cycles and atmospheric fluctuations. This is discussed further in Section 4.2.

A more exciting set of possibilities, which are a major focus of this report, would exploit the unique features of concentrated solar energy for new applications or new process chemistry. These features include

- availability of combined thermal (infrared heating) and photon (visible and nearUV) energy from the same source;

- high flux in the near-infrared region of the spectrum;

- rapid heating of irradiated materials to ca. $4000 \mathrm{~K}$; 
- large bandwidth of simultaneously available photon energies; and

- lack of coherence, as contrasted with laser sources.

In Section 5 we describe a number of possible processes in a variety of application areas that may benefit from these unique feal'ures of the solar source. In doing so, we have tried to make some assessment of the risk of failure and chance of success for a particular process to prove feasible, and to assess the required level of development effort that may be necessary for proof-of-concept at a comniercially relevant scale. Such judgments are difficult and subjective at best, however, and can rarely be projected with success before the research is actually carried out.

\subsection{Economic and Practical Considerations}

Detailed costing and economic evaluations of concentrated solar furnaces and/or their process applications are outside the scope of the present study. However, these analyses would need to be made at some point in the development cycle of technically encouraging processes, and ample written (e.g., Perry et al. 1984, Peters and Timmerhaus 1980) and software resources (Aspen Tech 1990; SRI 1990) are available for quantitative process cost estimating. There is value here in discussing qualitatively, how economic and related constraints may be expected to impact the selection and development of different options for viable commercial applications of concentrated solar photons.

\subsubsection{Qualitative Cost Considerations}

Simplified economic evaluations divide total process cost into capital charges (the cost to borrow and pay back over a prescribed period, the money needed to purchase major items of equipment, real-estate, buildings, etc.), operating charges (the costs to actually run the process, e.g., labor, maintenance, expendable supplies, feedstocks), and process utilities, e.g., energy to run the process. Compared to alternative technologies such as lasers or arc lamps, solar furnaces offer economic advantages in the energy component of their operating costs since the input energy is free. For lasers and arc lamps one must consider the cost of electricity $C_{E}$ and the efficiency with which the device converts electrical energy to photons ( $\eta \mathrm{EP})$ to obtain the comparable energy component of the cost of photolytic energy $C_{p}$ :

$$
\mathrm{C}_{\mathrm{p}}=\mathrm{CE} / \eta \mathrm{EP}
$$

Of course, the other operating costs of each device must also be accounted for, i.e., labor, maintenance, etc. Solar furnaces may also offer economic advantages in these categories under certain circumstances, e.g. when the competing candidate hardware is unusually sensitive to environmental and other operating factors and thus very costly to maintain and operate continuously.

Capital costs offer special challenges for solar concentrators because diurnal variations, and shorter term fluctuations arising from clouds, storms, etc. change the available solar flux density, as shown in Fig. 2. Near maximum daily solar insolation is typically available for only 2 to 3 hours before and after 12:00 noon, i.e., for about 4 to 6 hours per day. If a furnace and process are sized to utilize essentially $100 \%$ of this near-peak intensity, steady operation will thus be limited to about one-fourth to one-sixth of each day. Capital amortization charges accrue to manufactured product cost as a quotient of the plant capacity factor -- simply stated the higher the daily output per unit of capital invested, the lower the 
impact of capital charges (essentially interest) on the cost of the product and hence on the marketplace competitiveness of the process of interest. Because of these lower capacity factors, capital charges per daily unit of output from the solar concentrator must be multiplied by factors of 4 to 6 , or the capital cost of the plant must be amortized over periods four to six times shorter than thuse of other processes. Particular attention must be given to processes where the solar concentrator accounts for a relatively small fraction of the total capital cost. In this case, the relatively short duty cycle of the concentrator is holding captive the rest of the process capital. These considerations will not necessarily render solar-furnace-based processes economically non-competitive, but they must be carefully accounted for even at relatively early stages of examining the benefits and tradeoffs of each process option.

An additional cost-related factor is that the maximum solar insolation $\mathrm{S}$ is inherently limited to about $1 \mathrm{~kW} / \mathrm{m}^{2}$ at the earth's surface. This means that per unit area of primary collector there is a maximum energy available for useful applications. This energy collection capacity of the collector will in turn set an upper bound on the capacity per collector area of the intended process application. If the solar energy required to manufacture a pound of product from the process is $E_{S}$, the process capacity $C$ per unit collector area is given by

$$
\mathrm{C}=\mathrm{S} / \mathrm{E}_{\mathrm{S}}
$$

in units of for example, pounds per square meter of collector area. Because the quantity $S$ is fixed, the "unit capacity" (pounds per unit area of collector) of solar furnace processes will depend on $E_{S}$. Products requiring significant added energy for manufacture (high $E_{S}$ values) will be attainable in lower unit capacity. However, some of these products (e.g., fine ceramic powders) are of high commercial value and may command selling prices that will offset capital and operating costs of the solar furnace. As discussed below, high value added products require much smaller markets to break even. Thus, trade-offs in process capacity due to available solar furnace capacity, market requirements, and product selling price must be carefully evaluated in reaching decisions on the potential viability of a process based on use of a solar concentrator.

\subsubsection{Related Operational Issues}

The duty cycle variations of solar furnaces may also impact strategies for the design, operation, and control of solar concentrator processes. Systems must be designed to detect and respond to short-term variability in delivered photon fluxes, e.g. by adjusting optics, process feed rates, or workpiece dimensions or exposure time. Effects of both underpowering and overpowering on process dynamics must be understood, in turn requiring knowledge of the rates of key chemical reactions and of heat transmission to and within workpieces. For example, excessive attenuation of incoming solar flux may slow process rates or even terminate operability. Excessive heating may produce undesired effects including workpiece degradation by ablation, or by generation of unwanted side products. These effects may become especially critical in processing small workpieces with insufficient thermal inertia to dampen fluctuations in incoming solar power. Small workpieces generally have short thermal response times and hence will require process control systems capable of detecting and correcting for modifications in delivered photon flux densities in times that are shorter than the thermal response time of the workpiece. 


\subsubsection{Analysis Tools}

There are many commercially available software "tools" to help analyze the technical and economic merits of proposed new processes. The most important type of software program is a process flow sheet simulator. ASPEN PLUS (Aspen Tech 1990), marketed and maintained by Aspen Technology, Inc. of Cambridge, Massachusetts, is one such simulator that is widely used by industry and academia in the United States and abroad. The original development of ASPEN PLUS was carried out by the MIT Energy Laboratory's ASPEN Project from 1975-1981 under sponsorship from the U.S. Department of Energy (DOE) and industry.

A simplistic view of a generic chemical process is shown in Figure 4 . At its heart is a chemical reaction, which in the present context would involve the solar furnace. The reaction products usually need to be separated and/or purified before they are sold. Further, the process should be integrated to use energy and materials efficiently, for example, by designing and operating heat exchanger networks for efficient heat recovery. Finally, process utilities are required to provide heat, power, cooling, etc., to the appropriate process operations (e.g. distillation). A process simulator helps a user model this entire complex system, and to easily compare different process options (e.g. equipment configurations and operating conditions) and by these means to select a final design that is both technically and economically sound.

Figure 5 shows that at the core of a flow sheet simulator is a set of mathematical models that are used to solve the problem specified by the user. The user must input pertinent information about the process such as defining the unit operations and unit processes to be modeled, describing how these unit operations and processes are connected together, and specifying the process inputs. For example, in ASPEN PLUS, this may all be done graphically and through pop-up forms. The results generated by the simulator include heat and material balances, equipment performance parameters, and, if desired, an economic evaluation of the process. By running case studies and sensitivity analyses, the user can select the best design from arnong several prescribed alternatives, and begin to optimize that design. ASPEN PLUS also gives the user flexibility to add new models to the system, such as a solar furnace model.

While a flow sheet simulator is good at modeling and improving an existing flow sheet, it relies on the user to synthesize the original design. New tools are now becoming available to assist in synthesis of the process itself. One such tool is ADVENT (also marketed and maintained by Aspen Technology), which is based on a technique called "pinch technology" (see Karp et. al, 1990 for a detailed discussion). Pinch technology allows the design engineer to set process energy targets a priori and then guides the engineer in designing a flow sheet to meet these targets. Used in conjunction with a process simulator, pinch technology helps a design engineer to synthesize a process that optimally balances capital and energy costs.

\subsubsection{Responsiveness to National Needs}

Concentrated solar photons offer potential to make significant contributions in several areas of current national concern. Concerns in these areas may increase in the national consciousness over the next decade and well into the twenty-first century. Among these areas of concern are: (1) environmental issues, e.g., emissions from fossil fuel combustion of gases associated with greenhouse effects on global climate change, emissions of pollutants that contribute to adverse environmental health effects and/or acid rain (e.g. $\mathrm{SO}_{\mathrm{X}}, \mathrm{NO}_{\mathrm{X}}$, particulates and polycyclic matter), and the production of solid or 


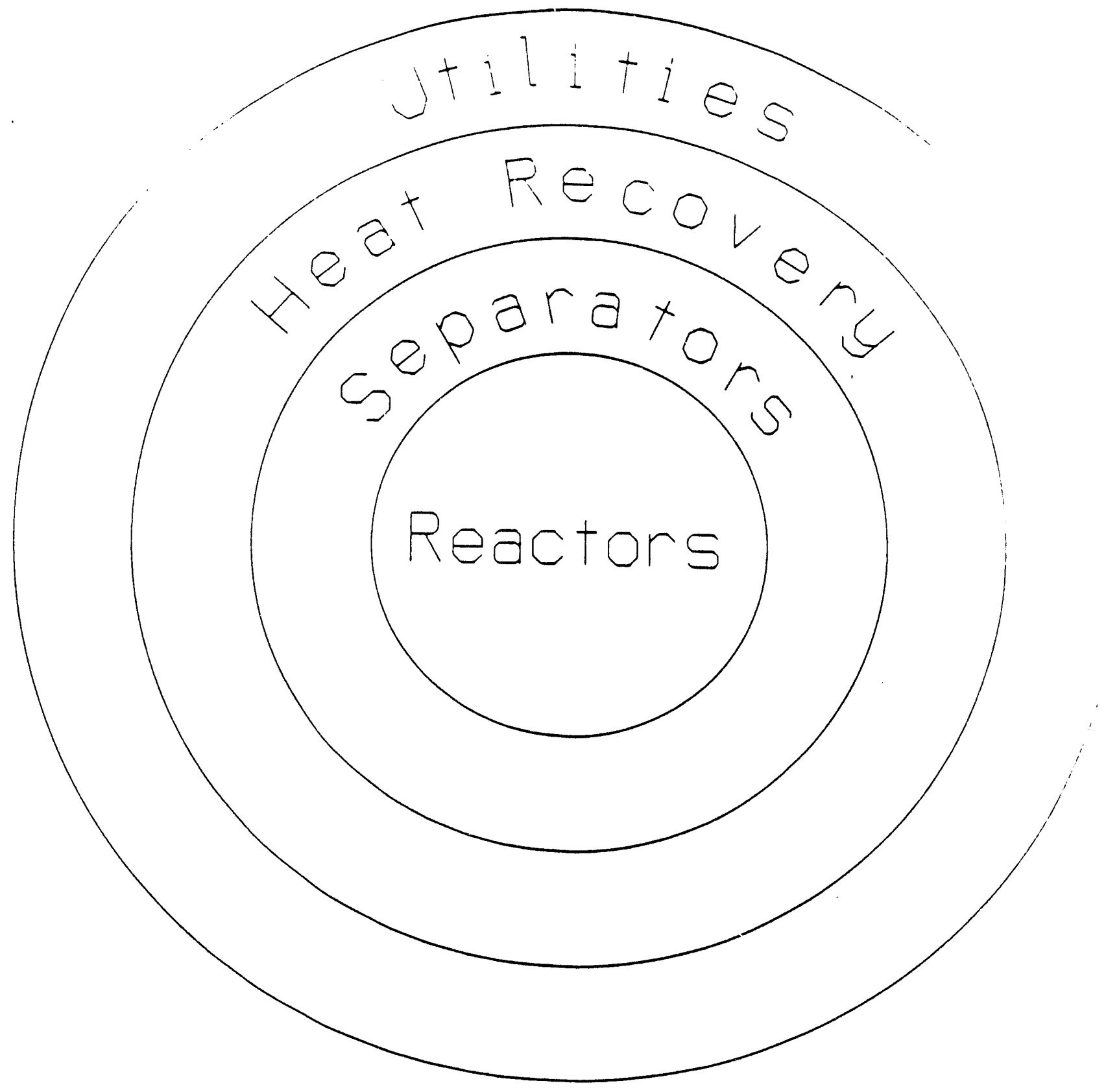

Figure 4. A generic chemical process flow sheet. 


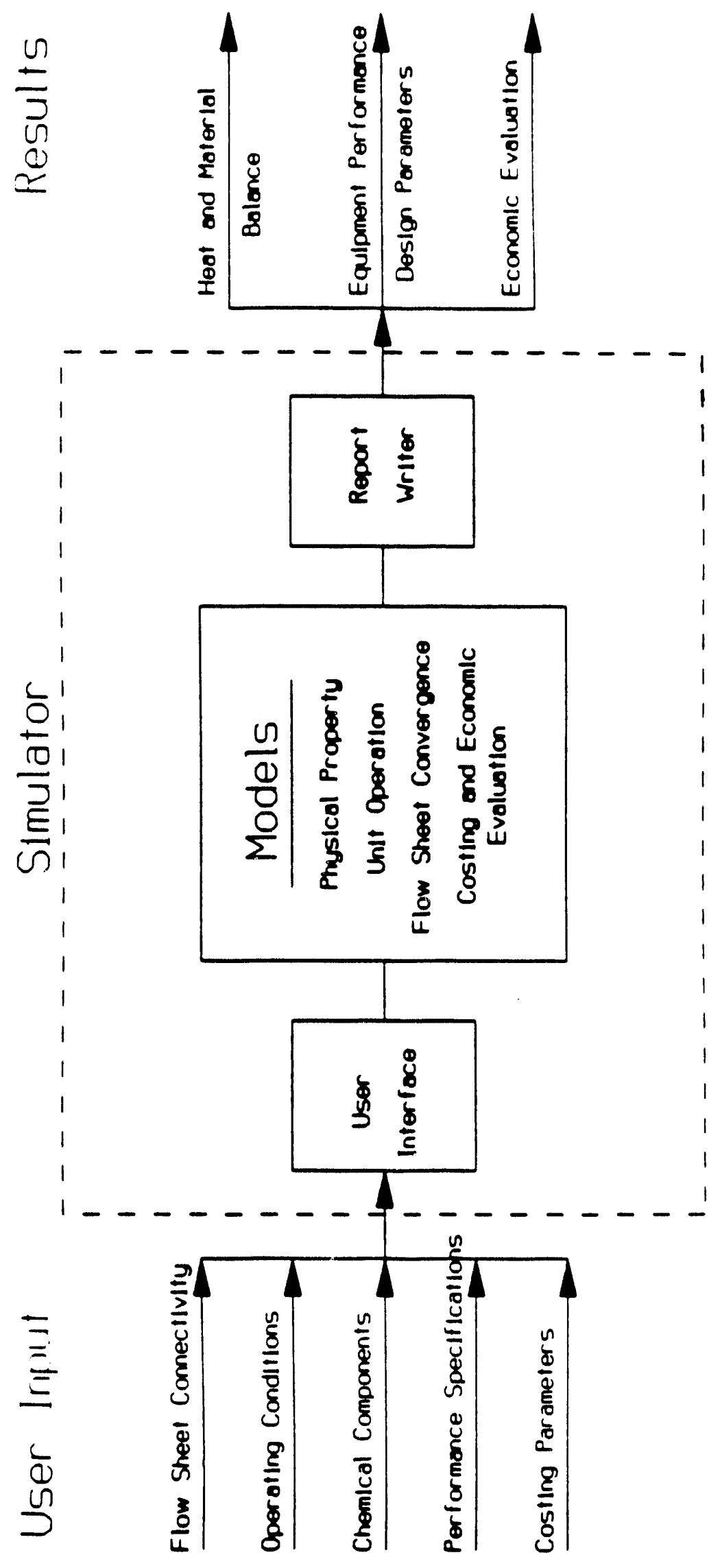

فํ.

$4 \cdot 6$ 
hazardous wastes; (2) reduction of national dependence on imported energy, especially energy supplies subject to political instability or cartel- rather than market-driven prices; (3) the need to enhance global competitiveness of U.S. technology and to expand markets for U.S. manufacturing industries; and (4) the desire for sound national, continental, and global stewardship of energy and all resources.

Regarding environmental issues, aside from relatively minor amounts of electricity for lighting and instrumentation, solar furnaces use renewable solar energy as their main energy input. There is potential for significant displacement of fossil or nuclear Btu's in high-intensity process applications especially when recognizing the energy losses associated with the different efficiencies of energy conversion processes. Thus, to compute the fossil Btu's displaced (EFD) by deriving high-grade process energy from a solar furnace one must account for the efficiency of converting fossil fuels to electricity ( $\eta \mathrm{FE}$ ) and of converting electricity to photon energy, EP, in candidate competing photon sources such as lasers or arc lamps ( $\eta \mathrm{EP}$ ), giving

$$
\mathrm{EFD}=\mathrm{EP} /(\eta \mathrm{FE} \eta \mathrm{EP})
$$

At present, a typical value for $\eta \mathrm{FE}$ is about 0.37 for a good pulverized coal plant using current technology and pollution controls to limit both $\mathrm{SO}_{\mathrm{X}}$ and $\mathrm{NO}_{\mathrm{X}}$ emissions (EPRI 1990). Currently available first-generation integrated coal gasification-combined cycle technology has achieved $\eta F E$ values of 0.42 . There are projections that with molten carbonate fuel cells fired by gas from advanced coal gasification technologies $\eta$ FE could approach 0.6 by the year 2020 (EPRI 1990). Even with this high value for $\eta \mathrm{FE}$, the previous equation shows that. given the small value of $\eta E P$ for lasers and arc lamps (see Section 3.3), solar furnaces offer substantantial opportunity for displacing fossil-based energy in certain applications.

This displacement impacts all of items (1) through (4) above. It eliminates the corresponding emissions of $\mathrm{CO}_{2}, \mathrm{NO}_{\mathbf{x}}, \mathrm{SO}_{\mathbf{x}}$, particulates, and polycyclics associated with the fossil source, and for coal-fired electric generation stations it eliminates substantial quantities of solid waste. For example, conventional pulverized coal-fired utility boilers equipped with flue gas desulfurization equipment produce about $360 \mathrm{lb}$. of solid waste for each $1000 \mathrm{kWh}$ of electricity generated (EPRI 1990). Future coal-based electricity generation technology is expected to include advanced molten carbonate fuel cell systems fueled by state-of-the-art coal gasifiers. However, even these systems, which are projected to be in commercial operation by the year 2020, are estimated to produce solid wastes exceeding $100 \mathrm{lb}$. per $1000 \mathrm{kWh}$ of electricity generated. Solar furnaces have no solid wastes. This could lead to major benefits in terms of societal acceptance and reduced operating charges, especially given that solid waste management costs are expected to increase rapidly as additional landfills are permanently closed and as federal, state and local regulations of solid wastes become more restrictive. For example, legislation continues to be proposed in Congress to prohibit interstate transport of hazardous wastes.

Regarding energy dependence, augmented use of solar energy contributes to reduced need for energy from nondomestic sources and thus to greater security and stability of energy supplies. Clearly, such security is desirable in light of uncertainties regarding the possible future behavior of some major holders of fossil minerals and of expected persistence of significant volatility in petroleum prices. Solar furnaces offer potentially significant advantages when the energy to be displaced is of high quality, e.g., high-temperature process heat that would otherwise be derived from electrically driven thermal plasmas or 
from photolytic or photothermal energy that would otherwise be obtained from lasers or arc lamps. The reason is that significant losses in energy in converting fossil fuels to electricity and electricity to photons (see previous equation) means that several-fold more Btu's of raw fossil fuel energy would be required to remit the equivalent amount of prime value energy.

Regarding competitiveness, successful development of economically competitive processes using solar concentrators could open up new domestic and international markets for U.S. technology and thereby contribute to job growth, exports, and a better balance of payments position. As a final point, concentrated solar technologies may cpen up special opportunities for industrial applications in less developed countries poor in fossil or other mineral energy, but rich in solar resources. This could afford these nations the opportunity to enter new markets and achieve improved living standards, assisted in part by U.S. developed technologies. Further, U.S. national, regional, and global stewardship of fuel minerals and other natural resources could also be enhanced by the reduced pollution, solid waste, and fossil fuel consumption achievable with successful applications of solar furnaces.

Quantitative evaluation of economic and national security benefits of success in arenas (1) (4) is difficult at this time. Indeed, an active research area for economists is learning how to measure the true cost of environmental impacts from different technologies and thus the cost of benefits potentially realizable from alternative technologies that mitigate or eliminate adverse environmental or other societal effects. In this regard, global climate change and the cost and benefits of current and alternative energy technologies have attracted particular attention. Results of these economic studies are expected to provide over the next few' years data and modeling methodologies that will be of great value in evaluating the costs and benefits to the global environment of solar concentrators, and of other alternative energy scenarios.

\subsubsection{Global Cost Comparison Methods}

Figure 3 shows the cost of photon energy from several sources, e.g. arc lamps, various lasers, and concentrated solar furnaces. Figure A.1 in appendix A shows, as would be expected, that higher value added products generally are demanded in lower quantities. These figures can be used together to identify potentially economically acceptable nitches for use of solar furnaces in the manufacture of very high value added products. More detailed process definition and costing using the methodologies and considerations discussed above can then be used to examine further cumulative economic attractiveness of solar furnace options that show initial promise. 


\section{SECTION 5 \\ SPECIFIC PROCESSES SHOWING POTENTIAL PROMISE FOR CONCENTRATED SOLAR ENERGY APPLICATIONS}

In this section, we identify a number of photochemical, materials-processing, and other types of processes that emerged from our discussions and literature survey as having at least potential promise as an application of concentrated solar energy. For each such process, we have attempted to assess the current state of knowledge (including identified centers of expertise in each area) and the research needed to advance potential commercial viability. In order to make a more quantitative assessment of the estimated potential for technical demonstration, and on what time scale this is likely to occur, we recommend the use of the quantitative process modeling tools described in the preceding section.

\subsection{Basic Photochemistry}

From a scientific point of view, the most interesting potential applications of concentrated solar energy are those in which the solar optical photons directly produce an excited state, with the ensuing photochemistry leading to useful products. For the purpose of discussion we have divided this wide-ranging topic into two parts. For many processes, the underlying photochemical mechanisms and rate coefficients are not well enough determined to even begin to assess its potential usefulness. These cases are discussed in this section. In other cases, the mechanisms and kinetic parameters are known, and process modeling is appropriate to determine potential commercial viability. Applications of known photochemical processes of this sort will be discussed in Section 5.3.

\subsubsection{Evaluation of Multiphoton Processes}

A fundamental question that needs to be addressed at the outset is whether concentrated solar radiation could induce multiphoton processes in molecular systems, or whether the systems' response is strictly linear. Nonlinear or multiphoton processes, such as two-photon absorption, frequency multiplication, and sub-Doppler spectroscopy, depend on the sequential absorption of two photons within a time defined by one of the relaxation times of the system (Lin et al. 1984; Lin 1986). Some examples follow:

- In sub-Doppler spectroscopy and in two-photon absorption with a nearresonant intermediate state, collisional relaxation can depopulate the initially populated levels before another photon can be absorbed.

- In two-photon absorption with a remote intermediate state, the time delay between absorption of successive photons is given by the uncertainty principle to be

$$
\delta \mathrm{t}=\mathrm{h} /\left(\mathrm{E}_{2}-\mathrm{E}_{1}\right)
$$

so that large detunings of the intermediate state require extremely high peak powers.

- In the case of frequency doubling, internal crystal relaxation times affect the minimum powers required and help determine the nonlinear coefficients of the material. 
Solar radiation, even at the highest levels achievable by concentrators, is too broad banded and not sufficiently intense to drive nonlinear or multiphoton processes. The cross sections for strongly allowed molecular absorptions are typically on the order of $10^{-17}$ or $10^{-16} \mathrm{~cm}^{2}$. The total solar flux at the $10,(0)$-sun level is about $3.5 \times 10^{21}$ photons $/ \mathrm{sec} / \mathrm{cm}^{2}$. If $1 \%$ of the solar radiation is absorbed (for a solid or liquid absorber), then on the order of 1000 photons may be absorbed per second, requiring millisecond lifetimes. However, solid or liquid relaxation times are generally in the range of $10^{-12}$ seconds. In gas samples, a much smaller fraction of the solar spectrum is absorbed, although relaxation rates may be longer, in the $10^{-6}$ second range. Solar tluxes are thus too weak for multiphoton absorption processes. Frcyuency doubling crystals generally require powers in the range of $1 \mathrm{MW} / \mathrm{cm}^{2}$, compared to the flux at the surface of the sun of $6.3 \mathrm{~kW} / \mathrm{cm}^{2}$. This understanding has propelled the development of solar-pumped lasers (see Section 5.6) with an eye to the development of intracavity frequency doubling or mode-locked designs, which can piovide narrow bandwidths and high peak powers.

Although direct multiphoton excitation is not possible with solar sources, the temperature associated with concentrated solar radiation, ranging up to $3000 \mathrm{~K}$, corresponds to Boltzmann excitation of many vibrational overtone and combination levels to about $2100 \mathrm{~cm}^{-1}$ and beyond. Because isolated molecules do not reradiate as black-bodies, some vibrational ladders may be somewhat hotter than the bulk temperature. This level of vibrational excitation may enhance the reactivity of species by extending "hot-band" absorption of UV bands out to longer wavelengths, where the solar source is richer. Another mechanism for enhanced reactivity is sequential absorption via metastable states or reactive intermediates, which may be populated at the high temperatures in the solar field. High-temperature photochemistry studies by T. Milne at SERI have shown that high light levels may enhance reactivity beyond the level provided by heat alone. This type of reactivity enhancement has received little attention, at least as compared with the current rage in chemical physics for studying supersonically cooled molecules and clusters. A research emphasis on high-temperature high-intensity photochemistry is strongly recommended. Such research could lead to significant new applications of concentrated solar energy.

\subsubsection{Example of New Photochemistry Possibilities}

An example of a new photochemistry that could have intriguing implications for concentrated solar energy applications is the $C_{60}$ cluster molecule (Pool 1990; Mackay 1990; Curl and Smalley 1991). This new form of pure carbon was identified in laser vaporization/supersonic beam experiments (Kroto et al. 1985) and given the cognomen "buckminsterfullerene" because of its geodesic truncated icosahedral structure. It had not been possible to isolate significant quantities of this material, however, until late in 1990 when Kratschmer et al. (1990) devised a preparative method that employs evaporation from an electrically heated graphite in an inert-gas atmosphere, followed by solvent extraction of the $\mathrm{C}_{60}$ product. This provided enough material for measurements to be carried out on the substance, including spectroscopic and photophysical properties. It was found, for example, that $\mathrm{C}_{60}$ possesses strong absorbance in the near-UV and visible regions [absorption coefficient $>10^{4} \mathrm{~cm}^{-1}$ for solid material below 500 $\mathrm{nm}$, with a tail extending out past $700 \mathrm{~nm}$ (Kiatichnic: 1990)] and that excitation in these bands generates large amounts of singlei oxygen via a triplet photosensitization process (Arbogast et al. 1991). Recently Howard et al. (1991) described production of significant quantities of $\mathrm{C}_{60}$ and $\mathrm{C}_{70}$ fullerenes in flarnes.

The preparation and photosensitized reactions of this material might fit very well with the properties of concentrated solar sources. The electrode vaporization may be simply a thermal process that could be driven by absorption of light in the graphite. $\mathrm{C}_{60}$ itself may be a good 
chromophore for solar wavelengths, particularly for singlet oxygen generation, which is a reactive species for many photochemical and biochemical transformations. The current price for commercially produced $\mathrm{C}_{60}$ is $\$ 1000$ per gram of pure material $(\$ 400,000 / \mathrm{lb}$ ) (Howard 1991) which is well above the current cost threshhold for photon processing While $\mathrm{C}_{60}$ is itself an intriguing subsiance, we are not necessarily suggesting a major research effort on this specific system. Rather, this example is an illustration of how new research opportunities in this area may arise rapidly and unexpectedly. If the solar concentrator were set up as a user facility, such opportunities could be investigated and exploited in an efficient, productive, and timely manner. The establishment of such a user facility is one of the principal recommendations of this report.

\subsection{Photothermal Conversion}

A number of heat-pump-like cycles have been suggested for capture, storage, transmission, and recovery of solar energy. A schematic of a generic cycle incorporating these operations with a solar concentrator is shown in Figure 6. The figure depicts energy capture by concentration of solar insolation $\mathrm{Q}_{\mathrm{s}}$ onto a working medium that may absorb energy by an increase in its sensible enthalpy and/or by enthalpy uptake by endothermic phase changes or chemical reactions. The energy release step frees up stored energy $\mathrm{Q}_{R}$, equal to $\mathrm{Q}_{\mathrm{S}}$ less energy lost during the collection and release processes, $Q_{L C}$ and $Q_{L R}$, respectively (i.e., $Q_{R}=Q_{S}$ $\mathrm{Q}_{\mathrm{LC}}-\mathrm{Q}_{\mathrm{LR}}$ ). The net energy released, $\mathrm{QR}_{\mathrm{R}}$, can then be used for the desired application, for example in production of electricity as shown in Figure 6. Typically associated with cycles of this type are losses of the working medium during energy collection and recovery $\left(\mathrm{M}_{\mathrm{LC}}\right.$ and $M_{L R}$, respectively), and additional, so called parasitic energy losses, $E_{P}$, reflecting partial utilization of the raw energy output of the cycle to operate plant utilities such as pumps.

Ignoring the material losses, the overall efficiency of the energy cycle of Figure 6, can be analyzed in terms of four contributing components:

- Energy capture efficiency:

- Energy release efficiency:

- Gross cycle efficiency:

- Net cycle efficiency:

$$
\begin{aligned}
& \eta_{\mathrm{C}}=\left(\mathrm{Q}_{\mathrm{s}}-\mathrm{Q}_{\mathrm{LC}}\right) / \mathrm{Q}_{\mathrm{s}} \\
& \eta_{\mathrm{R}}=\mathrm{Q}_{\mathrm{R}} /\left(\mathrm{Q}_{\mathrm{R}}+\mathrm{Q}_{\mathrm{LR}}\right) \\
& \eta_{\mathrm{g}}=\mathrm{E}_{\mathrm{g}} / \mathrm{QR}_{\mathrm{R}} \\
& \eta_{\mathrm{n}}=\mathrm{E}_{\mathrm{n}} / \mathrm{E}_{\mathrm{g}}
\end{aligned}
$$

where $E_{g}$ and $E_{n}$ are, respectively, the gross and net amount of electrical energy generated by the cycle per unit of solar energy input, i.e., the amount of electrical energy available before and after debiting for electrical energy utilized for parasitic purposes (Figure 6). The quantity $\eta\left(=E_{n} / Q_{s}\right)$ is then equal to the product of these four efficiencies.

Thus, attractive cycles should provide, for each of the above four efficiencies, values as high as possible, consistent with consiraints on capital and operating costs for the process. Two orientation calculations are helpful in illustrating possible limitations in cycle performance as well as opportunities for improved technology. Capture and release efficiencies are process dependent, but $80 \%$ can be taken as a nominal optimistic value for each. Typical efficiencies for conversion of heat to electricity in steam Rankine cycles are $30 \%$ to $35 \%$, although values as high as $40 \%$ can be obtained in modern plants if major pollution control equipment does not have to be operated (EPRI 1990). More importantly in the current context, these efficiencies depend on the steam temperature and pressure, and hence on plant materials and on the 


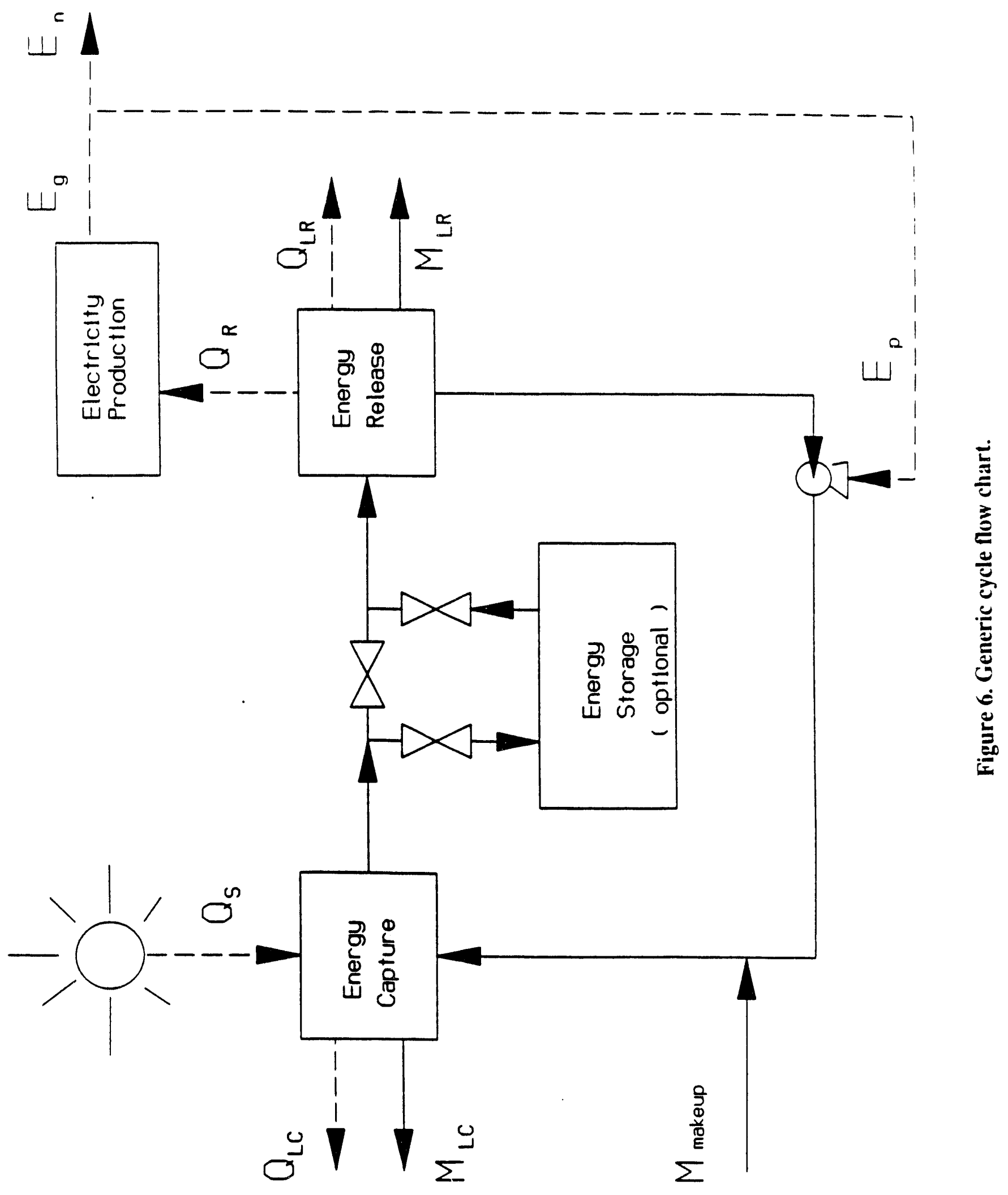


temperature at which $\mathrm{Q}_{\mathrm{R}}$ is made available. For example, at $250^{\circ} \mathrm{C}$, typical steam Rankine cycle conversion efficiencies are about $14 \%$ to $2.0 \%$ (Armstead and Tester 1987), whereas the $40 \%$ value would require supercritical steam at a temperature approaching $600^{\circ} \mathrm{C}$ (EPRI 1990). Assuming for the parasitic efficiency the quite reasonable value of $95 \%$, a net cycle efficiency of $24 \%(0.8 \times 0.8 \times 0.4 \times 0.95)$ is calculated for the very high efficiency Rankine cycle. However, if the Rankine cycle efficiency drops to $25 \%$ the net cycle efficiency would be $15 \%$ $(0.8 \times 0.8 \times 0.25 \times 0.95)$.

If electricity is the desired product of the cycle, then these efficiencies should be compared with other solar-based options. For example $15 \%$ is comparable to the upper end of the efficiency range for commercially available silicon photovoltaic cells (Glasstone 1982). However, the solar thermal cycle of Figure 6 may be more complex to operate and maintain and would probably have higher capital costs. On the other hand, an efficiency of $24 \%$, if economically competitive, could give the solar thermal cycle an advantage over photovoltaics. Furthermore, the cycle of Figure 6 offers the very important advantage of optional storage of solar thermal energy for use in electric power generation or other applications as desired. Photovoltaics would require battery or other means of storing electrical energy and may not be able to match the efficiencies of storing heat or chemicals capable of heat release by exothermic reactions.

The above discussion also shows that when using Rankine cycles there can be a significant efficiency penalty with declining temperatures for release of $\mathrm{Q}_{\mathrm{R}}$. A second observation is that there may be cases where solar furnace cycles of the type shown in Figure 6 may prove to be more valuable in applications requiring direct heat energy, including the option for energy storage, rather than electricity generation. Thirdly, a more detailed analysis would account for effects of loss of working medium $\left(\mathrm{M}_{\mathrm{LC}}\right.$ and $\mathrm{M}_{\mathrm{LR}}$ ), and the need for a makeup materials stream.

The take-home lesson of this discussion is the importance of carrying out further process simulation, economic, and marketing analyses to define preferred application opportunities for such cycles under a range of conditions.

\subsection{Photochemical Applications}

In light of the overall constraints on applications of photochemistry to chemical synthesis and processing, as detailed in appendix $\mathrm{A}$, we have focused our attention on those processes that exploit the properties of concentrated solar photons to the greatest advantage. The primary property in this context, is the high overall photon flux over a range of wavelengths between 300 and $2000 \mathrm{~nm}$. The absence of hard-UV (below $300 \mathrm{~nm}$ ) radiation significantly limits the types of primary photochemical reactions that can be exploited, but several processes have emerged as candidates for further exploration and possible application.

\subsubsection{High-Intensity Laser-Jet Photochemistry.}

R.M. Wilson and co-workers at the University of Cincinnati have been investigating novel photochemical processes that can be made to take place in a flowing solvent jet under highintensity laser irradiation. The technique involves sequential excitation of transient photochemical intermediates, in which photochemically generated transient species with suitable absorption properties are excited further and produce relatively large amounts of photoproducts that are not observed under low intensity conditions (Wilson et al. 1990). The jet acts as a light trap, increasing the effective photon flux on the reactants to the order of a few Einsteins $\mathrm{sec}^{-1} \mathrm{~cm}^{-2}$. While the $1 \mathrm{KW} / \mathrm{cm}^{-2}$ available from the solar concentrator corresponds to only 0.01 Einsteins $\mathrm{sec}^{-1} \mathrm{~cm}^{-2}$, the large available bandwidth may compensate for the lower 
flux. One process in particular, the conversion of methylbenzophenone to anthrone, requires simultaneous irradiation by two ion lasers at wavelengths in the 334 to $364 \mathrm{~nm}$ and 458 to 514 $\mathrm{nm}$ bands. Replacement of two expensive, energy-inefficient lasers by a single solar source appears to be a particularly attractive possibility in this case. The solvent-jet apparatus might be particularly compatible with the dielectric concentrator described in Section 3.2.1. A similar jet technique has also been used on photodeposition applications (see Section 5.5.2).

\subsubsection{Photoelectrochemistry at High Intensities.}

We have distinguished three generic types of applications for photon-driven electron transport processes: direct photovoltaic electricity generation (not considered in this study), chargetransfer and electron-transfer processes in solution, and photochemical processes at electrode surfaces.

A principal desired application for photoelectrochemistry is the "water-splitting" reaction producing hydrogen gas as a storable, transportable fuel. Despite extensive prior work in this area, a practical system for accomplishing this has not yet been identified and the applicability of concentrated solar energy to the present generation of systems appears to be limited (Glandt and Myers 1976), although Nozik and co-workers at SERI have suggested that quantum-well devices might permit more efficient utilization of high-intensity solar radiation (Parsons et al. 1990). Langhoff (1990) has suggested, in this connection, a role for broadband absorbers such as the diatomic halogens, which produce reactive free radicals by photodissociation. Attack of $\mathrm{Cl}$ or $\mathrm{Br}$ (from $\mathrm{Cl}_{2}$ or $\mathrm{Br}_{2}$, respectively) on water to produce $\mathrm{O}_{2}$ and $\mathrm{HX}$, for example, might be studied as part of a solar-driven water-splitting cycle, with the acid HX decomposed by solar-energy-based electrolysis or metal surface reaction. This reaction system might be a prototype for setting up a solar-driven gas-phase reaction facility. Another set of compounds having possible applications in water-splitting reactions has been identified by H.B. Gray and co-workers at Cal Tech. Use of $\operatorname{IrX}_{6}^{-3}(\mathrm{aq})$, for example, in reduction of $\mathrm{X}^{-}(\mathrm{aq})$ to halogen dimer may be particularly promising, particularly when combined with the radical attack of $\mathrm{X}$. on water for production of $\mathrm{HX}$, as mentioned above. The $\mathrm{C}_{60}$-catalyzed photogeneration of oxygen mentioned in Section 5.1.2 could also have potential for water splitting, but much more needs to be known about this process before a realistic assessment could be made.

There are additional areas in which heterogeneous photoelectrochemistry could find applications; one of these is in deposition or etching of thin films on surfaces, which is discussed in Sections 5.5.2 and 5.5.3.

\subsubsection{Photomedicine and Photobiology}

Much of the current research on the biological effects of light focuses on understanding the molecular biology of what happens when plant or animal tissues absorb light. Examples include:

- $\quad$ effects of low-intensity UV radiation on the immune system;

- $\quad$ effects of short-duration light pulses on human vision;

- mechanisms of selective action of phototherapeutic drugs, such as hematoporphyrin derivatives;

- $\quad$ effects of visible light on human physiology and psychology. 
Most of these studies utilize continuous light sources such as CW lasers or spectrographically dispersed arc lamps (Watanabe et al. 1982).

Most biological and biomimetic processes do not function well at irradiation levels greater than 1 sun; indeed, many organisms' metabolic processes are photoinhibited at higher brighunesses (Brown 1990). Work at the Weizmann Institute on the carotene-producing algae Dunaliella suggests that a few organisms, such as this, may benefit from a fractionally higher flux level of solar radiation, but concentrations greater than a few suns would generate temperatures in excess of $1000^{\circ} \mathrm{C}$, which would of course be fatal to any form of life with which we are familiar.

\subsection{Materials Processing and Surface Photechemistry}

Materials processing encompasses the production and modification of materials. Many different techniques are used to process materials, ranging from presses for compressing pellets of materials together, vacuum chambers for layer-by-layer growth of materials, lasers for ablating materials, and grinders for removing unwanted edges. The most pertinent set of techniques that relate to possible applications for a solar concentrator are those utilizing lasers and other light sources.

There are several advantages of using light over traditional means. Lasers provide precise control for the localization of reactions. The light comes from a remote source so samples can be easily moved or repi، ced, and it can be coupled into any environment, from liquids to toxic gases. Also, because of the localization, the amount of precursor used can be reduced by injecting directly into the interaction area. This is very important when either expensive or hazardous chemicals are used.

In the literature search procedure described in Section 2.4 and appendix B, we retrieved a large number of published references about photon-driven surface chemistry and materials processing. These were sorted by the identity of the material and the nature of the process into the categories listed in Table 5.

Table 5. Photon-driven surface chemistry materials and processes

Materials

carbon (and diamond)

ceramics (incl. powders)

II-VI (CdTe, HgCdTe,...)

III-V (GaAs, InP,...)

metals

metal-oxides

polymer

silicon (also $\mathrm{SiC}$, etc.)

silicon nitride

silicon oxide

steel (and iron)

superconductors

\author{
Processes \\ ablation \\ alloying \\ annealing \\ cladding \\ deposition \\ desorption, vaporization \\ doping \\ drilling \\ etching \\ hardening \\ melting \\ plasma (ionization, charge \\ carrier generation) \\ recrystallization \\ surface treatment \\ (general, unspecified)
}


From this extensive list, we sought to identify those materials and processes that would potentially benefit from the use of concentrated solar energy. We excluded processes that required light at wavelengths below $300 \mathrm{~nm}$ or that exploited the spatial coherence of a laser to produce micro-scale features, as in direct writing of semiconductor devices.

The solar concentrator could replace light sources that drive thermal reactions where the light is used to heat a substrate. Traditionally, these reactions are done with $\mathrm{CW}$ lasers with power densities up to $100 \mathrm{KW} / \mathrm{cm}^{2}$. A major advantage of the solar source is the ability to produce large speckle-free beam profiles caused by the incoherent nature of the light source (for example neglecting losses, flux densities of $10 \mathrm{KW}$ over a $10 \mathrm{~cm}^{2}$ area would be obtained by a 10,000 -fold concentration of the natural solar energy received by a $10 \mathrm{~m}^{2}$ primary collector). This will produce even heating from the beam profile and allow faster scan rates and increased total energy delivery to the material.

Among the areas of materials processing identified as benefiting from concentrated solar light are surface treatment of metals, thin-film deposition and etching, production of fine ceramic powders, and materials testing and evaluation for high-temperature conditions. A great deal of research is still needed on many of these topics before process development can take place, because in many cases the basic mechanisms and kinetic parameters have not been well established.

\subsubsection{Surface Treatment}

A number of photon-induced processes have been used to produce increased hardness, corrosion resistance, or friction reduction in the processing of metals, alloys, and machined parts, such as cladding, alloying, melting and transformation hardening. The present technology for these processes uses $\mathrm{CW} \mathrm{CO}_{2}$ lasers or more traditional thermal methods. Much of the technological development in this area has taken place in Korea and Europe (U.K., Germany, and the Swiss Federal Institute of Technology in Lausanne).

Cladding and alloying are processes in which the outer surface (up to several $\mathrm{mm}$ ) of a workpiece is chemically changed. Cladding bonds an outer layer that is pre-deposited on the surface, either by electrodeposition $(\mathrm{Cr}, \mathrm{Ni})$, thermal spray ( $\mathrm{Cr}, \mathrm{Mo}$, carbides) or vapor deposition ( $\mathrm{Zn}, \mathrm{W})$ (Dekumbis 1987) to the base material. Alloying actually melts the base material and allows the mixing of the pre-deposited layer with the base material. $\mathrm{High} \mathrm{CO}_{2}$ laser powers, on the order of $10^{4} \mathrm{~W} / \mathrm{cm}^{2}$ are required for this process.

In transformation hardening, the surface of a material is heated to just below the melting point, then rapidly cooled. The effect of the thermal cycle on iron and steel is the conversion from an austenite structure to a hard martensite structure. A surface graphite layer can be sprayed onto the workpiece to increase absorption. Lower $\mathrm{CO}_{2}$ laser powers, on the order of $10^{3} \mathrm{~W} / \mathrm{cm}^{2}$, are required for these applications.

The feasibility of using a concentrated solar source for alloying and cladding operations is marginal, because of the high intensities required, but may be more favorable for transformation hardening. The $\mathrm{CO}_{2}$ laser produces a wavelength of $10.6 \mu \mathrm{m}$, at which the absorption of metals is around $3 \%$. In the solar spectral region, the absorptivity of metals increases, up to a value of $50 \%$ to $70 \%$, at the shorter wavelengths, as shown in Fig. 7 . In addition, several processes require the addition of a deposited layer to the workpiece that will undergo the processes, which can further increase the absorption of the solar radiation. 


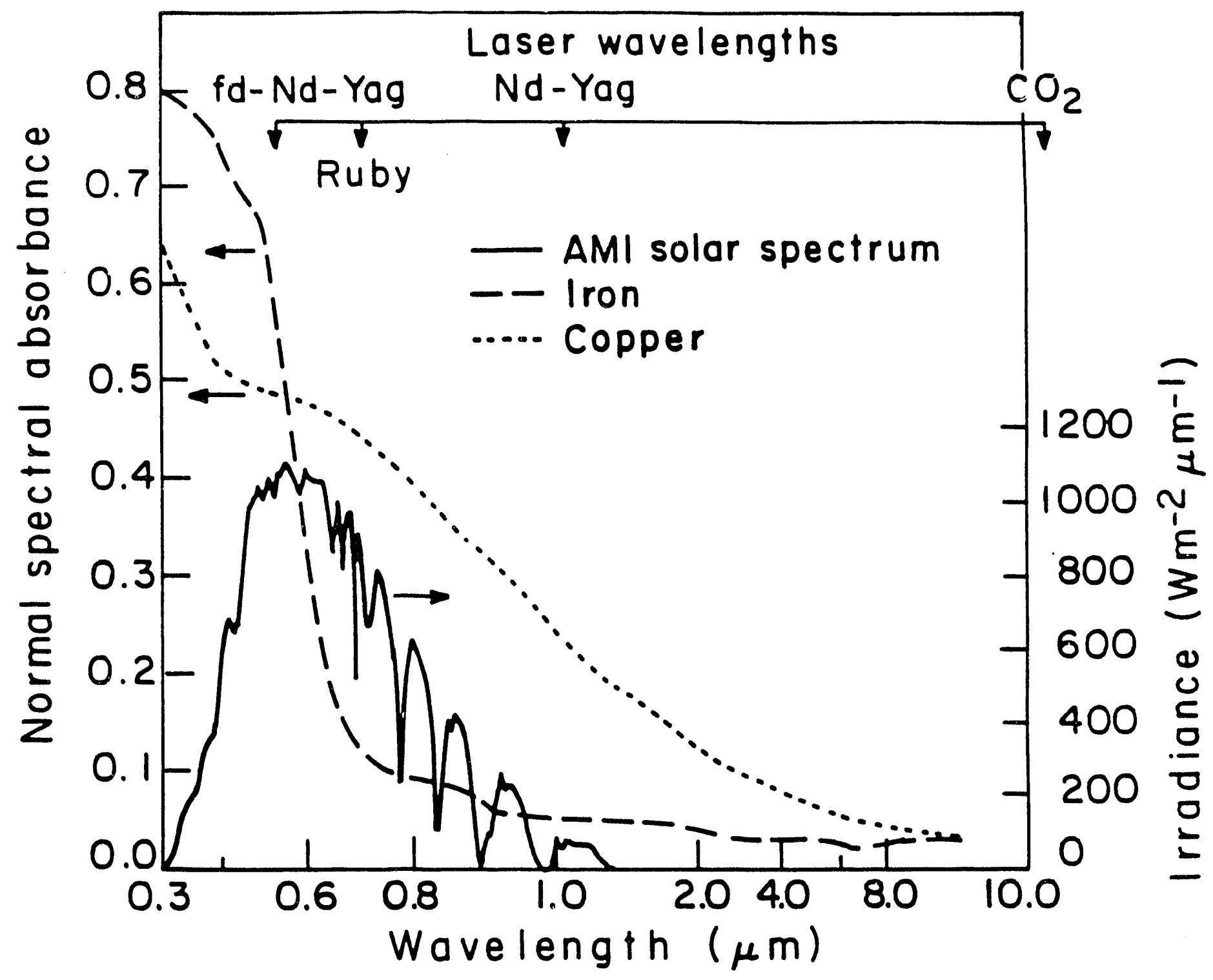

Figure 7. Comparison of AM1 solar spectrum with metal absorptives (from Pitts et al., 1990). 
As a first step to assessing the viability of concentrated solar energy for these applications, detailed calculations should be carried out on energy coupling to the surface for a variety of conditions of interest. In doing so, the restrictions on proximity of the workpiece to source optics discussed in Section 3.2.1 must be taken into account. Preliminary estimates suggest that the required intensities may be available from the solar concentrator. Additional benefits may accrue from the large irradiation area of the solar source. This could provide a broader. more uniform working zone, and could raise throughput by allowing faster scan rates and fewer passes over the workpiece.

\subsubsection{Deposition}

The deposition of materials is an area of industrial importance. Using light as a source of energy to drive deposition reactions has been studied for many years (Herman 1989; Haigh and Aylett 1988). The outcome of these studies has indicated that there are three typical routes for the deposition to occur. These are thermal, photochemical, and reactions involving both.

The deposition route taken is controlled generally by the type of light source used. Typically for photochemical deposition, high-power, pulsed UV and IR lasers are used. This allows several photons to be absorbed by the precursor molecule, thus producing a well fragmented, sometimes atomic, reactive species to interact with both gas phase species and the deposition substrate. Photothermal reactions use both pulsed and CW lasers in the whole wavelength range from the UV to the IR to heat a substrate and cause the incident precursors to adsorb dissociatively. This is directly analogous to thermal chemical vapor deposition (CVD) in which the substrate is electrically heated. The mixed photochemical/photothermal route will typically occur when the laser beam interacts simultaneously with the substrate and the gas-phase precursor.

The solar concentrator can be used for deposition in most cases where CW laser heating has been used. Two advantages of the concentrator are the ability to provide uniform speckle-free illumination over broad areas because of its noncoherent nature and a large total energy delivery to the substrate so faster scan rates can be used. The concentrator would have many of the existing advantages of laser processing, such as the ability to limit gas loads, which is important when working with hazardous precursors, and use of a room temperature apparatus for high-temperature depositions and easier sample handling. The disadvantage of the concentrator is the inability to produce narrow features in the sub-micron range.

Photodeposition can be done in both the gas and liquid phases. Gas-phase deposition is used most often in the electronics industry when sample purity is of primary importance, e.g., in crystal growth. An advantage of gas-phase deposition is that no solvents are needed and the precursors can be obtained at very high purity levels. Liquid-phase deposition is typically used for lower purity, large area film growth. However, some examples are known of high-purity deposition from liquids.

\subsubsection{Gas-Phase Deposition Systems}

Metals. The deposition of metals from the gas phase, onto substrates using concentrated solar light will be primarily driven via thermal pathways. Most precursors are optically transparent in the gas phase in the solar spectral region. However, photon absorption by precursors adsorbed on substrates is possible due to the broadening of optical transitions to lower energies (Ehrlich and Osgood 1981). This enhanced absorption may help facilitate thinfilm deposition at slightly lower temperatures than at which purely thermal deposition would occur. 
There are three typical precursor types that are used for thermal CVD and should be good for solar-assisted CVD. These are metal carbonyls, metal halides, and metal organics.

Metal carbonyls have been studied the most and can be used to deposit Fe (Allen and Tringubo 1983; Jackman et al. 1986, Xu and Steinfeld 1990), Ni (Allen et al. 1985, Petzoldt et al. 1984), and the refractory metals W, Cr, and Mo (Singmaster et al. 1989; Allen and Tringubo 1983). Pure films can be formed by simply flowing the gaseous metal carbonyl evenly over a heated substrate. The solar concentrator can be used to either heat the substrate directly, if it absorbs in the solar spectrum, or to photo-initiate the reaction on a transparent substrate, then heat the newly formed film. The photolytic reaction alone, at the intensities and wavelengths available from the concentrator, is not sufficient to produce high-purity thın films.

Tungsten can also be deposited from its fluoride $\left(W_{6}\right)$ in a similar thermal deposition scheme (Zhang et al. 1987; Gottsleben and Stuke 1988). In one case, a mixture of $\mathrm{WF}_{6}$ and $\mathrm{SiH}_{4}$ is used with a $150^{\circ} \mathrm{C}$ substrate to initiate the very exothermic reaction that leads to pure tungsten thin-film deposition (Black et al. 1990). Also because of the low-temperature, highscan rates can be used to cover large areas with a smooth nilm. This is the best source for photo-assisted deposition of tungsten. Another halide that can be used is $\mathrm{TiCl}_{4}$ to produce pure titanium films (Tsao et al. 1983).

To complement the metals from the carbonyl and halide deposition ( $\mathrm{Fe}, \mathrm{Ni}, \mathrm{W}, \mathrm{Cr}, \mathrm{Mo}, \mathrm{Ti}$ ), metal films of $\mathrm{Au}, \mathrm{Cu}, \mathrm{Pt}, \mathrm{Pd}, \mathrm{Ir}, \mathrm{Al}, \mathrm{Cd}$, and $\mathrm{Ga}$ can be deposited with metal organics. Again, photothermal techniques are used to obtain films of $>95 \%$ purity. The first class of these is the acetylacetonates (AcAc).

Acetylacetonates readily decompose at temperatures around $200^{\circ} \mathrm{C}$, so relatively lowtemperature depositions can be done. In addition to the low-temperature decomposition, these precursors absorb in the near UV so the deposition can be photochemically assisted. The low temperature and the possibility of a photochemically assisted mechanism could allow high scan rates for large area, smooth film deposition, as seen earlier with the $\mathrm{WF}_{6} / \mathrm{SiH}_{4}$ system. This should be a very good system to use with the solar concentrator, taking advantage of its broadband frequency nature to provide a synergistic effect tying both photochemical and photothermal processes together with the speckle-free imaging of noncoherent light to deposit very pure films both evenly and speedily. The metals that can be deposited in this way include $\mathrm{Au}, \mathrm{Cu}, \mathrm{Pt}, \mathrm{Pd}$, and $\mathrm{Ir}$.

The second major type of metal organics is trimethyl and triethyl complexes. These are frequently used in thermal and photothermal CVD to deposit $\mathrm{Al}$ and $\mathrm{Ga}$, but have also been used for $\mathrm{Cd}$ deposition. Typically, these precursors are used for the metal component in complex semiconductors, GaAs or AlGaAs. A hybrid of these metal-organic-type precursors is trimethylamine aluminum hydride. This hybrid has been used to photothermally deposit $\mathrm{Al}$ films of $>97 \%$ purity levels.

The best systems for using concentrated solar light to deposit pure metal films from the gas phase are the halides for $\mathrm{W}$ and $\mathrm{Ti}$, the AcAc's for $\mathrm{Au}, \mathrm{Cu}, \mathrm{Pt}, \mathrm{Pd}$, and $\mathrm{Ir}$, and the trimethyl compounds for $\mathrm{Al}$ and $\mathrm{Ga}$. In all these systems, the main driving force for deposition is thermal.

Elemental Semiconductors. The deposition of elemental semiconductor films can be done with a photothermal scheme very similar to metal deposition mentioned earlier. Both silicon and germanium are deposited by using their methane analog, $\mathrm{SiH}_{4}$ and $\mathrm{GeH}_{4}$, respectively. Substrate temperatures of at least $350^{\circ} \mathrm{C}$ are required for silicon deposition, whereas germanium can be grown at $300^{\circ} \mathrm{C}$. Ge-Si alloys can also be deposited by simply mixing the 
two precursors in the correct ratios. Photochemical deposition would not be possible with the solar concentrator because of the lack of absorption of the hydrides at solar wavelengths and low power densities.

III-V Semiconductors, Compound semiconductor deposition is "very complex and poorly understood" (Herman 1989). As with the elemental semiconductors, photo-induced thermal deposition can be used to produce GaAs, and GaP semiconductors as well as the ternary III-V semiconductors: GaAsP, AlGaAs, and InGaAs. An alternative to the purely thermal deposition is photo-assisted atomic layer epitaxy (ALE). ALE uses alternating precursor gas pulses to deliver a layer of molecules to a substrate and visible and UV light to assist the dissociation by photochemical means. Trimethyl gallium and arsine are used for both the thermal deposition method and the ALE method. The other precursors for the ternary III-V semiconductors are trimethyl aluminium, triethyl indium and phosphine. Dimethyl zinc can be added to the precursor gases to incorporate $\mathrm{Zn}$ as a dopant.

II-VI Semiconductors. The deposition of II-VI semiconductors must be done at low temperatures to prevent atomic diffusion. It is therefore not feasible to deposit these material using the solar concentrator source, because of excessive substrate heating.

Insulators, Insulator deposition is feasible using the solar concentrator. Again, the reactions are photothermal and all the general considerations mentioned in the metal and semiconductor section pertain to this area. The insulators that can be deposited are silicon dioxide (Szikora et. al. 1984) and silicon nitride (Sugimura et al. 1987) from $\mathrm{SiH}_{4}$ with $\mathrm{N}_{2} \mathrm{O}$ and $\mathrm{NH}_{3}$. respectively; titanium dioxide from a $\mathrm{TiCl}_{4} / \mathrm{H}_{2} / \mathrm{CO}_{2}$ mixture; aluminum oxide or sapphire from trimethylaluminium and $\mathrm{N}_{2} \mathrm{O}$ (Minakota and Furukawa 1986); zinc oxide from dimethyl zinc and $\mathrm{NO}_{2}$ or $\mathrm{N}_{2} \mathrm{O}$ (Solanki and Collins 1983); tantalum oxide from pentamethoxy-tantalum and $\mathrm{N}_{2}$ (Yamagishi and Tarui 1986); phosphorous nitride from $\mathrm{PH}_{3}$ and $\mathrm{NH}_{3}$ (Hirota and Mikami 1985); and chromium oxide thin films and crystals from $\mathrm{CrO}_{2} \mathrm{Cl}_{2}$ (Arnone et al. 1986). Tin oxide has also been grown from $\mathrm{SnCl}_{4}$ and residual oxygen on $\mathrm{GaAs}$ (Tokuda et al. 1988).

Polymers. The deposition of polymer thin films using light has been accomplished by photolyzing precursors in the gas phase above a substrate with pulsed lasers. An example of this is the photolysis of 1-methyl-1-silacyclobutane to form an organosilicon polymer (Pola et al. 1988). The addition of $\mathrm{SF}_{6}$ to the precursor gas was used as an "energy conveyer" to assist the energy transfer from the 10.6- $\mu \mathrm{m}$ IR photons to the precursor. In this context, it would be useful to identify some inert absorbers that could act as photosensitizers in the solar spectrum.

Superconductors. The deposition of superconducting thin films is a field of intense research. It has been determined that one of the best current methods for depositing these materials is by "laser sputtering", which requires short, high-intensity light pulses (Bauerle 1989). Because such ablative transfer works best under short-pulse conditions, its use of concentrated solar light for the deposition of superconducting thin films would require significant innovations in the solar concentrator hardware for control of light intensity and exposure time of workpieces.

\subsubsection{Liquid Phase Deposition Systems}

Deposition of materials on substrates from solutions using light is also possible. There are trade-offs with using the liquid medium for depositing materials, however. A major advantage is the simplicity of the apparatus; all that is needed is a container that can hold a liquid and support a substrate below the liquid surface. In the simplest case there is no gas handling, except for vapor removal. The disadvantage is that the deposited films have more impurities than the gas-phase analogs. 
The main constraint of depositing from liquids is that the reactions must occur at the substrate surface. If the solution absorbs the light, thermal pluming will occur and nonuniform layers will be formed. Using solar light would be advantageous, because solution absorption wavelengths could be removed from the light source while still leaving sufficient intensity to drive the deposition.

A possible use for the liquid deposition would be to precoat workpieces that are going to undergo surface treatment. This could be an ideal case for a multistep solar-assisted materials processing plant.

Metal films can be deposited from solutions, either by thermal reactions on a substrate or photoelectrochemically on semiconductors. Both methods can be done with the solar concentrator.

Dibenzene complexes of chromium and molybdenum have been used to deposit $\mathrm{Cr}$ and $\mathrm{Mo}$ with carbon contamination levels below 10\% (Yokoyama et al. 1984). Gold and copper can be deposited from commercially available plating solutions. A technique has been developed that uses a jet (cf. Section 5.3) to deliver plating solution to the laser spot on a substrate giving good quality films and high deposition rates (von Gutfeld and Vigliotti 1985). This type of technique could be adapted to utilize fully the broadband nature of the solar spectrum. Some portions of the spectrum could be absorbed by the solution, facilitating the dissociation of the precursor in the solution, while the rest of the spectral intensity heats the substrate to ensure maximum adhesion of the partially dissociated precursor to the growing film.

Palladium has been deposited from a solution of acetonitrile, methanol and $\mathrm{Pd}(\mathrm{NCMe})_{6}\left(\mathrm{PF}_{3}\right)_{2}$ using a 325-nm source to photothermally heat a substrate (Montgomery and Mantei 1986). An aqueous solution of chloroplatinic acid solution has been used for platinum deposition (Karlicek et al. 1982).

Photoelectrochemical deposition has been demonstrated on p-type silicon and $\mathrm{p}$ - and $\mathrm{n}$-type GaAs. Both palladium/cyanide and gold/cyanide plating solutions were shown to deposit the metal, either Pd or Au, on illuminated p-type Si and GaAs, while depositing on dark areas of n-type GaAs when illuminated through a mask (Micheels et al. 1981). Similar results were seen using a copper, zinc and cadmium plating solution; $\mathrm{Zn}$ and $\mathrm{Cd}$ were efficiently deposited on illuminated p-type silicon and the Cu was not (Rose et al. 1983).

A variety of other materials, including semiconductors, insulators, and photovoltaic materials, can be deposited by photoreaction in liquids. In fact, the only example of solar-assisted deposition found in the literature is the work carried out in Mexico on deposition of highly photosensitive CdS thin films (Nair and Nair 1987). The deposition process uses an extremely simple technique: microscope slides are placed vertically into 50 -mL beakers that are filled with an aqueous mixture of thiourea, cadmium acetate, triethanol-amine, and ammonia. Then the apparatus is covered with a larger inverted beaker and placed in the noonday sun for 1 to 2 hours.

The films formed by this technique have optoelectric qualities that surpass films deposited by other techniques and the film growth and quality is highly reproducible. Film thicknesses of $0.5 \mu \mathrm{m}$ are obtained with photoconductivity of $0.5 \mathrm{ohm}^{-1} \mathrm{~cm}^{-1}$ and photo/dark conductivity ratios of $\sim 10^{7}$ for $\mathrm{AM}$.

These results demonstrate a purely solar-driven reaction in which no electrical energy was used. No real explanation of the deposition mechanism is given in the report on this work, and 
it is possible that the solar radiation is used simply to heat the solution, rather than to initiate a specific photochemical reaction.

\subsubsection{Etching}

Etching is the converse of deposition, in that material is removed from, rather than added to, a surface. Numerous instances of photoetching, using pulsed or CW lasers, have been reported in the literature. There is potential for using a solar source for these applications, particularly for broad area etching in either the gas or liquid phase. As mentioned in the preceding section, an advantage of using a noncoherent source is the ability to obtain uniform, speckle-free beam profiles, and thus uniform surface exposure. The corresponding disadvantage, of course, is the inability to focus the light for direct etching of narrow features.

\subsubsection{Gas-Phase Systems}

The gas-phase etching of silicon by $\mathrm{Cl}_{2}$ (Okano et al. 1984) has, been done using a $\mathrm{Hg}-\mathrm{Xe}$ arc lamp. Similar etching results are seen with $\mathrm{GaAs}$ (Ashby 1985) and $\mathrm{GaAs}$ 1.x $\mathrm{P}_{\mathrm{x}}$ alloys with $\mathrm{x}=0.2$ and 0.37 (Ashby 1986), using $\mathrm{HCl}$ as the etchant.

These reactions are believed to be photoelectrically driven, making it possible to carry out the process at lower substrate temperatures. Solar radiation cou:d be applicable to chlorine etching processes, because $\mathrm{Cl}_{2}$ absorbs to the red of $300 \mathrm{~nm}$.

\subsubsection{Liquid phase Systems}

Photoenhanced etching in the liquid phase has been studied more extensively than in the gas phase. The materials that have been etched are Si (Bunkin et al 1985), GaAs (Podlesnik et al. 1984), InP (Bowers et al 1985), GaP (Johnson and Tisone 1984), CdS (Tenne and Hodes 1983).

As in the gas-phase work, the majority of the etching reactions in the liquid phase are photoelectrically driven, giving up to a hundred times enhancement over the dark reaction (Bowers et al. 1985). A solar source could be a direct replacement for currently used light sources in such applications if the economic and source availability factors discussed in Section 4.2 can be satisfactorily addressed.

\subsubsection{Materials Testing}

Solar furnaces allow condensed phase samples to be heated to very high temperatures $(>4000$ $\mathrm{K}$ ), in the presence of inert, reducing, or oxidizing reagents, and under elevated pressures (100 atm or more, depending on availability of windows). Further, this can be accomplished while maintaining cold walls in the confinement chamber and cold supports for the workpiece; the sample, if thick enough and heated from one side, becomes its own support. The solar furnace can also provide controlled temperature-time histories, including rapid heating of shallow surface regions of a specimen, and thus can be used to interrogate melting and solidification phenomena in complex refractory materials. These features make solar furnaces well suited for measuring thermochemical and thermophysical properties of refractory and other specialized materials under the high severity conditions of temperature, pressure, and reactive atmosphere, often of current scientific and practical interest. One example is determination of phase diagrams for ultrahigh melting point refractories. Further, a solar furnace offers these capabilities while avoiding certain disadvantages of competing techniques. Electron beam heating requires a vacuum and may result in unwanted ionization of the specimen or of volatiles 
evolved during heating of the sample. Radio irequency heating requires that the workpiece be. or contain, an electrical conductor.

Research needs on high-temperature ceramics for energy applications have been reviewed by Bowen (1980). Some of the potential benefits of the solar furnace approach are rather well illustrated by the work of Foex (1965), who determined the melting point of calcium oxide in a solar furnace using a calibrated pyrometer. His result $(3223 \mathrm{~K})$ was significantly higher than the previously reported value of $2887 \mathrm{~K}$. Foex's method is believed to have been little affected by sample contamination arising from high-temperature reactions of the specimen with its support (JANAF 1974). Foex also reasoned that a previous measurement technique in which the $\mathrm{CaO}$ was held on tungsten supports at high temperature was probably flawed caused by the reaction of $\mathrm{CaO}$ and the metallic tungsten to form $\mathrm{WO}_{3} \cdot 3 \mathrm{CaO}$, with the $\mathrm{WO}_{3} \cdot 3 \mathrm{CaO}$ depressing the observed melting point of the $\mathrm{CaO}$. This could account for the lower melting point value that had apparently been accepted for many years prior to Foex's work (JANAF 1974).

\subsubsection{Synthesis of Ceramic Powders *}

- Haggerty and co-workers at MIT have developed processes for producing fine, sinterable ceramic powders by $\mathrm{CO}_{2}$-laser-driven gas-phase reactions (Haggerty and Cannon 1981). As a part of the present study, we attempted to identify areas of opportunity for producing such materials from gaseous precursors using the concentrated solar spectrum to effect the reaction. Only a very select group from the wide range of ceramic materials used as powders are practical candidates for a solar-heated powder synthesis process. Bases for selection include cost, purity, diameter, size uniformity, shape, agglomeration, and process chernistry. Essentially, all of the criteria must satisfy critical targets before a material and process will find usage in the marketplace.

Cost alone will eliminate powders of traditional ceramic materials from consideration. Typical of the materials eliminated on this basis include standard grades of alumina $(\$ 0.40-\$ 0.60 / \mathrm{kg})$, clays $(\$ 0.02-\$ 0.20 / \mathrm{kg})$, magnesia $(\$ 0.60 / \mathrm{kg})$, silica $(\$ 0.025-\$ 0.22 / \mathrm{kg})$ and titania $(\$ 1.58 / \mathrm{kg})$. It is only the so-called "advanced ceramics" that have costs that can justify premium synthesis processes.

Advanced ceramic materials used as powders include special grades of alumina, alumirum nitride, aluminum titanate, barium titanate, beryllium oxide, boron nitride, lead titanate, molybdenum disilicide, sialon, silicon carbide, silicon nitride, zirconia, etc. Others could include several of the rare earth phosphors, and the formation of dianiond powder in the $\mathrm{CO}_{2}-$ laser-induced gas-phase decomposition of ethylene has recently been reported (Buerki and Leutwyler 1991). The sales prices of these powders are extremely variable, depending on specifications. Although many sell at prices as much as $\$ 200 / \mathrm{kg}$, there is considerable pressure for achieving significant price reductions so that finished components can compete with alternative lower cost, frequently well-established materials. An example of this is silicon nitride exhaust valves for automotive engines for which the cost of the constituent $\mathrm{Si}_{3} \mathrm{~N}_{4}$ powders approximately equals the cost of a finished metal valve. Unless powder costs are reduced significantly, ceramic valves cannot be manufactured at a price at which they can be sold.

The second generalization is that the application must require powders with diameters less than approximately 2 to $3 \mu \mathrm{m}$. If larger particle sizes are acceptable, it will probably be less

* This section was prepared by Dr. J.S. Haggerty. 
expensive to synthesize the material in a bulk form and to reduce powders to their final particle size by comminution processes.

Figure 8 summarizes 1982-1983 sales prices of Acheson $\mathrm{SiC}$ in $5(K)$ - $\mathrm{kg}$ lots as a function of particle size (solid circles). The sales price is essentially constant for particle sizes greater than $1(0) \mu \mathrm{m}$. Below $\mathrm{l}(10 \mu \mathrm{m}$, the cost of these powders increases rapidly with decreasing particle size. A $1 / d$ extrapolation was used to project prices into the submicron range needed for consolidation by sintering mechanisms at practical temperature levels.

The cost of small diameter powders increases rapidly because of factors contributing to the process energy per kilogram of material. This parameter is also shown on Figure 8 . The specific energy increases with smaller p.wders because the specific surface area of the powders becomes increasingly significant and because the comminution process becomes progressively less efficient. Combined, these effects generally give between a $1 / \mathrm{d}^{2}$ and a $1 / \mathrm{d}^{2}$ relationship between cost and diameter. The correlation between cost and process energy curves is evident.

Figure 8 also shows current selling prices of nominally $1 \mu \mathrm{m}$ diameter $\mathrm{SiC}$ powders as a circular cross-hatched region. These prices, $\sim \$ 20 / \mathrm{kg}$, are approximately an order of magnitude less than projections based on the extrapolated curve. The difference results from a combination of improved processing, increased competition for a growing market for highquality structural ceramics, and prices that are closer to manufacturing costs. To relate these prices to the inherent comminution costs, dashed lines have been drawn with slopes corresponding to $1 / \mathrm{d}$ and $1 / \mathrm{d}^{2}$ dependencies through the extremes of the price range until they intercept the horizontal curve corresponding to the muimum cost. The region defined by the dashed lines probably represents nearly the minimum price of $\mathrm{SiC}$ powders made by comminution. By this analysis, powder prices begin to rise rapidly for diameters smaller than $\sim 8 \mu \mathrm{m}$ rather than $\sim 100 \mu \mathrm{m}$.

The horizontal shaded region on this figure summarizes a range of projected manufacturing costs for $\mathrm{SiC}$ powders made from $\mathrm{CO}_{2}$ laser-heated $\mathrm{SiH}_{4}$-based reactant gases. Although absolute costs are subject to specific cost assumptions, the solar-heated powder synthesis process should exhibit many of the same characteristics. Unlike a comminution process, a powder synthesis process need not exhibit a cost dependence on particle size. Provided the process is capable of ralaking agglomerate-free, small diameter powders, direct synthesis pron $r$ sses can enjoy an important cost advantage for very small diameter powders. Gas-phase syniicsis represents one of the lowest cost options for the 0.2-to-0.3- $\mu \mathrm{m}$ diameter powders currently used for state-of-the-art structural ceramics. Additionally, these synthesis processes yield powders with narrower size distributions and with higher purities than are characteristic of ceramic powders made by comminution processes.

Figure 9 illustrates an important criterion for selecting viable particle formation and growth mechanisms for making cost-competitive, small diameter powders. To yield a high-value powder, the exposure timie, the particle number density, and the growth mechanism must be selected to avoid formation of agglomerated powders in the finished product. Interparticle collision times, defined by number density, size, and temperature, are critical in this regard. Growth by CVD mechanisms requires low number densities to avoid interparticle collisions during relatively long exposures to slow grow... rate conditions (low supersaturation) that are needed to suppress sustained nucleation of new particles. Decreasing particle number density and increasing growth time both proportionally reduce a reactor's specific production rate $(\mathrm{kg} / \mathrm{liter}-\mathrm{h}$ of reactor volume). In contrast, growth by collision-coalescence mechanisms depend on high collision rates between high number density particles. Reported operating conditions for high-quality, uniform size Si powders are indicated by the "collision - 


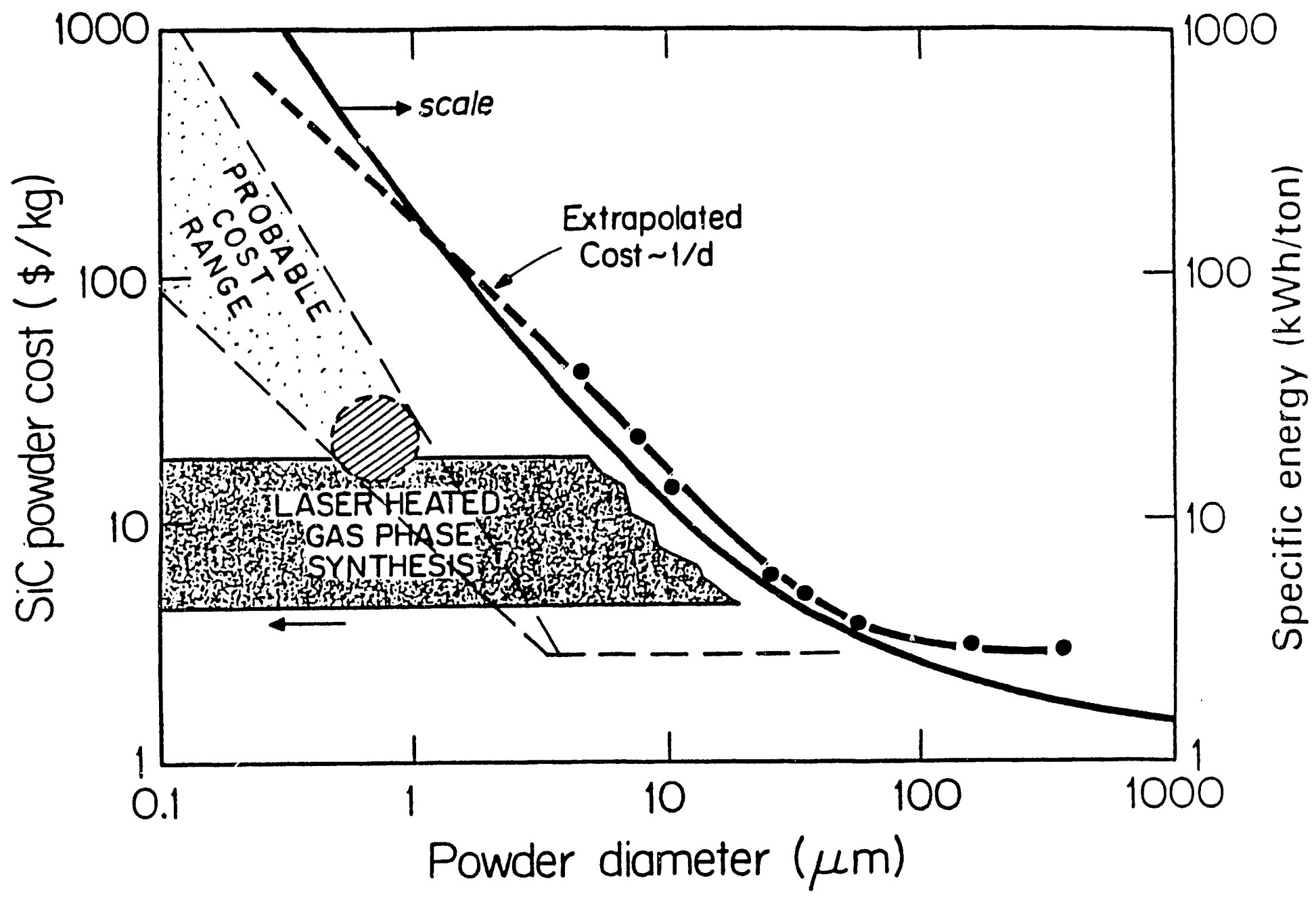

Figure 8. Cost estimates for $\mathrm{SiC}$ powders as a function of particle size, d. Comminution processes typically exhibit $1 / \mathrm{d}$ to $1 / \mathrm{d}^{2}$ dependencies. Gas-phase synthesis processes do not exhibit this size dependence, and thus can have a significant cost advantage for the submicron size powders needed for state-of-the-art ceramic parts. 


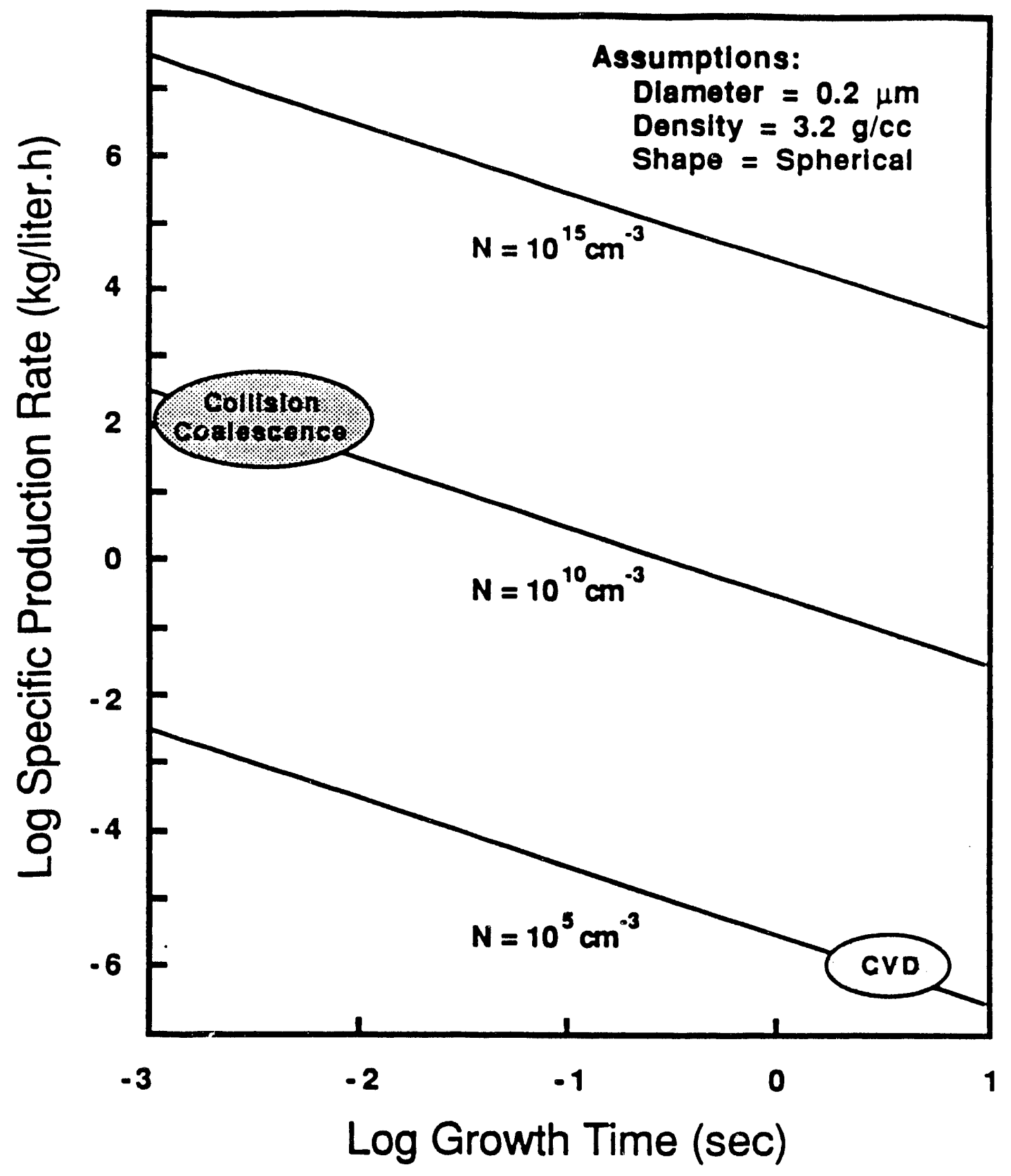

Figure 9. Hourdy mass flow rates per unit volume as a function of residence (growth) time for $0.2 \mu \mathrm{m}$ diameter spherical powders. The collision-coalescence domain is typified by number densities on the order of $10^{10} \mathrm{~cm}^{-3}$ and growth times between 1 and $10 \mathrm{~ms}$. The CVD domain requires much lower number densities $\left(-10^{5} \mathrm{~cm}^{-3}\right)$ to avoid interparticle collisions during the long growth times $(\sim 5 \mathrm{~s})$ required under low supersaturation conditions. 
coalescence" and the "CVD" areas in Figure 9. The difference between the specific production rates of the two types of processes is in excess of $10^{8}$. The CVD process produces $\sim 10$ grams for each liter of reaction volume in a year, whereas the collision-coalescence process produces $\sim 2,000$ tons. Even with displacements that could result from process improvements or changes in assumptions, it is obvious that the difference between the specific production rates will have important cost ramifications that favor synthesis by collision-coalescence mechanisms. This conclusion means that the synthesis chemistry and the reaction sequence must permit formation of liquid particles so that coalescence can keep up with high rates of collision during growth of particles greater than $\sim 100 \AA$ in diameter.

Reaction enthalpies provide another important criterion for determining whether solar-heated processes will be able to produce cost-competitive products. Amortization costs for capital expenses of sophisticated, controlled-atmosphere powder synthesis equipment demand high mass flow rates and essentially continuous duty cycle production processes. Many of the reactions based on the lower cost candidate reactants are highly endothermic. Because it is unlikely that solar sources will ever practically deliver industrial levels of process power (hundreds of kilowatts), solar-heated reactors will be forced either to use typically more expensive exothermic chemistries or to operate at a significant cost disadvantage because of low throughput if endothermic chemistries are used.

The selection process for identifying suitable ceramic powders presents a formidable challenge in terms of identifying chemistries that will give reasonable prognosis of satisfying production cost targets defined by highly competitive alternative materials and processes. Potential applications, existing and candidate materials, and existing and alternative processes must be evaluated critically. Both commodity and high-value niche markets must be studied. If likely candidates are identified, engineering design criteria have been developed that will permit the solar-heated synthesis processes to be designed and developed with a high level of confidence.

\subsection{Solar-Pumped Lasers}

Although the prospects for solar-pumped laser development are not a primary focus of this study (a more complete evaluation is being done in a parallel study at SRI), we want to discuss briefly the current research directions, and the future promise, of this use of concentrated solar energy.

The purpose of developing solar-pumped lasers is the development of solar-powered sources capable of driving nonlinear processes (e.g., harmonic generation), and providing sources for applications requiring narrow-band radiation, (e.g., isotope separation). There are two types of solar-pumped laser systems being developed: lasers pumped by direct solar irradiation and lasers driven indirectly by black-body radiation in a cavity heated by solar irradiation.

\subsubsection{Direct Solar Pumping}

Direct solar pumping has beer used successfully to side-pump Nd-YAG in a CPC concentrator at the Weizmann Institute in Israel. Prototypes have been developed at the University of Chicago for Nd-YAG end-pumped by a dielectric non-imaging concentrator, and for a Rhodamine dye laser side-pumped inside a specially designed non-imaging concentrator; however, they have not yet operated successfully (Winston 1990).

The important design requirements in both cases include efficient collection and coupling of the solar radiation to the lasing medium, minimizing losses in the laser cavity and cooling of the lasing medium. Calculations for the most promising solid state lasers operating in the near-IR and visible regions and for dye lasers indicate that lasing thresholds can be reached, and overall 
efficiencies of $2 \%$ to $3 \%$ achieved ( $1.2 \%$ actual in the Weizmann laser). Limitations on efficiency include the incomplete absorption of the solar spectrum and the incomplete conversion of absorbed energy to lasing levels.

An important barrier to scale-up of solid state lasers is the heat load because of energy absorbed by levels not involved in lasing. Removal of excess heat from the laser rod will have associated costs in terms of energy and equipment. The variability of solar flux will also be a major problem at high output levels. Lasing rods used in commercial solid state lasers must be designed for specific operating temperatures and pump levels to prevent thermal lensing effects and thermal damage.

Dye lasers are susceptible to the same thermal load problems as solid state lasers because the dye solution must be cooled and the thermal instabilites in the dye flow affect lasing. It is believed by Prof. Winston of the University of Chicago that these problems may be more manageable in the case of dye lasers. Dr. Janes, an affiliate of the MIT Spectroscopy Laboratory, feels that thermal instabilities will also provide limits to dye laser scale-up, similar to those for solid state systems.

Solar pumping of both solid state and dye lasers is a field at a very early stage of development. Considerable research needs to be done on cavity designs and heat load/scale-up requirements. A user facility with a large aperture, high-flux solar source will make it much easier to design and test prototypes at a variety of scales.

\subsubsection{Black Body Pumping}

One of the problems of direct pumping of lasing media by concentrated solar energy is the incomplete absorption of the solar spectrum. Pumping by a black-body cavity overcomes this limitation because energy that is not absorbed by the lasing medium is absorbed and reradiated by the cavity itself. Thermal problems caused by incomplete conversion of absorbed energy to lasing levels still limit the efficiency of the laser and require a considerable investment in cooling.

Gas or liquid lasing media may be circulated through the black-body cavity, and then into a heat exchanger or radiator. Solid state lasers require a flow of cooling liquid or gas in an envelope around the rod, which must then be cooled. For Nd-YAG, optimum efficiency of absorption into $1.06-\mu \mathrm{m}$ lasing bands occurs at temperatures above $2500 \mathrm{~K}$ (Christiansen 1990). At that temperature, $30 \%$ of the energy is expected to be absorbed by the $1.06-\mu \mathrm{m}$ levels, leaving $70 \%$ of the absorbed energy to be dissipated as waste heat. Frequency-selective coatings on the lasing rods may reduce the excess heat.

\subsection{Special Applications}

Unusual manufacturing requirements or constraints, or special geographical situations, may provide opportunities for new or unconventional utilization of solar concentrators. In remote locations, solar concentrators may prove useful as the heat source for Stirling or Rankine engines (Langhoff 1990). These would provide shaft power to operate electrical generators and water storage pumps to counteract the effects of diurnal variations in solar energy availability. There is a need to carry out cycle efficiency analyses for this application and to compare it with other renewables- and nonrenewables-based options for generating shaft power (and electricity) in remote locations. Technical areas in need of further research include materials problems associated with sodium heat pipes for transferring concentrated solar energy to the free piston expansion chamber of the Stirling engine (Langhoff 1990). 
While displacement of an imported joule or Btu of energy by a domestically available and renewable amount is of interest, the quality of that displaced energy, i.e., the temperature at which it must be delivered to be effective in the process of interest, is also important. In this regard, the solar concentrator is capable of generating thermal energy at very high temperatures and thus may offer special advantages as a renewable source of high-temperature process heat, especially above 30$)^{\circ} \mathrm{C}$. Alternative sources of high process temperatures include combustion of fossil and other fuels, and electricity-driven thermal plasmas. The solar furnace provides high-temperature process heat from a renewable, domestically secure source. Further, the solar furnace does not contribute to net increases in atmospheric carbon dioxide concentrations. For these reasons, carbon taxes or other regulatory factors, or national security considerations, may enable solar furnaces to be viewed as more competitive with some of the above alternatives for certain applications.

Applications of solar concentrators to destruction of hazardous wastes was not within the scope of the present study, although this application now commands significant interest as a potential practical use for solar concentrators. In the present study, it is instructive to examine another potential application of solar concentrators in the waste management area, namely waste recycling rather than waste destruction. The rationale is as follows. Toxic or otherwise hazardous or unwanted coproducts from chemical processes and other industries are often so dilute, so contaminated, or so refractory, that they must be permanently disposed of, for example, by incineration or biodegradation. In contrast, some hazardous industrial residues are also amenable to thermal recovery of valuable chemicals or their precursors. For example, pyrolysis has been used to recover $\mathrm{HCl}$ or other monomers from waste samples of thermoplastics such as polyvinylchloride, teflon, polystyrene, and polymethyl-methacrylate (Hong 1987). However, there remains opportunity to optimize for hazardous and other industrial process residues, thermal or partially thermal, recovery/recycling technologies, including approaches based on solar concentrators. Successful development of such technologies would allow industry to recycle at least some of their toxic residues to valuable chemicals, thereby reducing the volumes of process wastes requiring expensive treatment, storage, and disposal. Candidate wastes for solar thermal processing include solid halogenated organic residues from polymer manufacturing processes.

The literature on polymer pyrolysis is supportive of this proposed application. Table 6 shows data from Fong (1986) and Fong et al. (1986) on effects of temperature and treatment time on the major products from pyrolysis of a rather complex thermoplastic natural polymer (an eastern U.S. bituminous coal). External hydrogen was not employed in these experiments. Here "extractables" were recovered by rapidly quenching the partially reacted material, and then extracting the residue with pyridine at roughly its boiling point $\left(115.5^{\circ} \mathrm{C}\right)$. Extractables are a potentially valuable product, precursor, or recycle feed. Other data from Fong (1986) and Fong et al. (1986) show an optimum treatment "severity" (temperature and time) for recovering large extract yields (up to about $70 \mathrm{wt} . \%$ of the starting material). Inadequate treatment provides too little conversion, while excess severity causes molecular weight growth and further conversion of the extracts to a carbonaceous residue (char or coke).

The parent chemical structure and thermal decomposition chemistry of coal are sufficiently complicated that extractables are generally complex mixtures of hundreds of aromatic, heteroaromatic, and aliphatic compounds. Literature data (Cullis and Hirschler 1981; Boonstra and van Amerongen 1949; Shafizadeh and Fu 1973) show that controlled pyrolysis of simpler starting materials, including cellulose, rubber, and several synthetic polymers such as polymethylmethacrylate, poly ( $\mathrm{p}$-chlorostyrene), and poly(alpha-methylstyrene) remits high yields of the corresponding parent monomer $(80$ to $>90 \mathrm{wt} \%)$. Pyrolysis of other simple polymers (e.g., polyethylene, polyvinylchloride) gives low yields of monomers (Cullis and Hirschler 1981), although improvements may be possible if a suspected rapid repolymerization of reactive intermediates can be prevented. 
Solar concentrators could provide the means to subject process wastes and residues to properly chosen heating and cooling cycles, allowing at least partial reprocessing of those wastes to monomers or other valuable products. Research is needed to establish technically and economically viable treatment conditions. These are expected to depend on the thermal degradation chemistry and on the composition, phase, morphology, and overall heterogeneity of the waste. Research should focus on identifying treatment conditions optimizing recycle product yields and quality (measured in terms of recovery of separable quantities of specific monomers or other premium value feedstocks, intermediates, or by-products). Even those recycling conditions providing high yields of desired products can be expected to generate some "secondary" residues that may be hazardous. The composition, toxicity, and gasification/oxidation reactivity of secondary residues should be determined to index their potential hazard and assess possible remediation options.

A related opportunity is to learn how to optimally use the thermal and photochemical effects of concentrated solar photons, with or without added heterogeneous catalysts, to achieve desired yields and quality of recycled products. The potential of solar furnaces to drive combined thermal, photochemical, and catalytic processes may offer special advantages in recycling mixed wastes, e.g., by tuning certain wavelength bands to chromophores unique to one waste component or by use of recoverable photosensitizers. Success here would address one of the very challenging current problems for waste recycling technologies, namely the desire to reprocess mixed wastes to useful products without first separating the mixture into individual components.

Potential benefits to industry of recycling process wastes would include recovery of valuable feedstocks, intermediates, or by-product chemicals, and reductions in the amounts of hazardous process residues that would require expensive treatment, storage, and disposal.

TABLE 6. Yield of Coal Extractables from Controlled Heating without External Hydrogen or Donor Solvents $\mathrm{a}, \mathrm{b}, \mathrm{c}$

\begin{tabular}{ccccc}
$\begin{array}{c}\text { Heatup } \\
\text { Rate }{ }^{\circ} \mathrm{C} / \mathrm{s}\end{array}$ & $\begin{array}{c}\text { Final } \\
\text { Temp. }{ }^{\circ} \mathrm{C}\end{array}$ & $\begin{array}{c}\text { Total Thermal } \\
\text { Soak Time,s }\end{array}$ & $\begin{array}{c}\text { Quench } \\
\text { Rate }{ }^{\circ} \mathrm{C} / \mathrm{s}\end{array}$ & $\begin{array}{c}\text { Extractables } \\
\text { Yield, wt\% DAFd }\end{array}$ \\
\cline { 2 - 5 } 3300 & 635 & 0.5 & 4500 & 60 \\
450 & 582 & 2 & $\mathrm{e}$ & 69 \\
470 & 540 & 4 & 1100 & 71 \\
\hline
\end{tabular}

aData of Fong (1986); Fong et al. (1986).

bTotal pressure $1 \mathrm{~atm}$ of helium.

cCoal: Pittsburgh No. 8 bituminous.

dExtractables yield determined as described in text.

eNot known. 


\section{SECTION 6}

\section{FINDINGS AND RECOMMENDATIONS}

In this report, we reviewed numerous suggested possibilities for applications of photochemistry to chemical and materials processing, with particular attention to concentrated solar energy. The purpose of the thorough review of previous work in these areas was to ensure that "that which has been done" is not simply duplicated, unless there is a strong prospect that by doing so new, useful information and/or new potential processes may be discovered.

Our overall conclusion is that there may be a number of processes which, if not entirely novel, represent essentially new applications for concentrated solar energy. Furthermore, they appear to be feasible with present or anticipated near-term technology, and therefore merit further investigation. In addition, it is our view that ongoing developments in many diverse areas of science and technology will open new, unforeseen opportunities in applications of concentrated solar energy relevant to national needs.

At present our consensus is that the most economically defensible applications for solar concentrators will most probably be found in the manufacture or processing of high value added materials, in specialized situations where solar resources are readily available and other energy sources are in short supply, or in central user facilities for research and testing applications. During the next one to two decades it is possible that changes in national or international policies or priorities, advances by economists in learning how to measure costs and benefits of environmental factors, national security issues, or advances in technology may produce situations where additional applications become economically interesting.

In order to respond to this diversity of potential applications, our principal recommendation is to establish a National Solar Concentrator Research Facility at the NREL Solar Furnace site in Golden, Colorado. This would promote testing and evaluation of a wide range of proposed processes. The Department of Energy has had extensive and, for the most part, rewarding experience with specialized user facilities, such as the synchrotron radiation sources at Brookhaven and Wisconsin and the new electron-beam metal processing consortium at Sandia (Dagani 1990). A National Solar Concentrator Research Facility would provide a unique resource for the country and would promote applications of solar concentrator technology by drawing on the considerable expertise available in academic, industrial, and national laboratories.

Among the many possibilities which might be explored in depth at such a facility are the new $\mathrm{C}_{60}$ chemistry and "laser-jet" photochemistry, discussed in Sections 5.1 and 5.3; applications to materials processing and synthesis of fine ceramic powders, discussed in Section 5.5; and special applications such as solar-powered waste recycling, discussed in Section 5.7. A further suggestion which arose during our discussions was that effective use could be made of the high near-infrared flux in the solar source by installing a near-IR Fourier-Transform spectrometer at such a facility. This instrument could find extensive use in measurement of the optical properties of compounds and materials in this wavelength range. Such il . ormation, which is needed for solar process design and optimization, is frequently not available.

The intermittency and limited duty cycle of the solar source could potentially be a problem in scheduling user time; however, when compared with the extended downtimes frequently encountered in large central user facilities, such as particle accelerators, the overall duty cycle of a Solar Concentrator Research Facility may be quite favorable. 
Our recommendations now follow.

1. Establish a National Solar Concentrator Research Facility with an extramural support program. Such a user facility, which would be located at the current NREL site in Colorado, can be modeled after the synchrotron light source facilities at Brookhaven and Wisconsin or the recently established Sandia Electron-Beam Facility for Specialty Metals Processing. The extramural support program would provide an incentive for users to come to the facility, and would enable them to carry out the necessary preliminary work and apparatus construction in their own laboratories. In such a facility, a variety of concentrator designs may be appropriate for applications requiring a range of solar flux:

- a paraboloidal trough (100 suns, no tracking) for relatively low-flux applications;

- the existing primary concentrator for applications requiring 1000 to 5000 suns; and

- a secondary (dielectric) concentrator capable of exceeding 20,000 suns, for solar-pumped laser research and applications such as laser-jet photochemistry.

A corollary of this recommendation is that no large-scale demonstration facility is recommended at this time, pending further research and analysis.

2. Among the most promising near-term potential applications identified are those in the areas of materials processing and materials testing. Of particular interest are certain types of surface treatment of metals and alloys, deposition of selected thin-film materials, synthesis of fine ceramic powders, and testing of materials for high severity environments, such as solar thermal reactors and space and nattonal defense applications.

3. A research emphasis on high-temperature, high-intensity photochemistry is strongly recommended. Such research could lead to significant new applications of concentrated solar energy.

4. Several additional specialized "niche" applications for concentrated solar energy have been identified in Section 5.7, such as driving Stirling engines or on-site waste $r \in$ cycling. Such applications may have export potential to and be suitable for situations in which conventional energy sources are unavailable or especially expensive.

5. Methodologies should be established for systematic continuing evaluation of identified and other potential applications for concentrated solar energy, based on the criteria developed during this study. These criteria include the scientific and technical aspects discussed in Section 4.1, the practical and economic aspects discussed in Section 4.2, and context externalities such as environmental impact and energy security.

6. Detailed economic analysis of a few candidate processes should be carried out using the quantitative process modeling tools described in Section 4 . The objective of such analysis would be to define the energy price breakeven point at which a process may become economically viable with respect to alternatives. The "carbon cost" (for energy derived from fossil fuels), "radwaste cost" (for nuclear energy), and other costs associated with downstream environmental and health burdens, should be accounted for in such comparisons. 
7. A high priority should be placed on involving industry in solar energy applications development. During the course of this study, several sites of potential interest in industry were identified. These included Cummins (Stirling Engine), Inrad (photochlorination), and Coors (ceramic powders). Given the limited time available. however, it was not possible to pursue these contacts at greater length to estaulish the nature and level of industrial interests. Mechanisms to facilitate collaborative interactions between the public and private sectors, such as the recently enacted CRADA Program, are expected to be valuable in matching industrial needs and interests with solar concentrator capabilities.

8. There is a need for increased public awareness about solar energy programs and about possible funding for solar energy applications. In the study team's discussions with other scientists, a frequently encountered response was lack of information about current programs, and pleasant surprise on learning of efforts under way to utilize solar energy in the United States. One possible mechanism for accomplishing this would be to hold a symposium on solar concentrator optics and applications at a venue such as a Society of Photo-Optical Instrumentation Engineers (SPIE) Conference or the Intersociety Energy Conversion Engineering Conference. 


\section{SECTION 7}

\section{REFERENCES}

Albach, G., 1991, "New Roles for Lamps in Materials Processing," Photonics Spectra. January, 1991, p. 149.

Allen, S.D. and A.B. Tringubo, 1983, L.Appl, Phys. 54, 1641.

Allen, S.D., R.Y. Jan, S.M. Mazuk and S.D. Vernon, 1985, L Appl. Phys. 58, 327.

Arbogast, J.W., A.P. Darmanyan, C.S. Foote, Y. Rubin, F.N. Diederich, M.M. Alvarez, S.J. Anz and R.L. Whetten, 1991, L. Phys. Chem. 95, 11.

Armstead, H.C.H. and J.W. Tester, 1987, Heat Mining, E.\& F.N. Spon, New York, p. 403.

Arnone, C., M. Rothschild, J.G. Black and D.J. Ehrlich, 1986, Appl. Phys Lett. 48, 1018.

Ashby, C.I., 1985, Appl, Phys, Lett. 46, 752.

Ashby, C.I., 1986, L Vac. Sci. Technol A4, 666.

AspenTech, 1990: Aspen Technology, Inc. of Cambridge, Mass. supports and maintains the ASPEN PLUS process simulator, which includes an integrated preliminary grade cost estimation system. The software is available commercially.

Avron, M., 1990, The Biotechnology of Cultivating Dunaliella Rich in Beta-Carotene: from Basic Research to Industrial Production, presented at SERI NRC/NAS Workshop on the Use of Concentrated Solar Energy, Golden, Colorado.

Bassett, I.M., W.T. Welford and R. Winston, 1989, "Non-imaging Optics for Flux Concentration," in Progress in Optics XXVII, (E. Wolf, ed.), Elsevier, Amsterdam (NL).

Bauerle, D., 1989, Appl. Phys. A 48, 527.

Bilgen, E., 1990, Thermal, Thermochemical and Hybrid Solar Hydrogen Production, SERI NRC/NAS Workshop on the Use of Concentrated Solar Energy, Golden, Colorado.

Black, J.G., S.P. Doran, M. Rothschild and D.J. Ehrlich, 1990, Appl. Phys. Lett. 56, 1072.

Boonstra, B.B.S.T. and G.J. van Amerongen, 1949, "Pyrolytic Decomposition of Rubber into Isoprene," Ind. and Eng. Chem., 41, 161.

Bowen, H.K., 1980, "Basic Research Needs on High Temperature Ceramics for Energy Applications," Mat, Sci, and Eng, 44, 1-56.

Bowers J.E., B.R. Hemenway and D.P. Wilt, 1985, Appl. Phys Lett. 46, 453. 
Brown, L.M., 1990, Production Potential of Biochemicals from Algae Under Increased Solar Irradiance and Other Biotechnological Innovations Enabled by Higher Solar Concentration, presented at SERI NRC/NAS Workshop on the Use of Concentrated Solar Energy, Golden, Colorado.

Buerki, P.R. and S. Leutwyler, 1991, LAppl Phys, 69, 3739.

Buhl, M.L., R.E. Bird, R.U. Bilchak, J.S. Connolly and J.R. Bolton, 1984, Solar Energy 32, 75 .

Bunkin F.V., B.S. Luk'yanchuk, G.A. Kozlova, A.I. Portniagin, A.A. Yerymenko and P. Mogyorosi, 1985, Appl. Phys. A 37, 117.

Carasso, M. and A. Lewandowski, 1990, private communication.

Chemical Marketing Reporter, 1991, various issues. Source of many of the data on costs and yearly production volume of chemicals in Figure A.1.

Christiansen, W.H., 1990, SERI NRC/NAS Workshop on the Use of Concentrated Solar Energy, Golden, Colo.

Cullis, C.F. and M.M. Hirshcler, 1981, The Combustion of Organic Polymers, Oxford University Press, New York, p. 119.

Curl, R.F. and Smalley, R.E., 1991, Scientific American 265 (4), 54.

Dagani, R., 1990, "DOE. Technology To Be Shared with Industry," Chem, and Eng. News 68, 31, pp. 20-21.

Dekumbis, R., 1987, Chem. Eng. Prog. 83, 23.

Ehrlich, D.J. and R.M. Osgood, Jr., 1981, Chem. Phys. Lett. 79,381.

EPRI, 1990, "Breaking Through Performance Limits Beyond Steam," EPRI Journal 15. 8, pp. 4-11.

Foex, M., 1965, Solar Energy 9, 61.

Fong, W.S., 1986, "Plasticity and Agglomeration of Coal Pyrolysis," Sc.D. Thesis, Dept. of Chemical Engineering, MIT, Cambridge, Mass.

Fong, W.S., Y.F. Khalil, W.A. Peters and J.B. Howard, 1986, "Plastic Behavior of Coal Under Rapid-Heating High-Temperature Conditions," Fuel 65, 195-201.

Glandt, E.D. and A.L. Myers, 1976, Ind Eng Chem, Process Des. Dev, 15, 100.

Glasstone, S., 1982, Energy Deskbook, sponsored by the USDOE, available as DE82013966 (DOE/TR/05114-1), National Technical Information Service, U.S. Department of Commerce, Springfield, Va., p. 350.

Gleckman, P., J. O'Gallagher and R. Winston, 1989, "Concentration of Sunlight to SolarSurface Levels Using Non-imaging Optics," Nature 339, 198-200.

Gottsleben, O. and M. Stuke, 1988, Appl, Phys, Lett. 52, 2230. 
Haggerty, J.S. and W.R. Cannon, 1981, "Sinterable Powders from Laser-driven Reactions" in Laser-in luced Chemical Processes, (J.I. Steinfeld, ed.), Plenum Press, New York, p. 165.

Haigh, J. and M.R. Aylett, 1988, Prog Quant. Electr. 12, 1.

Hajaligol, M.R., W.A. Peters and J.B. Howard, 1988, "Intraparticle Nonisothermalities in Coal Pyrolysis," Energy \& Fuels, 2, 430-437.

Hajaligol, M.R., W.A. Peters and J.B. Howard, 1991, "Effects of Transient Heat Transfer on Kinetics Parameters for Cellulose Pyrolysis," Cembustion and Flame (submitted).

Hammache, A. and E. Bilgen, 1988, Intl.J.Hydrogen Energy 13, 539.

Herman, I.P., 1989, Chem, Rev, 89, 1323.

Hirota, Y. and O. Mikami, 1985, Electr. Letts. 21, 77.

Hong, K.C.C., 1987, "Plastic Waste and the Environment," Term paper in Subject 10.72J/TPP52J, MIT, Cambridge, Mass.

Howard, J.B., 1991, private communication.

Howard, J.B., J.T. McKinnon, Y. Makarovsky, A.L. Lafleur and M. E. Johnson, 1991, "Fullerenes $\mathrm{C}_{60}$ and $\mathrm{C}_{70}$ in Flames," Nature 352, 139-141.

JANAF, 1974, JANAF Thermochemical Tables, 1974 Supplement, entry "Calcium Oxide (CaO) (crystal)."

Jackman, R.B., J.S. Foord, A.E. Adams and M.L. Lloyd, 1986, L. Appl. Phys. 59, 2031.

Johnson A.W. and G.C. Tisone, 1984, Mat. Res. Soc. Symp. Proc 29, 145.

Karlicek, R.F., V.M. Donnelly and G.J. Collins, 1982, L.Appl, Phys, 53, 1084.

Karp, A., R. Smith and S. Ahmod, 1990, Pinch Technology: A Primer, Report by Linnhoff March, Inc. to the Electric Power Research Institute, Palo Alto, CA. EPRI Report No. CU-6775.

Kolb, G., 1990, Solar Furnaces vs Arc Lamps -- A Comparison of the Economics of Energy Delivery, SERI NRC/NAS Workshop on the Use of Concentrated Solar Energy, Golden, Colorado.

Kratschmer, W., L.D. Lamb, K. Fostiropoulos and D.R. Huffman 1990, Nature 347, 354.

Kroto, H.W., J.R. Heath, S.C. O'Brien, R.F. Curl and R.E. Smalley 1985, Nature 318, 162.

Langhoff, P.W., 1990, private communication. 
Lin, S.H., Y. Fujimura, H.J. Neusser and E.W. Schlag, 1984, Multiphoton Spectroscopy of Molecules, Academic Press, New York.

Lin, S.H., 1986, Advances in Multiphoton Processes and Spectroscopy Vol. 2, World Scientific Publishing Pte Lid, Singapore.

Mackay, A.L., 1990, Nature 347, 336.

Micheels, R.H., A.D. Darrow and R.D. Rauh, 1981, Appl. Phys Lell. 39, 418.

Minakota, M. and Y. Furukawa, 1986, LElectr. Mater, 15, 159.

Montgomery, R.K. and T.D. Mantei, 1986, Appl. Phys. Lell 48, 493.

Nair, P.K. and M.T.S. Nair, 1987, Solar Energy Materials 15, 431.

Neugebauer, G., and E.E. Becklin, 1973, "The Brightest Infrared Sources," Sci. Am. 228, 28.

Noyes, R.W., 1976, "New Developments in Solar Research." in Frontiers in Astrophysics (E.H. Avrett, ed.), Harvard Univ. Press, Cambridge, Mass.

Okano, H., Y. Horiike and M. Sekine, 1985, Japanese J. Appl, Phys. 24, 68.

Parsons, C.A., B.R. Thacker, D.M. Szmyd, M.W. Peterson, W. F. McMahon and A.J. Nozik, 1990, L. Chem. Phys, 93, 7706.

Perry, R.H., D.W. Green and J.O. Maloney, 1984, Perry's Chemical Engineers' Handbook, Sixth Edition, especially F.A. Holland, "Process Economics," Chapter 25, McGraw-Hill, New York.

Petets, M.S. and K.D. Timmerhaus, 1980, Plant Design and Economics for Chemical Engineers, Third Edition, McGraw-Hill, New York.

Petzoldt, F., K. Piglmayer, W. Krauter and D. Bauerle, 1984, Appl. Phys A. 35, 155.

Pitts, J.R., J.T. Stanley, E. Tracy, Y. Shacton and C.L. Fidd, 1990, Materials Processing with Concentrated Solar Radiation, presented at SERI NRC/NAS Workshop on the Use of Concentrated Solar Energy, Golden, Colorado.

Podlesnik D.V., H.H. Gilgen and R.M. Osgood, 1984, Appl. Phys. Letl 45, 563.

Pola J., V. Chvalovsky, E.A. Volnina and L.E. Guselnikov, 1988, L. Organometallic Chem. 341, C13.

Pool, R., 1990, Science 250, 209.

Richtmyer, F.K., E.H. Kennard and T. Lauritsen, 1955, Intreduction to Modern Physics. McGraw-Hill Book Co., New York, pp. 110-113.

Rose, L.T., D.H. Longendorfer and R.D. Rauh, 1983, Appl. Phys. Lett. 42, 193.

Ross, P.R., 1990, "A Million Watts of Light," Sci, Amer, 263 (11), p. 138. 
Shafizadeh, F. and Y.L. Fu, 1973, "Pyrolysis of Cellulose," Carbohy, Res, 29, 113.

Singmaster, K.A., F.A. Houle and P J. Wilson, 1990, L. Phys. Chem. 94, 6864.

Smoluchowski, R., 1983, The Solar System, Sci. Am. Books, New York.

Solanki, R. and G.J. Collins, 1983, Appl. Phys. Lell. 42, 662.

SRI, 1990), The Stanford Research Institute Process Engineering Program (PEP) is available to subscribers for a fee. Programs are used to perform in-depth economic evaluations of chemical processes.

Sugimura, A, Y. Fukuda and M. Hanabusa, 1987, L Appl. Phys, 62, 3222.

Szikora, S., W. Krauter and D. Bauerle, 1984, Mater. Letl. 2, 263.

Tenne, R. and G. Hodes, 1983, Surf, Sci. 135, 453.

Thekaekara, M.F., 1974. Appl. Opt. 13, 518-522.

Tokuda, J., M. Takai, K. Gamo and S. Namba, 1988, Mater. Res, Sec. Symp. Proc. $101,261$.

Tsao, J.Y., R.A. Becker, D.J. Ehrlich and F.J. Leonberger, 1983, Appl. Phys, Lell, 42, 559.

von Gutfeld, R.J. and D.R. Vigliotti, 1985, Appl. Phys, Lett. 46, 1003.

Watanabe, M., M. Furuya, Y. Miyoshi, Y. Inoue., I. Iwahashi and K. Matsumoto, 1982, Photochem. Photobiol_ 36, 491.

Welford, W.T. and R. Winston, 1989, High Collection Non-imaging Optics, Academic Press, San Diego.

Wilson, R.M., K.A. Schnapp, K. Hannemann, D.M. Ho, H.R. Memarian, A. Azadnia, A.R. Pinhas and T.M. Figley, 1990, Spectrochim. Acta 46A, 551.

Winston, R., 1990, private communication.

Winston, R., 1991, Sci.Am., 264, 76.

Woodin, R.L., D.S. Bomse and G.W. Rice, 1990, Chem. and Eng News 68, 51, p. 20.

Xu Xin and J.I. Steinfeld, 1990, Appl. Surf. Sci. 45, 281.

Yamagashi, K. and Y. Tarui, 1986, Jap. J. Appl. Phys, 25, L306.

Yokoyama, H., S. Kishida and K. Washio, 1984, Appl. Phys. Lett. 44, 755.

Zhang, G.Q., T. Szorenyi and D.J. Bauerle, 1987, Appl. Phys. 62, 673. 


\section{APPENDIX A. GENERAL PRINCIPLES OF PHOTON-DRIVEN CHEMISTRY}

\section{A.1 Fundamental Principles}

Ever since the laser became generally available as a source of intense, tunable, coherent radiation, many chemists, physicists, and materials scientists have sought to make use of these devices in chemical processing. Numerous studies and reviews (Cantrell et al. 1979; Kaldor and Woodin 1982; Lyman 1987; Steinfeld and Wrighton 1976; Steinfeld et al. 1979; Steinfeld 1981; Woodin et al. 1990) have suggested possibilities, and also delineated the constraints that must be taken into account in evaluating these possibilities. Because many of these considerations apply equally well to solar-driven as to laser-driven processes, we summarize here some of the principal findings in these studies.

Several mechanisms exist by which chemical reactions may be induced or accelerated by absorption of optical radiation. If the absorbed energy is rapidly dissipated in the material, the resulting bulk temperature increase may simply induce a photothermal acceleration of the reaction rate. If absorbed infrared energy is retained in the vibrational degrees of freedom of an isolated molecule. in which thermalization is not possible, decomposition or isomerization caused by vibrational photochemistry may ensue. Because the energies of infrared photons corresponding to vibrational fundamental absorptions (3000 to $\left.500 \mathrm{~cm}^{-1}\right)$ are, in general, considerably less than the activation barriers for such reactions, absorption of several infrared photons is required to reach the reaction threshhold. This infra-red multi-photon excitation (IRMPE) process has been widely studied using pulsed $\mathrm{CO}_{2}$ lasers (Ambartzumian and Letokhov 1977; Francisco and Steinfeld 1986). However, as has been shown in Section 5.1, the spectral brightness of even the highest attainable concentrated solar flux is many orders of magnitude less than that which would be required for IRMPE. Excitation through vibrational overtone absorptions in the near-infrared part of the spectrum can, in principle, deposit sufficient energy in a single molecule for a reaction to occur. The limitation on this process is that cross sections for overtone absorption are much smaller than for fundamental absorption; the decrease is about a factor of 10 for each increment in vibrational quantum number change. A further mechanism for photochemical excitation is via electronic states, which typically lie in the ultraviolet part of the spectrum.

Opportunities for solar-driven photochemistry are somewhat restricted by these fundamental constraints. Because the solar spectrum does not extend below $300 \mathrm{~nm}$, only low-lying $\left(<30,000 \mathrm{~cm}^{-1}\right)$ electronic states can be accessed directly. In favorable situations, vibrational overtone excitation may be possible with the near-infrared flux from highly concentrated sources. In most instances, the simple photothermal process will be dominant. This may be advantageously combined with photoexcitation of vibrationally "hot" species and/or chemical intermediates, as considered in Section 5.

\section{A.2 Economic Constraints on Applications}

Despite extensive efforts in academic, industrial, and national research laboratories, relatively few applications of laser-driven chemistry have emerged to date. A primary reason for this is the high cost of photons as chemical reagents, compared with the selling price of typicai commercial and commodity chemicals. This comparison, which has been made by Kaldor and Woodin (1982) and Woodin et al. (1990), among others, is shown in Figure A1. It is clear that high-volume commodity chemicals, which appear in the lower right-hand part of the figure, must have a low selling price to be economically viable. This places them below the cost threshhold associated with photon-driven chemistry. Only small-volume specialty chemicals, in the upper left-hand part of the figure, can be sold at prices high enough to 


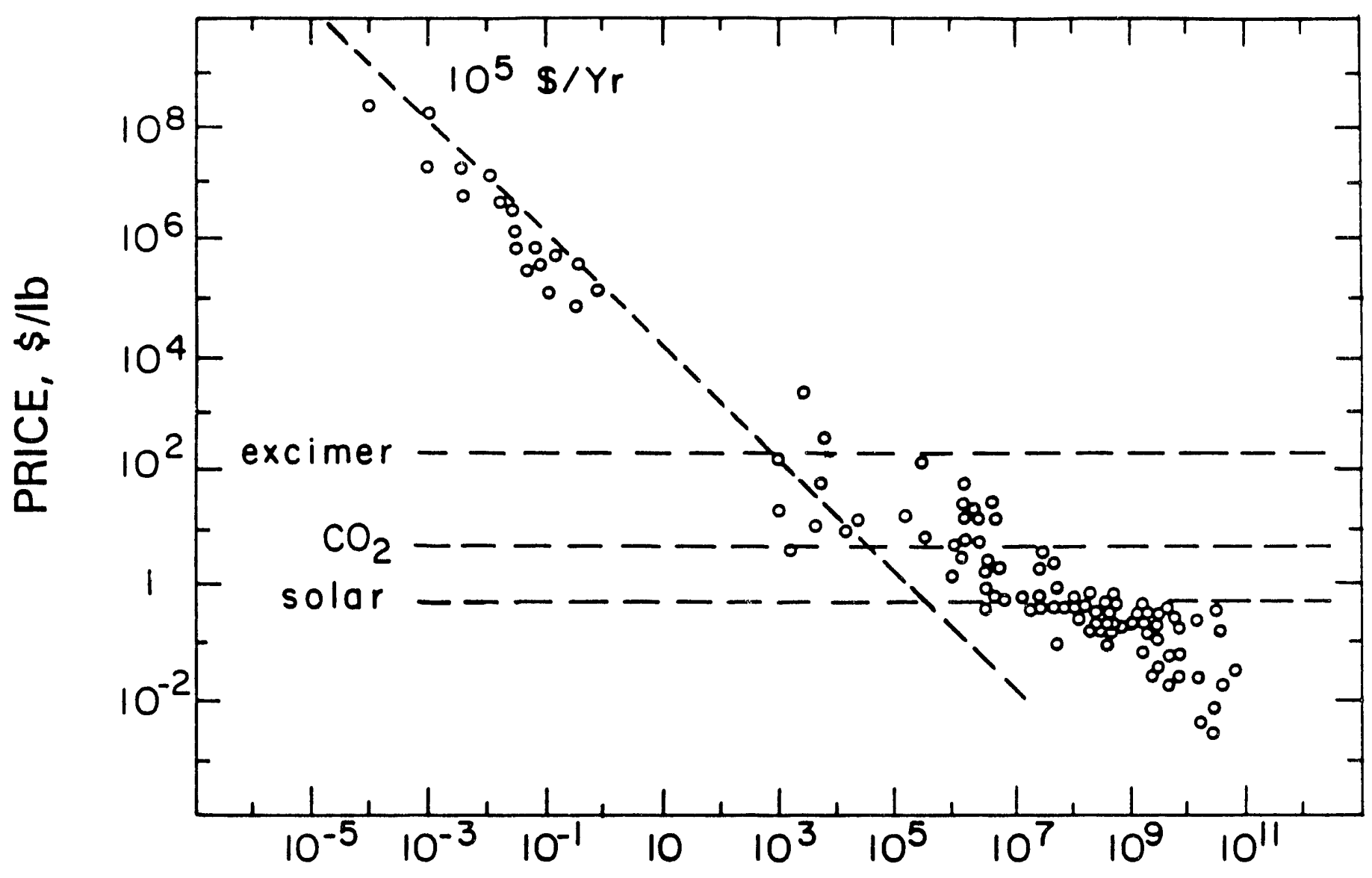

PRODUCTION, Ib/Year

Figure A1. Price production volume correlation for industrial chemicals: The excimer, $\mathrm{CO}_{2}$, and solar cost lines are those estimated for processing a nominal "1 $\mathrm{lb}^{\text {" }}$ of material, using photon energy cost estimates from Section 3: adapted from Kaldor and Woodin (1982) and Yardley (1990). 
recover the photon energy costs. Examples of such specialty products might be pharmaceuticals, biological materials, and isotopically enriched compounds.

In summary, while the costs associated with concentrated solar photon processing are slightly more favorable than for laser processing, its applicability is still largely limited to high-valueadded materials in which the photon energy cost is only a small part of overall processing costs. Examples of such high-value-added materials and processes include surface treatment of microelectronic devices and complex biological (possibly genetically engineered) compounds in which additional high-cost processing steps are required. This limitation can be relaxed somewhat if the photons are used non-stoichiometrically, e.g., to initiate a chain reaction with a long chain length or to activate a catalyst with a large turnover number. This may be realized in a photoinitiated exothermic reaction in which the reaction is maintained by energy released following an initial activation step. Fine powder synthesis (Section 5.5.3) may be an example of such a process. Finally, there may be special situations in which solar energy is available in the absence of other energy sources, such as those described briefly in Section 5.7 .

\section{References}

Ambartzumian, R.V. and V.S. Letokhov, 1977, "Multiple Photon Infrared Laser Photochemistry," in Chemical and Biochemical Applications of Lasers, Vol. 3 (C.B. Moore, ed.), Academic Press, New York, pp. 167-314.

Cantrell, C.D., S.M. Freund and J.L. Lyman, 1979, "Laser-Induced Chemical Reactions and Isotope Separation," in Laser Handbook. Vol. 3 (M. Stitch, ed.), North-Holland Publishing Co., Amsterdam, pp. 485-576.

Chemical Marketing Reporter 1991, various issues. Source of many of the data in Figure A.1 on costs and yearly production volume of chemicals

Francisco, J.S. and J.I. Steinfeld, 1986, "Photochemistry, Photophysics, and Spectroscopy of Molecular Infrared Multiple Photon Excitation," in Advances in Multiphoton Processes and Spectroscopy, Vol. 2 (S.H. Lin, ed.), World Scientific Publishing, Singapore, pp. 79-173.

Kaldor, A. and Woodin, R.L., 1982, Proc. I.E.E.E. 70, 565.

Lyman, J.L., 1987, "Laser-Induced Molecular Dissociation: Applications in Isotope Separation and Related Processes," in Laser Spectroscopy and Its Applications (L.J. Radziemski, R.W. Solarz, and J.A. Paisner), M. Dekker Inc., New York, pp. $417-$ 505.

Steinfeld, J.I. and M.S. Wrighton, 1976, "The Laser Revolution in Energy-Related Chemistry," National Science Foundation Workshop Report, Washington, D.C.

Steinfeld, J.I. et al., 1979, Laser Photochemistry and Diagnostics: Recent Advances and Future Prospects, Report on a NSF/DOE Seminar for Government Agency Representatives, Washington, D.C.

Steinfeld, J.I. (ed.), 1981, Laser-Induced Chemical Processes, Plenum Press, New York.

Woodin, R.L., D.S. Bomse and G.W. Rice, 1990, "Lasers in Chemical Processing", Chem. and Eng. News 68, (51), pp. 20-31. 
Yardley, J.T., 1990, Potential Industrial Applications of Photons, presented at SERI Workshop on Potential Applications of Solar Photons.

A -4 


\section{APPENDIX B \\ A Guide to the Data bases}

The following 16 data bases within Pro-Cite were created:

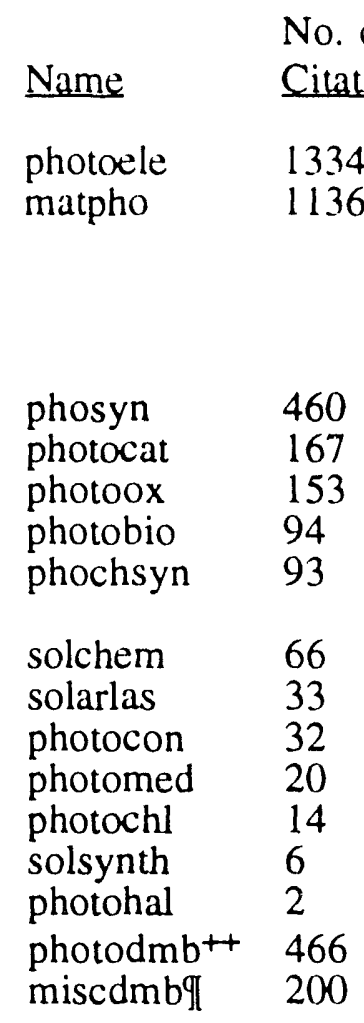

\author{
General Content \\ photoelectrochemistry \\ light and materials
}

light induced synthesis

photocatalysis

photooxidation

photobiology

photochemical synthesis

solar chemistry

solar lasers

photoconversions

photomedicine

photochlorination

solar synthesis

photohalogenation

photodegradation of wastes

photodegradation of wastes

\author{
Search Criterias \\ (electr* AND photo*)OR photoelectr* \\ (photo* OR lase*) AND deposit* \\ OR (photo* OR lase*) AND etch* \\ OR (photo* OR lase*) AND anneal* \\ OR photo* AND chem* AND surface \\ OR lase* AND surface \\ photo* AND synth* \\ photocat* \\ photoox* \\ photobio* \\ synth* AND (photochem* OR \\ (photo* AND chem*)) \\ solar* AND chem* \\ solar* AND lase* \\ photoconv* \\ photomed* \\ photochl* \\ solar* AND synth* \\ photohal*
}

$+\quad$ The value for the number of citations is intended only as a rough estimate.

+ The complete data bases as obtained from Dr. D. M. Blake of NREL. Many of the citations can also be found in other data bases in which they are relevant.

II A data base consisting of those citations that were not relevant to any of the other data bases and appear only here; subset of photodmb.

$\S \quad$ The "*" is the usual DOS filename extender.

The search criteria listed were used to search the SCI but in no way define a limit to those citations that may be found in each data iase (i.e., citations discovered and entered individually may have titles that do not satisfy the criteria but nevertheless belong).

In accord with the scope and guidelines of our literature search, a group of irrelevant subjects was devised and incorporated into every search. The intent of this was to eliminate those citations that satisfied the various data base criteria but dealt with an area irrelevant to our purposes. The following areas comprised our list of irrelevant subjects: photolithography, electronics, nuclear reactions, photography, photoemissions, and reactions dealing with photoaffinity.

For convenience, the two data bases containing more than 1000 citations (photoele and matpho) were partitioned into more manageable subsets. These subsets can be selected out of the whole data base using a preformulated search procedure that utilizes the ability to search using 
authority lists saved within Pro-Cite. These preformulated searches are in no way perfect--they merely return citations whose titles match their criterion. Indeed, in eyes of their creators, these searches yield a workable, coherent group of references that can be useful given the volume of material, and may serve as starting points for other individualized searches.

Instructions telling how to select the subsets are provided in this Appendix as well as in the Pro-Cite manual starting on page 8-44. The following authority lists with their individual criteria have been created to subdivide the two large data bases, photoele and matpho.

Photoele Authority List

$\begin{array}{lll}\text { Name } & \text { Citations } & \text { General Content } \\ \text { phelech } & 430 & \text { pure photoelectrochemistry } \\ \text { eletrans } & 361 & \text { electrons and charge transfer (donating and accepting) } \\ \text { phovolt } & 29 & \text { photovoltaics }\end{array}$

Matpho Authority List

\begin{tabular}{lll} 
Name & Citations & General Content \\
\cline { 2 - 3 } metal & & \\
silicon & 413 & pure metals \\
III-V & 151 & silicon \\
supercon & 81 & III-V type semiconductors \\
steel & 58 & superconductors \\
metaloxi & 48 & steel and cast iron \\
siloxide & 35 & metal oxides \\
carbon & 16 & silicon oxides \\
II-VI & 16 & carbon \\
silnitr & 10 & II-VI type semiconductors \\
titannit & 4 & silicon nitride \\
& & titanium nitride
\end{tabular}

+ Because of the excessive size of a search dealing with metals, a few citations that clearly belong are not selected with this preformulated criterion. For a more complete search of metals, search for the metal name in the title.

\section{Quick instructions for selecting subsets}

1. OPEN one of the two large files.

2. Choose the SELECT option.

3. Choose the SEARCH option

4. In the search box, type "\#4=" (This code corresponds to a title search in Pro-Cite.)

5. Press F4 to see listing of authority lists, and choose the authority list corresponding to the search you wish to implement. This can be done by moving the cursor with the "up" and "down" keys and hitting RETURN at the desired list name.

6. What you see before you is the actual preformulated criterion for your search. Copy this into the search window by hitting RETURN next to the first line of criteria. 
7. Repeat steps 5 and 6 until all lines of criteria are copied into the search window.

8. Hit RETURN to prompt the search. The desired subset will be those citations that are now called "selected."

Of course, one is not limited to those searches that have been preformulated. Any title search may be created simply by following steps $1-4$ and entering the desired words in accord with the guidlines detailed in chapter 8 of the Pro-Cite manual.

\section{A note about the disks}

Data bases are divided among the three disks as follows:

\section{Disk 1}

photobio

photocat

photoele

solsynth

phochsyn

\section{Disk 2}

matpho

phosyn

solchem

photoox

photorhl

photohal

photomed

photocon

solarlas

\section{Disk 3}

photodmb

miscdmb

The following authority lists are all on Disk 3:

eletrans

phovolt

phelech

metaloxi

metal

carbon

silicon silnitr

siloxide

steel

supercon

titannit

II-VI

III-V 


\section{APPENDIX C. INITIAL LIST OF POTENTIAL PROCESSES FOR UTILIZATION OF CONCENTRATED SOLAR ENERGY}

The following is a list of possible areas for research, investigation, and possible development that emerged from the initial discussions of the study panel. No attempt was made at that stage to apply screening criteria or to prioritize. The order and numbering of topics in this list is essentially arbitrary. An initial version of this list was delivered to SERI on November 30, 1990 (subcontract task 2). This slightly revised version is being included with the Final Report in order to preserve all of the suggestions that arose during our discussions, even though they have not all been analyzed in detail.

1. High-temperature photochemistry, including

- synthesis of complex aromatic molecules from simple precursors;

- photothermal conversion of methane and other carbon-based feedstocks to acetylene and benzene;

- second-order photochemistry, i.e., absorption of high-intensity radiation by chemical intermediates. A related issue concerns avoiding photodecomposition of desired products in photochemical synthesis;

- identification of factors favoring absorption of radiation at visible and near-IR wavelengths, such as adsorption on surfaces (see below), valence unsaturation, hot bands at high temperatures;

- flash vaporization (dielectric concentration in liquid droplets).

2. Photosensitized reactions, including

- 1,3-cycloaddition in presence of o-naphthoquinones;

- photolytic activation of crown ethers.

3. Identification of an efficient photolytic $\mathrm{H}$ or $\mathrm{OH}$ source for $500-1500-\mathrm{nm}$ irradiation.

4. Large-scale production of $\mathrm{C}_{60}$ (and perhaps related cluster materials) from carbon by photothermal processing under inert-gas atmosphere.

(Emphasis on this as case-in-point for user research facility; also new findings re singlet oxygen generation [see 9])

Related possibility: regeneration of activated charcoal sorbents

5. Solar furnaces for solid waste recycling (plastics, metals, glass).

6. Photoconversion, e.g., water splitting in quantum structures ("yuantum dots," microclusters, micelles) or stacked photoelectric membranes (R. Gordon).

6a. Possible new energy storage cycles (see 18).

7 Illum, linmill IIndir systems. 
8. Two-stage, in-situ photosplitting of water.

9. Reactions using photogenerated metastable singlet oxygen.

10. Photomedicine and photobiology, including

- research on effects of wavelength, bandwidth, and modest increases in insolation on plant and animal growth;

- photo-production of carotene in saline-water organisms (as currently practiced at Weizmann Institute of Science, Israel);

- photosensitization of drugs, including toxicity, therapeutic potency, and possible photoinduced toxic effects such as photocarcinogenicity;

- research on beneficial or toxic synergistic effects of solar radiation with environmental pollutants, personal care products, foodstuffs, and human physiology -- examples might include photo-induced relaxation of blood vessels, photo-induced release of endorphins (Seasonal Affective Disorder).

11. Kinetic measurements using concentrated solar photons, including

- in vitro experiments to explore kinetics of biological photoprocesses, e.g., of deep-sea organisms;

- studies of plant growth such as "action spectra" of metabolic processes;

- laboratory measurements of atmospheric photochemical processes, especially of longwavelength absorbers such as organic peroxides.

12. Adaptation of solar concentrator as source for rapid, high-brightness near-infrared Fourier transform spectroscopy

13. Materials processing applications, including

- production of diamondlike carbon materials and films from heated hydrocarbons;

- production of ceramics or composites;

- coating of fibers;

- cutting, scribing, and annealing of devices and components;

- photochemistry (photodissociation and photoreaction) of molecular species adsorbed on surfaces;

- production of metastable phases or alloys;

- precious metal (Au, Pt, Rare Earths) metallurgy under controlled atmospheres;

- spallation drilling for mining and construction applications;

- comminution applications; 
- cellulose delignification;

- crude-oil reforming (contained porphyrins as chromophores);

- solar thermal sources for primary metallurgy, coking, and calcining in energy-poor (e.g., third-world) regions.

14. Materials research and testing at high temperatures and heating rates, including

- space and high-altitude aircraft materials, e.g., solar thrusters;

- window and heat-pipe materials for solar furnaces and solar thermal engines (the optical properties of many materials at these high temperatures are not well known);

- measurement of phase diagrams for refractory materials under a wide range of practically important atmospheres;

- test conditions in which simulation of high-intensity thermal radiation fields (e.g., simulating nuclear blast effects) is essential;

- accelerated testing of solar panels, aerospace components, and consumer products.

15. Alternative to electron-beam methods for heating, ablation, or evaporation of refractory materials.

16. Solar propulsion schemes: specifically, how is solar energy efficiently transferred to a rapidly flowing gas at high temperatures?

17. Solar-driven Stirling engines, e.g., for third-world use in water pumping and storage: transfer of solar energy to working fluid, use of heat pipes, etc.

18. Methane $\longleftrightarrow$ "synthesis gas" $\left(\mathrm{CO}, \mathrm{H}_{2}\right)$ cycle; under development at Weizmann Institute of Science, Israel.

19. Solar-pumped laser (solid-state or dye solution); being pursued by R. Winston at the University of Chicago, and by others. Investigation of alternative materials (e.g., bulk diamond, cubic zirconia) for dielectric concentrator is suggested. 


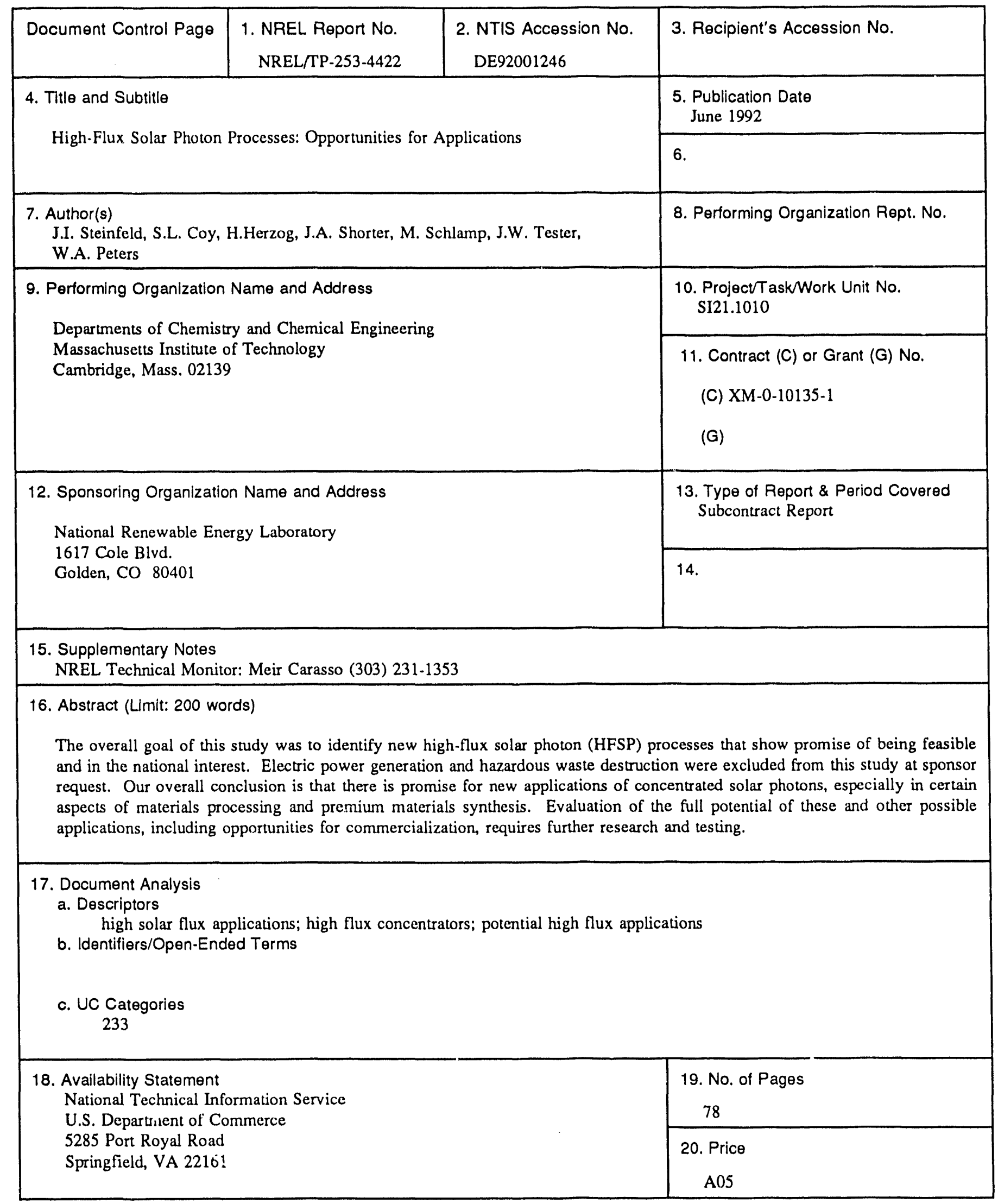

Form No. 0069E (6-30-87) 

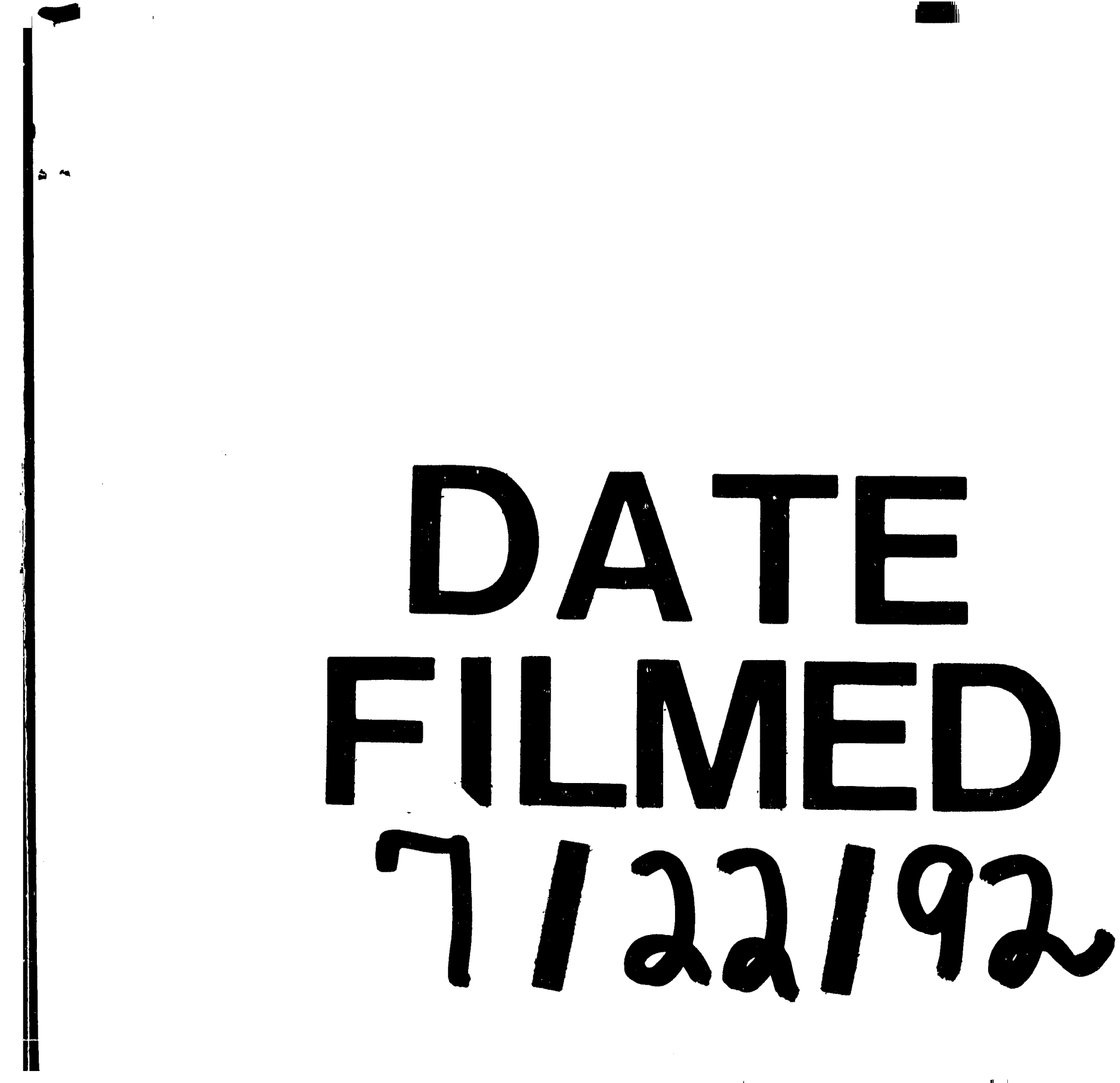
